Universidade de São Paulo

Instituto de Física de São Carlos

Vinicius Tadeu Santana

Ressonância paramagnética eletrônica em sistemas antiferromagnéticos 



\author{
Vinicius Tadeu Santana
}

\title{
Ressonância paramagnética eletrônica em sistemas antiferromagnéticos
}

Tese apresentada ao Programa de PósGraduação em Física do Instituto de Física de São Carlos da Universidade de São Paulo, para obtenção do título de Doutor em Ciências.

Área de Concentração: Física Aplicada

Orientador: Prof. Dr. Otaciro Rangel Nascimento

Versão Original

São Carlos 
AUTORIZO A REPRODUÇÃO E DIVULGAÇÃO TOTAL OU PARCIAL DESTE TRABALHO, POR QUALQUER MEIO CONVENCIONAL OU ELETRÔNICO PARA FINS DE ESTUDO E PESQUISA, DESDE QUE CITADA A FONTE.

Ficha catalográfica revisada pelo Serviço de Biblioteca e Informação do IFSC, com os dados fornecidos pelo(a) autor(a)

Santana, Vinicius Tadeu

Ressonância paramagnética eletrônica em sistemas antiferromagnéticos / Vinicius Tadeu Santana;

orientador Otaciro Rangel Nascimento -- São Carlos, 2016 .

$110 \mathrm{p}$.

Tese (Doutorado - Programa de Pós-Graduação em Física Aplicada) -- Instituto de Física de São Carlos, Universidade de São Paulo, 2016.

1. Dímeros. 2. Interação de troca dupla. 3. RPE. 4. óxidos de metais de transição. 5. Polianilinas. I. Nascimento, Otaciro Rangel, orient. II. Título. 


\section{FOLHA DE APROVAÇÃO}

Vinicius Tadeu Santana

Tese apresentada ao Instituto de Física de São Carlos da Universidade de São Paulo para obtenção do título de Doutor em Ciências. Área de Concentração: Física Aplicada.

Aprovado(a) em: 26/09/2016

\section{Comissão Julgadora}

Dr(a). Otaciro Rangel Nascimento

Instituição: (IFSC/USP)

Dr(a). Maria Oswald Machado de Matos

Instituição: (PUC/Rio de Janeiro)

Dr(a). Eduardo Ribeiro de Azevêdo

Instituição: (IFSC/USP)

Dr(a). Oswaldo Baffa Filho

Instituição: (FFCLRP/USP)

Dr(a). Rafael Calvo

Instituição: (UNL/Argentina) 



\section{AGRADECIMENTOS}

Agradeço a todos os meus mestres e em especial ao meu orientador Prof. Dr. Otaciro Rangel Nascimento e a minha coorientadora Prof. Dra. Lygia Christina de Moura Walmsley pelo incansável apoio emocional e intelectual, e pelas intermináveis discussões em busca da compreensão da física envolvida nos problemas escolhidos para estudo nesta tese.

Agradeço a todo pessoal do Instituto de Física de São Carlos: técnicos(as), bibliotecários(as), secretários(as) e demais servidores sem os quais evidentemente o trabalho se tornaria mais difícil e eventualmente não realizável.

Agradeço a minha família e aos meus amigos, que deram suporte e me acompanharam durante toda minha caminhada.

Agradeço à Silvana, pelo amor incondicional, dedicação e cuidado para que cada parte deste texto pudesse ter chegado ao seu estado final.

Agradeço a FAPESP pelo apoio financeiro (processo número 2012/24827-9). 

"Como escrever senão sobre aquilo que não se sabe ou que se sabe mal? É necessariamente neste ponto que imaginamos ter algo a dizer. Só escrevemos na extremidade de nosso saber, nesta ponta extrema que separa nosso saber de nossa ignorância e que transforma um no outro." 



\section{RESUMO}

SANTANA, V. T. Ressonância paramagnética eletrônica em sistemas antiferromagnéticos. 2016. 110 p. Tese (Doutorado em Ciências) - Instituto de Física de São Carlos, Universidade de São Paulo, São Carlos, 2016.

Neste trabalho, dois óxidos de metal de transição com ordem magnética de longo alcance e uma polianilina dopada com plastificante foram estudados através da técnica de ressonância paramagnética eletrônica. O sistema multiferróico óxido de bismuto-manganês, $\mathrm{BiMn}_{2} \mathrm{O}_{5}$, foi estudado em sua forma policristalina. Este material apresenta modos de ressonância antiferromagnética que foram identificados a partir de medidas multifrequência em altos campos magnéticos. Estes dados foram ajustados segundo a teoria de Yosida e Nagamiya da ressonância antiferromagnética para obtenção das constantes macroscópicas de anisotropia magnética

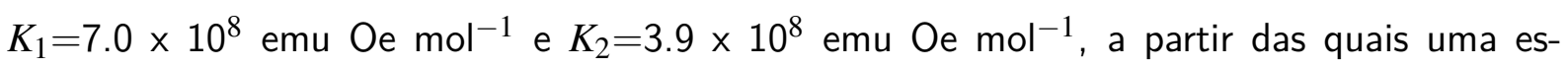
timativa da constate de anisotropia microscópica foi determinada. A caracterização destas grandezas pode ser importante para trabalhos futuros, uma vez que a anisotropia magnética é considerada uma das causas da magnetoelasticidade que dá origem a ferroeletricidade neste material. A ludwigita homometálica de ferro, $\mathrm{Fe}_{3} \mathrm{O}_{2} \mathrm{BO}_{3}$, foi estudada em sua forma monocristalina. Este óxido de ferro possui uma estrutura com duas sub-redes de ferro praticamente independentes, que se ordenam magneticamente em temperaturas distintas, além de apresentar correlações eletrônicas desde temperatura ambiente. A existência dessas correlações numa dessas estruturas, conhecida como "escada de três pernas", foi demonstrada através do espectro de RPE associado com a existência de dímeros $\mathrm{Fe}^{3+}-\mathrm{Fe}^{2+}$ nessa estrutura, desde temperatura ambiente até baixas temperaturas. Mostrou-se que os dímeros formam um estado antiferromagneticamente acoplado sujeito a interação de troca dupla, estimando valores da integral de transferência de carga $b$. Medidas de RPE em filmes automontados de polianilinas dopadas com plastificantes sugerem a população e despopulação de um estado tripleto a partir dos parâmetros dos espectros em função da temperatura, típica de dímeros de spin 1. Diferenças nos parâmetros com ciclagens térmicas sugere o congelamento da estrutura em diferentes estados condizente com a existência de termocromismo nesses polímeros. Enfim, demonstrou-se a relevância da técnica de espectroscopia de ressonância paramagnética eletrônica na caracterização de sistemas sujeitos a interação de troca antiferromagnética.

PAlavras-Chave: Dímeros. Interação de troca dupla. RPE. Óxidos de metais de transição. Polianilinas. 



\section{ABSTRACT}

SANTANA, V. T. Electron paramagnetic resonance in antiferromagnetic systems. 2016. 110

p. Tese (Doutorado em Ciências) - Instituto de Física de São Carlos, Universidade de São Paulo, São Carlos, 2016.

In this work, two transition metal oxides presenting long range magnetic order and a plastdoped polyaniline were investigated via electron paramagnetic resonance. Polycrystalline samples of the multiferroic manganese oxide, $\mathrm{BiMn}_{2} \mathrm{O}_{5}$, showed antiferromagnetic resonance modes which were identified from high magnetic fields multi frequency electron paramagnetic resonance. These data were fitted according to Yosida and Nagamiya theory of antiferromagnetic resonance. The macroscopic constants of magnetic anisotropy $K_{1}=7.0 \times 10^{8} \mathrm{emu} \mathrm{Oe} \mathrm{mol}^{-1}$

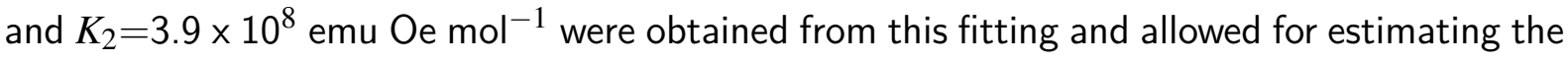
microscopic constant of anisotropy. Magnetic anisotropy may lead to magnetoelasticity, which is related to the ferroelectricity in this material. Thus, the characterization of this physical quantities may be useful to future research. Single crystals of a homometallic iron ludwigite, $\mathrm{Fe}_{3} \mathrm{O}_{2} \mathrm{BO}_{3}$, were investigated in its distinct magnetic phases. This system has two independent iron sub-lattices which order magnetically in two distinct temperatures, presenting electronic correlations from room temperature. Despite the broad and superposed lines in the EPR spectra, the presence of such correlations was demonstrated in one of these structures, which is known as "three leg ladders" (3LL). A dimer $\mathrm{Fe}^{3+}{ }_{-} \mathrm{Fe}^{2+}$ was identified at room temperature, showing an antiferromagnetically coupled state subjected to double exchange interactions. The charge transfer integral $b$ was estimated. Temperature sweep EPR measurements in films of plastdoped polyanilines suggested the population and depopulation if a triplet state typical of spin 1 dimers. Differences in the parameters after thermal cycling suggested the freezing of the structure at different states in accordance to observed thermocromism in these polymers. In conclusion, the relevance of the EPR technique was demonstrated to the characterization of exchange coupled systems.

KEyWords: Dimers. EPR. Double exchange. Transition metals oxides. Polianilines. 



\section{LISTA DE FIGURAS}

Figura 1.1 (a) (A) Exemplo de sítios numa cadeia unidimensional neutra exibindo (B) ordenamento de carga centrado no sítio, (C) ordenamento de carga centrado na ligação química e (D) uma combinação linear desses dois, que é ferroelétrica. As setas pretas mostram a polarização elétrica cuja soma é zero em (B) e (C) mas resulta num momento macroscópico não nulo indicado por uma seta vermelha em (D). (b) (A) Cadeia com cargas alternadas e estrutura $\uparrow \uparrow \downarrow \downarrow$. (B) Efeito da magnetostrição diminuindo as ligações ferromagnéticas, produzindo um polarização ferroelétrica, indicada pela seta vermelha. Fonte: BRINK; KHOMSKII. ${ }^{10} \ldots \ldots \ldots \ldots$. . . . . . . . . . . . . . . . . . . . . .

Figura 1.2 Estrutura cristalográfica do óxido de manganês $\mathrm{BiMn}_{2} \mathrm{O}_{5}$ vista no plano $a b$. Fonte: MUÑOZ et al. ${ }^{16} \ldots \ldots \ldots \ldots$ p. 27

Figura 1.3 Estrutura magnética de $\mathrm{BiMn}_{2} \mathrm{O}_{5}$ projetada no plano $a b$. A estrutura é mostrada em duas células unitárias, marcadas por linhas pretas ao longo dos eixos $a$ e $b$. As setas verdes e vermelhas representam os momentos magnéticos nos sítios de $\mathrm{Mn}^{4+}$ e $\mathrm{Mn}^{3+}$, respectivamente. Os poliedros $\mathrm{Mn}$ O correspondentes estão marcados com as mesmas cores. Fonte: Adaptada de VECCHINI et al. ${ }^{17}$

Figura 1.4 Dependência com a temperatura da (a) susceptibilidade magnética obtida com um campo magnético externo $\mathbf{H}$ de $2 \mathrm{kOe}$ ao longo dos eixos $a, b$ e $c$ e do (b) calor específico de monocristais de $\mathrm{BiMn}_{2} \mathrm{O}_{5}$. Fonte: GRANADO et al. 18

Figura 1.5 Difração de raio $X$ da amostra policristalina de $\mathrm{BiMn}_{2} \mathrm{O}_{5}$ à temperatura ambiente. A estrutura tem simetria Pbam com parâmetros de rede $(\AA)$ : $a=7.5605(1), b=8.5305(1), c=5.7594(1)$. Fonte: Elaborada pelo autor. . .

Figura 1.6 Espectros de RPE a $328.8 \mathrm{GHz}$ para amostra policristalina de $\mathrm{BiMn}_{2} \mathrm{O}_{5}$ em três temperaturas. As retas verticais tracejadas indicam ressonâncias devido ao oxigênio molecular e não estão relacionadas ao sinal intrínseco da amostra. Inset: espectro de RPE em banda X a $300 \mathrm{~K}$. Fonte: Elaborada pelo autor. 
Figura 1.7 Espectros de RPE em múltiplas frequências para amostra policristalina de $\mathrm{BiMn}_{2} \mathrm{O}_{5}$ a $5 \mathrm{~K}$. As linhas marcadas com um círculo preto são referentes à amostra. As linhas marcadas com asterisco correspondem ao oxigênio molecular. Inset: posição dos modos paramagnéticos do oxigênio molecular identificados de acordo com a referência ${ }^{20}$. Fonte: Elaborada pelo autor. .

Figura 1.8 Os pontos mostram a dependência do campo com a frequência da micro-onda das linhas de ressonância observadas nos espectros em múltiplas frequências da figura 1.7. Os modos AFMR obtidos com o modelo de Yosida e Nagamiya para o campo magnético paralelo ao eixo fácil (linha vermelha cheia e marrom tracejada), perpendicular ao eixo fácil (linha verde pontilhada) e fazendo um ângulo de $43^{\circ}$ com o eixo fácil (linha azul traço-pontilhada) são mostrados. Os parâmetros que melhor ajustam os dados experimentais são $g=2.2, K_{1}=7.0 \times 10^{8}\left(\mathrm{emu} \mathrm{Oe} \mathrm{mol}^{-1}\right)$ e $K_{2}=3.9 \times 10^{8}\left(\mathrm{emu} \mathrm{Oe} \mathrm{mol}^{-1}\right)$. Fonte: Elaborada pelo autor.

Figura 2.1 Vista perspectiva da estrutura de $\mathrm{Fe}_{3} \mathrm{O}_{2} \mathrm{BO}_{3}$ projetada no plano perpendicular ao eixo $c$. As tríades 4-2-4 formam "degraus" de uma "escada de três pernas" ao longo do eixo $c$, sendo que cada perna é dada por uma cadeia de íons 4,2 e 4 ao longo do eixo $c$ (perpendicular ao plano mostrado na figura). As linhas tracejadas indicam os lados $a$ e $b$ da célula unitária e as linhas contínuas vermelhas indicam "paredes" que delimitam estruturas quase bi-dimensionais em zig-zag no plano $a b$. Fonte: Adaptada de MIR et al. ${ }^{29}$

Figura 2.2 Colunas de tríades (escada) (a) acima e (b) abaixo da transição de fase estrutural. Fonte: MIR et al. ${ }^{29}$

Figura 2.3 Projeção da estrutura do oxiborato $\mathrm{Fe}_{3} \mathrm{O}_{2} \mathrm{BO}_{3}$ no plano ab evidenciando as duas tríades magneticamente não-equivalentes e o ângulo de $70^{\circ}$ entre os íons de Fe2 no centro de cada uma delas (linhas contínua e pontilhada). Fonte: Elaborada pelo autor.

Figura 2.4 Ordenamento de carga e formação do par de cátions de ferro em $\mathrm{Fe}_{3} \mathrm{O}_{2} \mathrm{BO}_{3}$. (a) Distâncias Fe-Fe dentro dos degraus Fe4-Fe2-Fe4 nas escadas. (b) Valências dos íons de ferro calculadas pelo método da soma das valências de ligação. ${ }^{35}$ (c) Parâmetro de deslocamento atômico para o Fe2. Fonte: BOR-

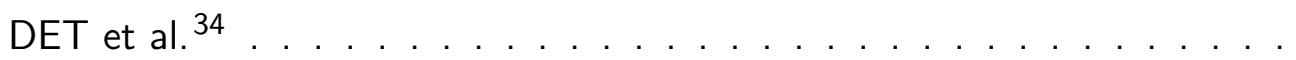


Figura 2.5 Calor específico da ludwigita homometálica $\mathrm{Fe}_{3} \mathrm{O}_{2} \mathrm{BO}_{3}, \mathrm{C} / \mathrm{T}$ em função da temperatura. A linha pontilhada é referência para evidenciar o comportamento constante de C/T. Fonte: FERNANDES et al. ${ }^{30} \ldots$. . . . . . . p. 44

Figura 2.6 (a) Fotografias do cristal de $\mathrm{Fe}_{3} \mathrm{O}_{2} \mathrm{BO}_{3}$ obtidas por estereomicroscópio em três planos distintos. (b) Ângulo entre as faces do cristal no plano $a b$. Fonte: Elaborada pelo autor.

Figura 2.7 Orientação do cristal de $\mathrm{Fe}_{3} \mathrm{O}_{2} \mathrm{BO}_{3}$ utilizada nas medidas orientadas, descrita no referencial do laboratório. Fonte: Elaborada pelo autor.

Figura 2.8 Micrografia ótica do monocristal de $\mathrm{Fe}_{3} \mathrm{O}_{2} \mathrm{BO}_{3}$ indicando os eixos cristalinos obtidos por difração de raios-X. O eixo $c$ pode ser visto ao longa da direção mais alongada do cristal em forma de agulha. Fonte: Elaborada pelo autor.

Figura 2.9 Espectros de RPE da amostra $\mathrm{Fe}_{3} \mathrm{O}_{2} \mathrm{BO}_{3}$ obtidos a partir da variação angular do cristal em relação ao campo magnético à temperatura ambiente no plano perpendicular ao eixo $c$, plano $x y$, bem como nos planos $z x$ e $z y$ em banda $X$ (superior) e em banda $Q$ (inferior). Observe que a faixa de varredura do campo em banda $X$ e banda $Q$ é a mesma. $O$ sinal estreito nos espectros em banda $\mathrm{Q}$ corresponde a um marcador com $\mathrm{Cr}^{3+}$. Fonte: Elaborada pelo autor. . . . . . . . . . . . . . . . . . . .

Figura 2.10 Variação angular dos campos de ressonância convertidos para $g_{\text {eff }}^{2}$ em banda $X$ (fileira superior) e $Q$ (fileira inferior) obtidos à temperatura ambiente para cada orientação nos planos $z y, x y$ e $z x$. É possível identificar dois conjuntos, I (triângulos azuis) e II (círculos vermelhos), anisotrópicos angularmente deslocados. Uma linha isotrópica em torno de g 2 também é observada e assinalada como conjunto III (quadrados pretos). As linhas cheias correspondem ao ajuste de $g^{2}(\theta, \phi)$ da expressão (2.4). Fonte: Elaborada pelo

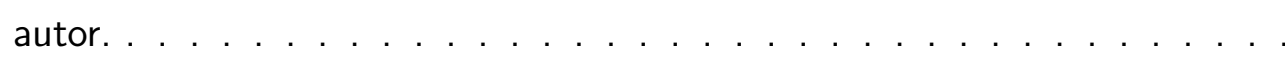

Figura 2.11 Valores principais do tensor $\mathbf{g}$ para um sistema de spin $\mathrm{S}=5 / 2 \mathrm{com}$ altos valores de separação de campo zero $D$ em função de $\lambda=E / D$. Fonte:

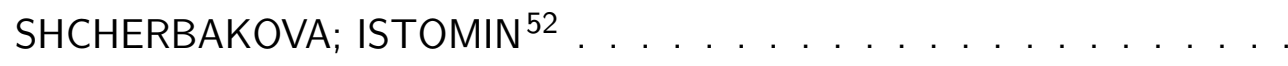

Figura 2.12 Esquema de energia para uma interação de troca isotrópica entre dois spins, $S_{A}=5 / 2$ e $S_{B}=2$, com $J<0$. Fonte: Elaborada pelo autor. . . . . . . . . . 
Figura 2.13 (a) Diagrama de correlação entre a energia de um dímero de valência mista e a razão $b /|J|$, em que $b$ é energia de transferência de carga (hopping) e $J$ é a constante da interação de troca isotrópica, Equação (3.12). Nesse diagrama, a interação de troca é antiferromagnética, isto é, $J<0$. (b) Detalhe para $b /|J|<5$. Fonte: Elaborada pelo autor. . . . . . . . . . . . . . p. 60

Figura 2.14 Estado fundamental da interação de troca no dímero $\mathrm{Fe}^{3+}{ }_{-} \mathrm{Fe}^{2+}, S_{A}=5 / 2$ e $S_{B}=2$, respectivamente, modificado pela presença da interação de troca dupla e sujeito a um campo magnético. Fonte: Elaborada pelo autor. . . .

Figura 2.15 Diagrama de níveis de energia em escala e transições que obedecem a regra de seleção $\Delta m= \pm 1$ em banda $\mathrm{X}$ e banda $\mathrm{Q}$ para o dímero em questão. Fonte: Elaborada pelo autor.

Figura 2.16 Simulação do espectro de RPE em (a) banda X e (b) banda Q com o campo magnético aplicado ao longo do eixo $y$, utilizando quatro linhas gaussianas. Fonte: Elaborada pelo autor. . . . . . . . . . . . . . . . . p. 63

Figura 2.17 Variação angular, $g_{e f f}(\theta, \phi)$, obtida em banda $\mathrm{X}$ para o cristal $\mathrm{Fe}_{3} \mathrm{O}_{2} \mathrm{BO}_{3}$ no plano $x y(a b)$ para algumas temperaturas. As linhas tracejadas são apenas guias para os olhos. Fonte: Elaborada pelo autor. . . . . . . . . . . . .

Figura 2.18 Variação da potência da micro-onda para o monocristal de $\mathrm{Fe}_{3} \mathrm{O}_{2} \mathrm{BO}_{3}$ à temperatura ambiente e a $5 \mathrm{~K}$ (resfriada com o campo ligado) em banda $\mathrm{X}$. Fonte: Elaborada pelo autor. . . . . . . . . . . . . . . . . .

Figura 2.19 (a) Recíproco da área (1/A), (b) área, (c) $g_{\text {eff }}$ e (d) largura de linha do sinal de RPE em função da temperatura para o campo magnético aplicado na direção paralela e perpendicular ao plano $a b$. Fonte: Elaborada pelo autor. p. 68

Figura 2.20 Medidas em função da orientação do cristal em relação ao campo magnético a $4 \mathrm{~K}$ com (a) ZFC e (b) FC. A linha fina em torno de $3200 \mathrm{G}$ é uma impureza do tubo que foi usado nesta medida. Fonte: Elaborada pelo autor. p.70

Figura 2.21 Variação angular no eixo $z$ a $4 \mathrm{~K}$ e em função da temperatura para a linha de mais alto campo, após ZFC. Fonte: Elaborada pelo autor. . . . . . . . p.70

Figura 3.1 Estrutura dos principais polímeros intrinsecamente condutores. Fonte: FAEZ et al. 69

Figura 3.2 Principais estados de oxidação da polianilina: leucoesmeraldina, esmeraldina (isolante e condutora) e pernigranilina. Fonte: FAEZ et al. ${ }^{69}$ 
Figura 3.3 Forma do sal esmeraldina (forma condutora) da polianilina e o dopante plastificante das amostras estudadas. O par $+\bullet$ indica a localização dos pólarons na cadeia da PANI. Fonte: SNIECHOWSKI et al. ${ }^{85}$; DUFOUR et al. ${ }^{86}$. . p. 79

Figura 3.4 Amostra encapsulada de (PANI-DDoEPSA) 0.5 . Fonte: Elaborada pelo autor. p. 80

Figura 3.5 (a) Exemplo de uma linha assimétrica de RPE. (b) Curva teórica de $A / B$ versus $\lambda$ baseada na teoria de Dyson no limite $d \leq \delta$. Fonte (a): Elaborada pelo autor. Fonte $(\mathrm{b})$ : WALMSLEY ${ }^{88} \ldots \ldots$. . . . . . . . . . . 82

Figura 3.6 (a) Exemplo do espectro de RPE para (PANI-DDoEPSA) 0.5 a $4 \mathrm{~K}, 14 \mathrm{~K}$ e temperatura ambiente. (b) Exemplo de um ajuste do espectro experimental obtido à temperatura ambiente usando uma linha dysoniana. Fonte: Elaborada pelo autor.

Figura 3.7 Área do sinal de RPE em função da raiz quadrada da potência para a amostra $(\text { PANIDDoEPSA })_{0.5}$ Fonte: Elaborada pelo autor.

Figura 3.8 Parâmetros da linha dysoniana utilizada para ajuste dos espectros experimentais do filme de (PANI-DDoEPSA) 0.5 medidos em função da temperatura com o campo magnético aplicado na direção perpendicular em relação a superfície do filme. (a) Área do sinal. (b) fator g. (c) Largura da linha. (d) Razão de assimetria $A / B$. As medidas M1, M2 e M3 correspondem a três medidas realizadas sob as mesmas condições experimentais na mesma amostra. Fonte: Elaborada pelo autor.

Figura 3.9 Exemplo do espectro de RPE e ajuste para (PANI-DB3ESSA) 0.5 a (a) $10 \mathrm{~K}$ e (b) temperatura ambiente. Fonte: Elaborada pelo autor.

Figura 3.10 Variação com a potência em banda $X$ para temperatura ambiente e $4 \mathrm{~K}$ do filme de (PANI-DB3ESSA $)_{0.5}$. Fonte: Elaborada pelo autor.

Figura 3.11 Variação térmica dos parâmetros do espectro de RPE em banda $X$ da amostra $(\text { PANI-DB3ESSA })_{0.5}$. Fonte: Elaborada pelo autor. . . . . . . . . . . .

Figura 3.12 Variação térmica da área do sinal de absorção da amostra (PANI-DB3ESSA) 0.5 . Fonte: Elaborada pelo autor.

Figura 3.13 Esquema da cadeia de PANI com a molécula do dopante mostrando o ângulo $\theta$ entre os anéis fenilênicos. Fonte: RANNOU et al. ${ }^{89} \ldots \ldots . . . . .$. 
Figura B.1 Gráfico do campo central das componentes dos espectros do plano $a b \mathrm{em}$ banda X. As linhas tracejadas correspondem a largura de linha dessas componentes distribuídas simetricamente em torno do campo central de cada uma delas. Fonte: Elaborada pelo autor. . . . . . . . . . . . . . . . . p. 105 


\section{SUMÁRIO}

1 Materiais multiferróicos: óxido de bismuto-manganês, $\mathrm{BiMn}_{2} \mathrm{O}_{5}$

1 Revisão bibliográfica . . . . . . . . . . . . . . . . . . . 25

2 Material e Métodos . . . . . . . . . . . . . . . . . . . . . . . 29

2.1 Material . . . . . . . . . . . . . . . . . . . . . . . 29

2.2 Métodos . . . . . . . . . . . . . . . . . . . . . 30

3 Resultados e discussão . . . . . . . . . . . . . . . . . . . . . . . 31

3.1 Teoria da ressonância antiferromagnética . . . . . . . . . . . . . . . . . . . 32

3.2 Aplicação da teoria aos dados de $\mathrm{BiMn}_{2} \mathrm{O}_{5} \ldots \ldots \ldots$. . . . . . . . . . . . . . . . . 34

4 Conclusões . . . . . . . . . . . . . . . . . . . . . . . . 38

2 Ludwigita homometálica de ferro, $\mathrm{Fe}_{3} \mathrm{O}_{2} \mathrm{BO}_{3}$

1 Revisão bibliográfica . . . . . . . . . . . . . . . . . . . . . . . . . 39

2 Material e Métodos . . . . . . . . . . . . . . . . . . . 46

2.1 Material . . . . . . . . . . . . . . . . . . . . 46

2.2 Métodos . . . . . . . . . . . . . . . . . . . . . . . 48

2.2.1 Ressonância paramagnética eletrônica . . . . . . . . . . . . . . . . . . . 48

2.2.2 Análise dos resultados . . . . . . . . . . . . . . . . . . . . . . . . . . . 48

3 Resultados e discussão . . . . . . . . . . . . . . . . . . . . . . . . . . 51

3.1 Determinação da orientação do cristal $\mathrm{Fe}_{3} \mathrm{O}_{2} \mathrm{BO}_{3} \ldots \ldots \ldots$. . . . . . . . . . 51

3.2 Variação angular do cristal e análise de $g_{\text {eff }} \ldots \ldots \ldots$. . . . . . . . . 52

3.3 Variação angular no plano $a b$ em função da temperatura . . . . . . . . . . . . . . 64

3.4 Curva de saturação do sinal de RPE . . . . . . . . . . . . . . . . . . 66

3.5 Variação térmica com campo orientado ao longo dos eixos $z$ e $y \ldots$. . . . . . . 67

3.6 Medidas a baixa temperatura . . . . . . . . . . . . . . . . . . . . . 69

3.7 Considerações sobre o dímero . . . . . . . . . . . . . . . . . . . . . . . . . 70

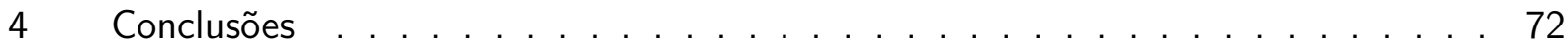

$5 \quad$ Perspectivas . . . . . . . . . . . . . . . . . . . . . . . . 73

3 Polianilinas dopadas com plastificantes $\quad 75$

1 Revisão bibliográfica . . . . . . . . . . . . . . . . . . . 75 
2 Material e Métodos . . . . . . . . . . . . . . . . . . . 79

2.1 Material . . . . . . . . . . . . . . . . . . 79

2.2 Métodos . . . . . . . . . . . . . . . . . . . . . 80

2.2.1 Ressonância paramagnética eletrônica . . . . . . . . . . . . . . . . . . . 80

2.2.2 Formas de linha . . . . . . . . . . . . . . . . . . . . . . . . . . . . . . . . . . 81

3 Resultados e discussão . . . . . . . . . . . . . . . . . . . . . . . . . . . . . . . . 82

3.1 (PANI-DDoEPSA $)_{0.5} \ldots \ldots \ldots \ldots \ldots$

$3.2(\text { PANI-DB3ESSA })_{0.5} \ldots \ldots \ldots \ldots \ldots$

3.3 Discussão sobre as variações entre medidas diferentes . . . . . . . . . . . . . . . . 89

4 Conclusões . . . . . . . . . . . . . . . . . . . . . . . . . . . . . . . . . . . 90

$\begin{array}{ll}\text { Considerações finais } & 91\end{array}$

$\begin{array}{ll}\text { REFERÊNCIAS } & 93\end{array}$

Apêndice A - Resultado dos ajustes de $g_{e f f}^{2}(\theta, \phi) \quad 103$

Apêndice B - Sobreposição das linhas do espectro em banda X 105

$\begin{array}{ll}\text { Anexo } & 107\end{array}$ 


\title{
Introdução
}

\author{
"Ainda não perdi a sensação de \\ surpresa, e de prazer, em perceber que \\ esse delicado movimento (precessão do \\ spin) esteja em todas as coisas \\ ordinárias ao nosso redor, revelando-se \\ somente àqueles que procuram por ele."
} Edward M. Purcell

Tradicionalmente, a técnica de espectroscopia de Ressonância Paramagnética Eletrônica (RPE) é empregada para identificação e estudo de centros paramagnéticos isolados, ou diluídos, dando informações a respeito do ambiente químico e da estrutura local em que estes centros estão inseridos. Além disso, materiais que possuem centros paramagnéticos acoplados via interação de troca (supertroca), ferro- ou antiferromagnética, também têm na técnica de RPE uma importante ferramenta na caracterização de suas propriedades magnéticas e estruturais. ${ }^{1,2}$ Sistemas que tem sido tipicamente estudados utilizando essa técnica incluem ${ }^{2}$ :

1. Radicais livres nas fases sólida, líquida ou gasosa. Por radical livre, entende-se uma espécie altamente reativa como um átomo, molécula ou íon contendo um elétron desemparelhado.

2. Íons de metais de transição incluindo actinídeos.

3. Defeitos pontuais em sólidos, definidos como imperfeições localizadas com spin eletrônico distribuído sobre uma pequena região ou quantidade de átomos. Por exemplo, elétrons aprisionados numa vacância em um cristal ou ausência de elétrons ("buraco" positivo).

4. Sistemas com mais de um elétron desemparelhado: i) sistemas com estado tripleto, como dímeros, em que a interação entre dois elétrons (ou "buracos") desemparelhados é forte; ii) biradicais, sistemas em que a distância entre os dois elétrons desemparelhados é suficientemente grande de modo que a interação entre eles é fraca; iii) multiradicais.

5. Sistemas com elétrons de condução, como metais e semicondutores.

Diferentemente das técnicas que medem magnetização em volume, a técnica de RPE é uma técnica local, no sentido de que fornece informações mais detalhadas das interações 
magnéticas entre os spins levando ao conhecimento de informações microscópicas do material estudado.

As informações são extraídas a partir do espectro da derivada da absorção de microondas pela amostra na cavidade de RPE, que está sujeita a um campo magnético externo aplicado. Os espectros obtidos através do experimento podem ser avaliados a partir de suas características como a forma e largura de linha, a área da curva e o campo central (fator $g$ ), e também a partir da simulação utilizando aproximações para a hamiltoniana de spin, que pode ser dada de um modo geral por

$$
\begin{aligned}
\mathscr{H}_{0} & =\mathscr{H}_{E Z}+\mathscr{H}_{Z F C}+\mathscr{H}_{H F}+\mathscr{H}_{S O}+\mathscr{H}_{E} \\
& =\mu_{B} \mathbf{B} \cdot \mathbf{g} \cdot \mathbf{S}+\mathbf{S} \cdot \mathbf{D} \cdot \mathbf{S}+\mathbf{S} \cdot \mathbf{A} \cdot \mathbf{I}+\lambda \mathbf{L} \cdot \mathbf{S}+\mathbf{S}_{\mathbf{i}} \cdot \mathscr{J}_{\mathbf{i j}} \cdot \mathbf{S}_{\mathbf{j}}
\end{aligned}
$$

em que $\mu_{B}$ é o magneton de Bohr, $\mathbf{B}$ é o campo magnético aplicado, $\mathbf{S}$ é o spin eletrônico efetivo, $\mathbf{D}$ é o termo de separação de campo zero, A é a constante de acoplamento hiperfino, L corresponde ao momento angular orbital, $\mathscr{J}_{i j}$ é a constante de troca quando há acoplamento entre spins vizinhos $\mathbf{S}_{\mathbf{i}}$ e $\mathbf{S}_{\mathbf{j}}$. O termo $\mathscr{H}_{E Z}$ corresponde a interação Zeeman entre o spin efetivo e o campo magnético externo aplicado; $\mathscr{H}_{Z F C}$ corresponde a interação de campo zero que remove a degenerescência entre os $(2 S+1)$ níveis para sistemas de spin com $S>$ $1 / 2$ e também inclui nessa forma o acoplamento dipolo-dipolo entre spins e a interação com o campo cristalino, entre outras; $\mathscr{H}_{H F}$ corresponde a interação hiperfina entre o spin eletrônico e nuclear; $\mathscr{H}_{S O}$ corresponde a interação spin-órbita entre o momento angular orbital e o spin com uma constante de acoplamento $\lambda ; \mathscr{H}_{E}$ corresponde a interação de troca equivalente ao acoplamento entre os spins de sítios vizinhos i e j. Dependendo do tipo de centro paramagnético estudado, da simetria do campo cristalino, do acoplamento com o momento angular orbital, do acoplamento dipolo-dipolo ou via interação de troca com vizinhos, cada um dos termos pode entrar como perturbação no cálculo da energia, levando a simplificações. A não ser pelas constantes fenomenológicas como $\mathscr{J}_{i j}$ e $\lambda$, todos os termos nessa expressão envolvem apenas coordenadas de spin descritas pelo spin eletrônico $\mathbf{S}$ e pelo spin nuclear $\mathbf{I}$, de onde $\mathscr{H}_{0}$ é chamado de hamiltoniana de spin. Essa expressão é modificada e adaptada de acordo com os problemas em estudo, de modo que uma variedade de exemplos bem estabelecidos bem como os principais aspectos da técnica de RPE podem ser consultadas nos livros-texto das referências 2-8.

Espectros de RPE com linhas estreitas são a situação ideal, pois permitem a identificação dos centros ressonantes bem como suas propriedades seja através de simulação dos parâmetros 
a partir da hamiltoniana de spin, seja através do ajuste das linhas para extração e análise dos parâmetros mencionados. Esse é o caso de alguns complexos metálicos orgânicos como, por exemplo, o complexo de cobre, $\mathrm{C}_{40} \mathrm{H}_{36} \mathrm{Cu}_{2} \mathrm{~N}_{8} \mathrm{O}_{8} \mathrm{~S}_{8}$, que contém dímeros $\mathrm{Cu}^{2+}$. Neste sistema, a técnica de RPE foi usada para a determinação dos parâmetros de troca isotrópica e anisotrópica. ${ }^{9}$ No entanto, podemos observar e interpretar espectros de RPE mesmo em sistemas inorgânicos, apesar do alargamento das linhas no espectro devido ao efeito spinórbita, interação dipolar ou outros mecanismos. Uma revisão sistemática da aplicação da técnica de RPE em sistemas com ordem magnética de longo alcance não foi encontrada na literatura, talvez devido à peculiaridade dos espectros quando essas interações estão presentes, levando a mecanismos de relaxação da magnetização não usuais e alterando dramaticamente a forma, largura e campo central das linhas presentes no espectro. Desse modo, não há um protocolo padrão para interpretar as possíveis peculiaridades nos resultados de medidas nestes sistemas. Essa característica impede o emprego de um protocolo único na análise dos resultados dificultando a interpretação dos resultados.

O presente trabalho versará a respeito da caracterização de sistemas sujeitos a interação de troca via ressonância paramagnética eletrônica. Os materiais a serem caracterizados são:

a) o sistema multiferróico óxido de bismuto-manganês, $\mathrm{BiMn}_{2} \mathrm{O}_{5}$ (amostras policristalinas);

b) oxiborato de ferro com estrutura ludwigita, $\mathrm{Fe}_{3} \mathrm{O}_{2} \mathrm{BO}_{3}$ (monocristal);

c) polianilinas dopadas com plastificantes.

Diferentes abordagens foram escolhidas de acordo com a característica do material estudado. O multiferróico óxido de bismuto-manganês $\left(\mathrm{BiMn}_{2} \mathrm{O}_{5}\right)$ foi analisado a partir de dados de RPE multi-frequências em altos campos magnéticos. Nesse caso, a técnica de RPE em frequências tradicionalmente utilizadas como $9 \mathrm{GHz}$ (banda $\mathrm{X}$ ) ou $35 \mathrm{GHz}$ (banda Q) apresenta limitações, uma vez que a largura dos sinais de absorção são maiores que a faixa de campo magnético varrida nessas frequências. Quanto ao monocristal de oxiborato de ferro, $\mathrm{Fe}_{3} \mathrm{O}_{2} \mathrm{BO}_{3}$, os espectros resultantes das medidas de RPE em banda $X$ e banda $Q$ com variação angular do campo magnético aplicado e variação térmica permitem uma caracterização do sistema. No caso das polianilinas dopadas com plastificantes, medidas de RPE em função da temperatura em banda $X$ foram realizadas, apresentando características de sistemas com centros paramagnéticos antiferromagneticamente acoplados.

Nesta tese, os três sistemas estudados estão divididos em capítulos, cada um apresentado suas peculiaridades e os resultados de RPE obtidos. Particularmente, os resultados do capítulo 1 referente ao sistema multiferróico $\mathrm{BiMn}_{2} \mathrm{O}_{5}$ já foram publicados (ver Anexo). 


\section{Materiais multiferróicos: óxido de bismuto-manganês, $\mathrm{BiMn}_{2} \mathrm{O}_{5}$}

"Não sabemos. Só podemos conjeturar." Karl Popper

\section{Revisão bibliográfica}

Materiais multiferróicos são aqueles que apresentam ferroeletricidade e ordenamento magnético, além de ter sua polarização elétrica alterada pela aplicação de um campo magnético. Estes compostos são raros e os possíveis mecanismos para sua existência ainda estão sendo investigados. A coexistência desses dois fenômenos é comumente classificada segundo o tipo de acoplamento entre eles, separando-se entre as classes I e II. Nos multiferróicos do tipo I, há ordem ferroelétrica e magnética coexistindo com certo acoplamento mas a ferroeletricidade está associada a geometria dos sítios e a uma onda de densidade de carga (CDW, charge density wave, da sigla em inglês), ocorrendo geralmente a uma temperatura bem maior em relação à temperatura do ordenamento magnético. Já nos multiferróicos do tipo II, a ferroeletricidade ocorre somente na fase ordenada magneticamente tanto em materiais com estruturas magnéticas não-colineares quanto em materiais com estruturas magnéticas colineares. Neste último caso, o efeito é baseado na elasticidade da rede cristalina quando sujeita a interações magnéticas (magnetostrição ou magnetoelasticidade) e requer a presença de íons magnéticos não equivalentes com diferentes cargas. ${ }^{10}$

Para um multiferróico do tipo I, a combinação de ordenamento de carga centrado nos sítios e centrado na ligação química resulta numa polarização total diferente de zero e é um efeito desacoplado do ordenamento magnético do material, Figura 1.1(a). Já para um multiferróico do tipo II, a frustração entre a interação ferromagnética e antiferromagnética na ligação entre sítios equidistantes é resolvida por uma distorção na rede cristalina que acarreta uma polari- 
zação elétrica total não nula cujo efeito é intrínseco ao ordenamento magnético do material, Figura 1.1(b). ${ }^{10} \mathrm{Um}$ forte acoplamento é esperado entre a ferroeletricidade e o parâmetro de ordem magnético resultando em efeitos magneto-elásticos como a magnetostrição. Quando uma amostra (anti)ferromagnética é magnetizada, uma deformação ocorre no cristal e essa deformação é usualmente expressa pela variação das dimensões lineares medidas ao longo de uma certa direção. A magnetostrição tem as mesmas origens da anisotropia magnética. ${ }^{11}$

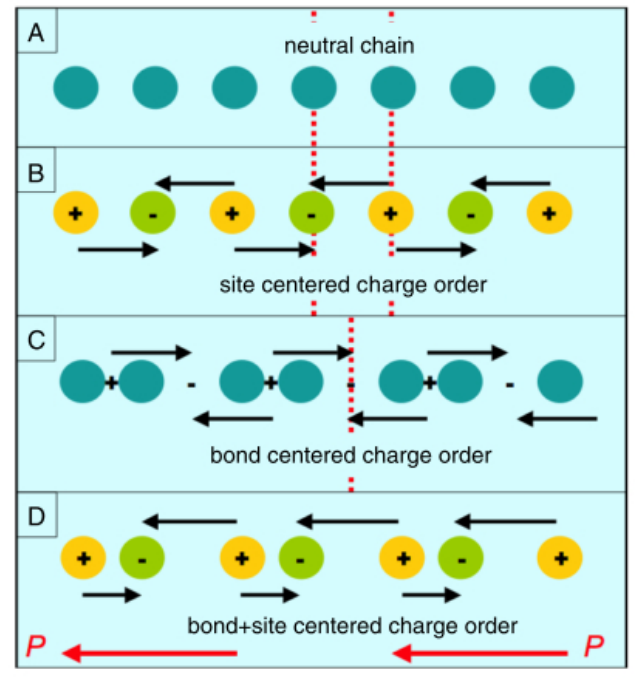

(a)

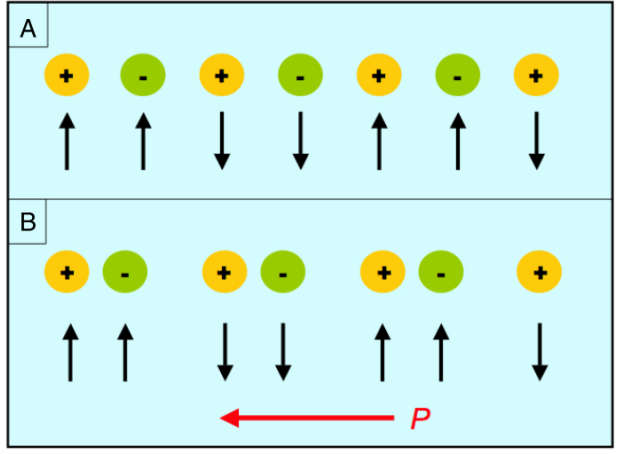

(b)

Figura 1.1 - (a) (A) Exemplo de sítios numa cadeia unidimensional neutra exibindo (B) ordenamento de carga centrado no sítio, (C) ordenamento de carga centrado na ligação química e (D) uma combinação linear desses dois, que é ferroelétrica. As setas pretas mostram a polarização elétrica cuja soma é zero em (B) e (C) mas resulta num momento macroscópico não nulo indicado por uma seta vermelha em (D). (b) (A) Cadeia com cargas alternadas e estrutura $\uparrow \uparrow \downarrow \downarrow$. (B) Efeito da magnetostrição diminuindo as ligações ferromagnéticas, produzindo um polarização ferroelétrica, indicada pela seta vermelha.

Fonte: BRINK; KHOMSKII. ${ }^{10}$

O estudo de óxidos de manganês, sobretudo os de valência mista, recebeu grande atenção desde a descoberta do efeito de magnetoresistência gigante em manganitas dopadas com terras raras. ${ }^{12}$ Entre os óxidos de manganês, encontra-se a classe $\mathrm{RMn}_{2} \mathrm{O}_{5}(\mathrm{R}=$ terra rara ou bismuto) que tem sido investigada devido à presença da ferroeletricidade em sua fase magneticamente ordenada. ${ }^{13,14} \mathrm{O}$ mecanismo para o surgimento da ferroeletricidade para esta família ainda não foi completamente compreendido. No entanto, um dos mecanismos propostos anuncia que mudanças magneticamente induzidas no comprimento das ligações entre íons de manganês de diferentes valências resulta num momento ferroelétrico líquido como o caso mostrado na Figura 1.1(b), o que encaixaria esta família no grupo de multiferróicos do tipo II. O composto $\mathrm{BiMn}_{2} \mathrm{O}_{5}$, cuja temperatura de transição ferroelétrica $T_{C}$ está em torno 
de $38 \mathrm{~K}^{13}$ e a temperatura de Néel $T_{N}$ está em torno de $40 \mathrm{~K}^{15}$, faz parte da família $\mathrm{RMn}_{2} \mathrm{O}_{5}$, com estrutura ortorrômbica $\mathrm{Pbam}$ e parâmetros de rede à temperatura ambiente $a=7.56$ $\AA, b=8.53 \AA$ e $c=5.76 \AA$. Octaedros $\mathrm{Mn}^{4+} \mathrm{O}_{6}$ e pirâmides quadradas $\mathrm{Mn}^{3+} \mathrm{O}_{5}$ estão interconectados por um oxigênio, como na representação da estrutura na Figura 1.2.

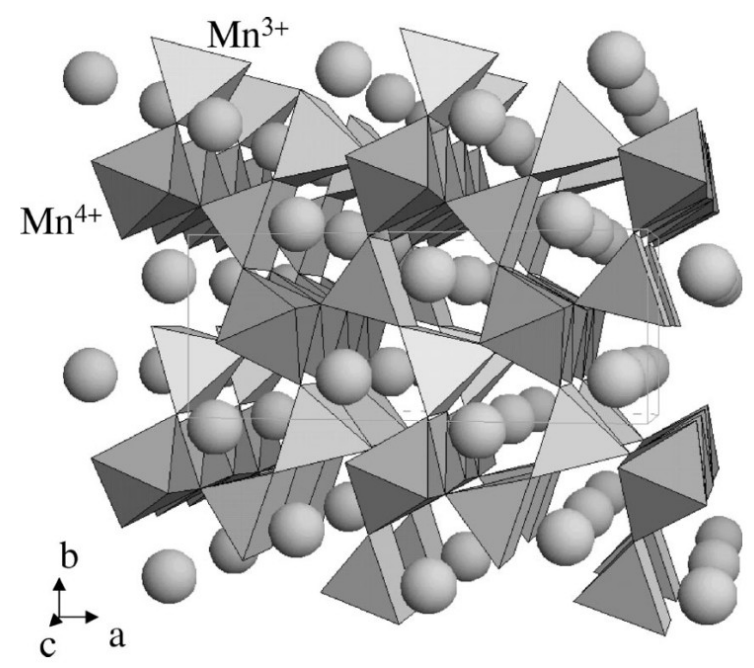

Figura 1.2 - Estrutura cristalográfica do óxido de manganês $\mathrm{BiMn}_{2} \mathrm{O}_{5}$ vista no plano $a b$. Fonte: MUÑOZ et al. ${ }^{16}$

Apesar de ser isoestrutural à família $\mathrm{RMn}_{2} \mathrm{O}_{5}$, o composto $\mathrm{BiMn}_{2} \mathrm{O}_{5}$ tem um estado fundamental magnético diferente do família, pois a estrutura magnética é comensurável abaixo da temperatura de transição antiferromagnética, $T_{N}$. Estrutura magnética comensurável corresponde a uma estrutura magnética cujas dimensões da célula unitária magnética são múltiplos inteiros da célula unitária estrutural e traduz-se em um ordenamento paralelo ou antiparalelo dos momentos nos sítios. No caso do $\mathrm{BiMn}_{2} \mathrm{O}_{5}$, os spins nos sítios de $\mathrm{Mn}^{3+}$ e de $\mathrm{Mn}^{4+}$ estão alinhados aproximadamente paralelos e antiparalelos na direção do eixo $a$ respectivamente, com um vetor de propagação $\mathbf{k}=(1 / 2,0,1 / 2)$, formando duas sub-redes como pode ser observado na Figura 1.3.

O ordenamento antiferromagnético dos spins ocorre a $\sim 9^{\circ}$ do eixo $a$, no plano $a b$ sem ordenamento espiral ${ }^{16}$ e com uma pequena polarização no eixo $b .{ }^{13}$ Para outros materiais dessa classe, os spins descrevem uma estrutura cicloidal ao redor do eixo $a$, correspondendo a uma estrutura incomensurável. A direção de ordenamento é chamada de eixo fácil, definido pela direção energeticamente favorável da magnetização espontânea. No caso de um ordenamento antiferromagnético, o eixo fácil corresponde àquele em que a susceptibilidade magnética começa a ir a zero a partir da temperatura de transição. O ordenamento antiferromagnético do composto $\mathrm{BiMn}_{2} \mathrm{O}_{5}$ é evidenciado tanto nas medidas de susceptibilidade magnética quanto no calor específico, como mostrado na Figura 1.4. O calor específico foi 


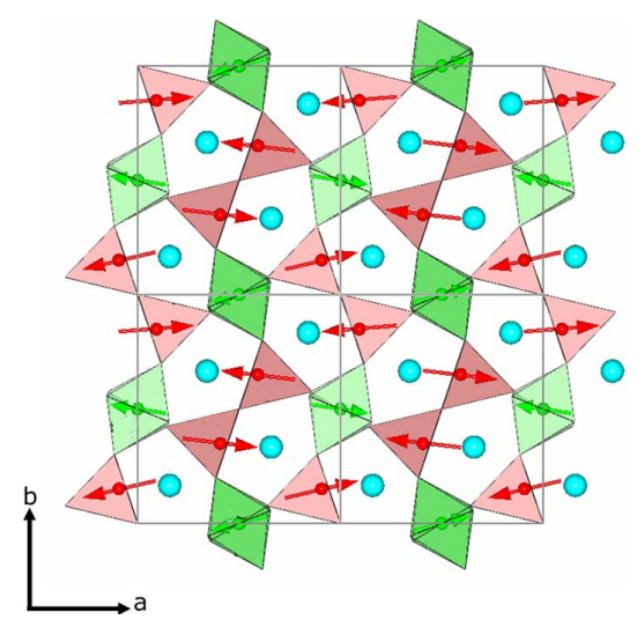

Figura 1.3 - Estrutura magnética de $\mathrm{BiMn}_{2} \mathrm{O}_{5}$ projetada no plano $a b$. A estrutura é mostrada em duas células unitárias, marcadas por linhas pretas ao longo dos eixos $a$ e $b$. As setas verdes e vermelhas representam os momentos magnéticos nos sítios de $\mathrm{Mn}^{4+} \mathrm{e} \mathrm{Mn}^{3+}$, respectivamente. Os poliedros $\mathrm{Mn}-\mathrm{O}$ correspondentes estão marcados com as mesmas cores.

Fonte: Adaptada de VECCHINI et al. ${ }^{17}$

ajustado por $C=\gamma T+\beta T^{3}+B T^{2}$, em que o coeficiente em primeira ordem na temperatura $(\gamma)$ é associado a contribuição de portadores livres de carga, a componente em $\mathrm{T}^{3}(\beta)$ a contribuição da rede e a componente em $\mathrm{T}^{2}(B)$ corresponde a ondas de spin antiferromagnéticas (mágnons antiferromagnéticos). ${ }^{18}$

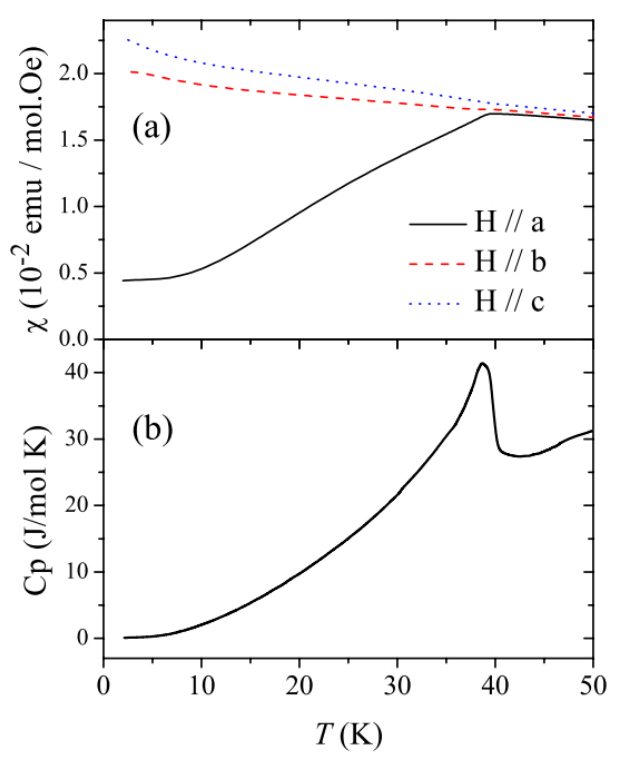

Figura 1.4 - Dependência com a temperatura da (a) susceptibilidade magnética obtida com um campo magnético externo $\mathbf{H}$ de $2 \mathrm{kOe}$ ao longo dos eixos $a, b$ e $c$ e do (b) calor específico de monocristais de $\mathrm{BiMn}_{2} \mathrm{O}_{5}$.

Fonte: GRANADO et al. ${ }^{18}$

A família $\mathrm{RMn}_{2} \mathrm{O}_{5}$ é particularmente interessante, pois nenhuma configuração de spin 
possível satisfaz todas as interações de super-troca $\mathrm{Mn}-\mathrm{O}-\mathrm{Mn}$ entre os octaedros e as piramides quadradas de oxigênio. Consequentemente, as estruturas magnéticas encontradas nestes materiais são frustradas. Abaixo da temperatura de ordenamento, pequenos deslocamentos atômicos ocorrem e fortalecem (enfraquecem) as interações não-frustradas (frustradas). Este é o mecanismo que explica qualitativamente o comportamento multiferróico da família $\mathrm{RMn}_{2} \mathrm{O}_{5}$, semelhante ao que foi ilustrado na Figura 1.1(b). Mudanças no parâmetro de rede a em função da temperatura para $\mathrm{BiMn}_{2} \mathrm{O}_{5}$ observadas a partir de difração de raios-X de alta resolução indicam a existência de deslocamento atômico na fase ordenada, sugerindo um comportamento de magnetostrição. ${ }^{18}$

Neste trabalho, apresentam-se informações a respeito das propriedades magnéticas deste material empregando medidas de RPE multi-frequência em amostras policristalinas de $\mathrm{BiMn}_{2} \mathrm{O}_{5}$. As constantes macroscópicas de anisotropia magnética foram obtidas a partir dos dados experimentais e permitiram uma estimativa da constante microscópica de anisotropia, que pode ser uma das contribuições mais relevantes para a anisotropia magnética neste sistema.

\section{Material e Métodos}

\subsection{Material}

Uma breve descrição dos detalhes experimentais da preparação da amostra será dada a seguir, mas informações mais detalhadas a respeito da preparação do material podem ser encontradas na referência 19. Sintetizou-se a amostra usando o método de Pecchini: quantidades estequiométricas de nitrato de bismuto $\left(\mathrm{Bi}\left(\mathrm{NO}_{3}\right)_{3}\right)$ e acetato de manganês II $\left(\mathrm{C}_{6} \mathrm{H}_{9} \mathrm{MnO}_{6}\right)$ foram dissolvidas numa solução $50 \mathrm{~mol} \%$ de ácido cítrico em etilenoglicol a qual foi posta em aquecimento em banho maria a $90^{\circ} \mathrm{C}$ e agitada até a formação de um gel amarelo homogêneo. Esta solução, por sua vez, foi aquecida a $600^{\circ} \mathrm{C}$ por $12 \mathrm{~h}$ para secagem. Após a homogeneização em almofariz de ágata do pó formado, a amostra foi calcinada por $12 \mathrm{~h}$ a $850^{\circ} \mathrm{C}$ em ar resultando em um pó cinza escuro que foi utilizado neste estudo. 


\subsection{Métodos}

Medidas de difração de raios- $X$ foram feitas no modo Debye-Scherrer usando um difratô-

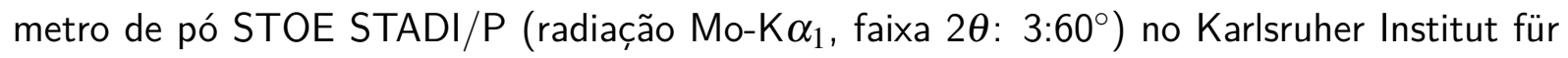
Technologie/Alemanha. O método de Rietveld foi utilizado para refinamento da estrutura usando software Winplotr para confirmar que a amostra só possui a fase cristalina desejada (Figura 1.5).

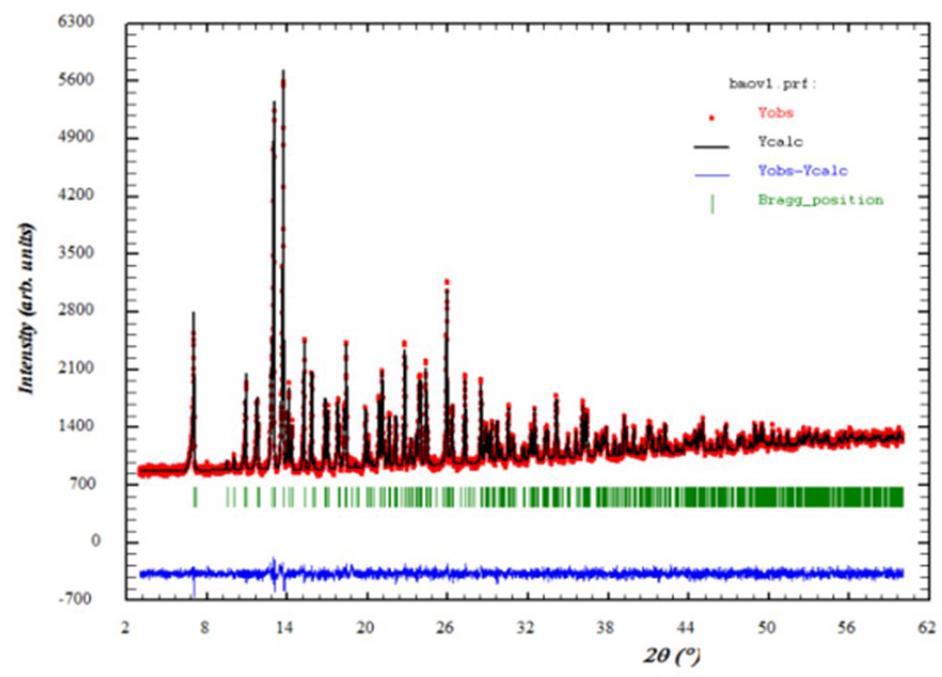

Figura 1.5 - Difração de raio $X$ da amostra policristalina de $\mathrm{BiMn}_{2} \mathrm{O}_{5}$ à temperatura ambiente. $A$ estrutura tem simetria Pbam com parâmetros de rede $(\AA)$ : $a=7.5605(1), b=8.5305(1)$, $\mathrm{c}=5.7594(1)$.

Fonte: Elaborada pelo autor.

Enviamos a amostra para o Laboratório Nacional de Altos Campos Magnéticos em Tallahasse/EUA, onde os espectros de RPE em alta frequência foram obtidos. Entre os experimentos realizados, temos:

- medidas na frequência de $328.8 \mathrm{GHz}$ de 0 a $14 \mathrm{~T}$ a três temperaturas distintas: na fase paramagnética a $50 \mathrm{~K}$ e na fase antiferromagnética a $20 \mathrm{~K}$ e $5 \mathrm{~K}$;

- medidas na fase antiferromagnética a $5 \mathrm{~K}$ de 0 a $5 \mathrm{~T}$ nas frequências de $203.2 \mathrm{GHz}$, $209.6 \mathrm{GHz}$ e $219.2 \mathrm{GHz}$;

- medidas na fase antiferromagnética a $5 \mathrm{~K}$ de 0 a $14 \mathrm{~T}$ nas frequências de $304.8 \mathrm{GHz}$, $328.8 \mathrm{GHz}, 406.4 \mathrm{GHz}$ e $435.2 \mathrm{GHz}$.

Experimentos de RPE em banda $X$ foram realizados no espectrômetro Varian E-109 equipado com criostato Oxford entre $4 \mathrm{~K}$ e $300 \mathrm{~K}$ (IFSC/USP). 


\section{Resultados e discussão}

Os espectros a 328.8 GHZ em três temperaturas distintas são mostrados na Figura 1.6. A $50 \mathrm{~K}$, acima da temperatura de Néel de $40 \mathrm{~K}$, uma linha de ressonância larga com g 2 é observada. Esta linha é atribuída ao $\mathrm{Mn}^{4+}$ e também é observada a $300 \mathrm{~K}$ em banda $\mathrm{X}$ com g $\sim 2$ e $\Delta H=680 \mathrm{mT}$ (inset da Figura 1.6). Abaixo da temperatura de Néel, tanto a $20 \mathrm{~K}$ quanto a $5 \mathrm{~K}$, duas ressonâncias são observadas as quais atribuímos a modos de ressonância antiferromagnética (AFMR). Uma delas, em campo menor, aparece somente na fase antiferromagnética. A outra, em campo mais alto, também está atribuída a um modo de ressonância antiferromagnética, embora também seja observada mais larga e em campo maior na fase paramagnética. As retas verticais tracejadas indicam ressonâncias devido ao oxigênio molecular condensado no ressoador e não estão relacionadas ao sinal intrínseco da amostra.

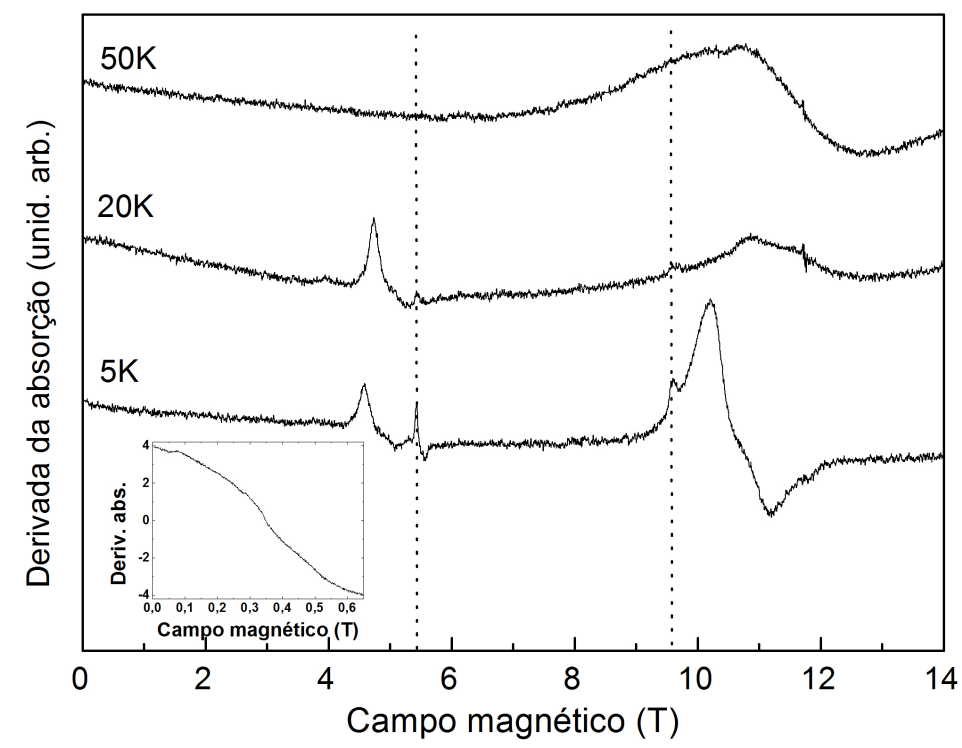

Figura 1.6 - Espectros de RPE a $328.8 \mathrm{GHz}$ para amostra policristalina de $\mathrm{BiMn}_{2} \mathrm{O}_{5}$ em três temperaturas. As retas verticais tracejadas indicam ressonâncias devido ao oxigênio molecular e não estão relacionadas ao sinal intrínseco da amostra. Inset: espectro de RPE em banda $\mathrm{X}$ a $300 \mathrm{~K}$.

Fonte: Elaborada pelo autor.

Na Figura 1.7, os espectros em várias frequências a $5 \mathrm{~K}$ são exibidos. As ressonâncias indicadas por um círculo preto correspondem aos sinais intrínsecos à amostra enquanto os asteriscos indicam a posição das linhas de ressonância do oxigênio molecular*. As ressonâncias referentes a amostra serão interpretadas segundo a teoria de Yosida e Nagamiya para a ressonância antiferromagnética. ${ }^{21}$ As expressões analíticas para os modos não foram encontradas

*Conforme simulado usando o EasySpin e identificado com os parâmetros retirados da referência 20 
explicitamente na literatura. Por isso, acreditamos que a relevância deste trabalho esteja na aplicabilidade da teoria de ressonância antiferromagnética.

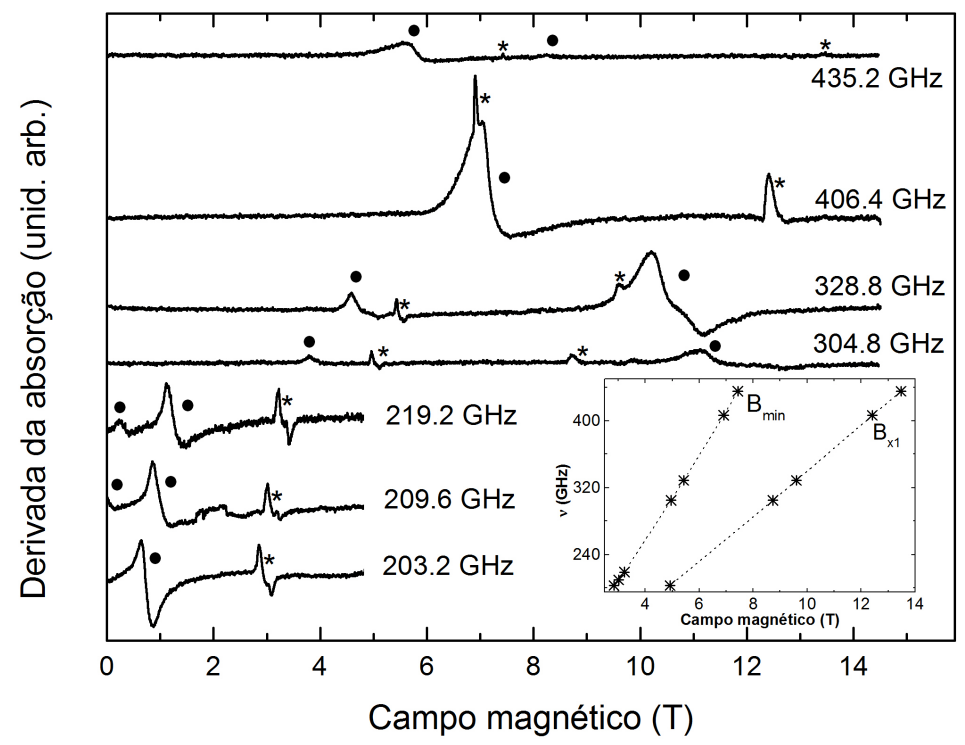

Figura 1.7 - Espectros de RPE em múltiplas frequências para amostra policristalina de $\mathrm{BiMn}_{2} \mathrm{O}_{5}$ a $5 \mathrm{~K}$. As linhas marcadas com um círculo preto são referentes à amostra. As linhas marcadas com asterisco correspondem ao oxigênio molecular. Inset: posição dos modos paramagnéticos do oxigênio molecular identificados de acordo com a referência ${ }^{20}$. Fonte: Elaborada pelo autor.

\subsection{Teoria da ressonância antiferromagnética}

Em substâncias antiferromagnéticas ordinárias, a rede de íons paramagnéticos é dividida em duas sub-redes. No estado antiferromagnético, os spins de uma das redes estão em paralelo uns com os outros e antiparalelos em relação aos spins da outra sub-rede. O estado pode ser visualizado como se houvessem dois vetores de magnetização $\mathbf{M}^{+}$e $\mathbf{M}^{-}$, antiparalelos entre si, cada um correspondendo a magnetização total da respectiva subrede. As discussões a seguir são para um modelo de duas sub-redes, desconsiderando campo de desmagnetização e efeitos dissipativos. Seguindo Nagamiya, Yosida e Kubo ${ }^{21}$, procuramos por uma expressão para as frequências de ressonância antiferromagnética, partindo da taxa de variação do momento angular total do sistema, que é proporcional ao torque atuando sobre o sistema. Para cada sub-rede, temos que a variação temporal da magnetização é dada por

$$
\frac{1}{\gamma} \frac{d}{d t} \mathbf{M}^{ \pm}=\mathbf{M}^{ \pm} \times\left(\mathbf{H}+\mathbf{H}_{\mathbf{E}}^{ \pm}+\mathbf{H}_{\mathbf{A}}^{ \pm}\right)
$$

em que $\gamma=g \mu_{B} / \hbar$ onde o fator $g$ é um fator de escala e $\mu_{B}$ é o magneton de Bohr e $\mathbf{H}$ 
é o campo externo aplicado. Os campos $\mathbf{H}_{\mathbf{E}}^{ \pm}$e $\mathbf{H}_{\mathbf{A}}^{ \pm}$são os campos de troca e anisotropia magnética de cada sub-rede, respectivamente. O campo de anisotropia origina-se do modelo fenomenológico da energia de anisotropia magnética. Para um cristal com simetria rômbica, essa energia é expressa como ${ }^{21,22}$

$$
E_{A}=\frac{1}{2}\left(K_{1} \beta^{+2}+K_{2} \gamma^{+2}\right)+\frac{1}{2}\left(K_{1} \beta^{-2}+K_{2} \gamma^{-2}\right)
$$

em que $\beta^{ \pm}$e $\gamma^{ \pm}$são, respectivamente, os cossenos diretores dos eixos y e $z$ dos momentos magnéticos nas duas sub-redes. Esta abordagem fenomenológica só é válida quando a interação de troca é tão forte que as magnetizações de cada sub-rede são aproximadamente anti-paralelas mesmo na presença de um campo externo. ${ }^{11}$ Se nenhum campo magnético é aplicado, o vetor magnetização aponta na direção para qual $E_{A}$ é mínima. Esta é a direção do eixo fácil de anisotropia que nós identificamos como a direção $x$. A aplicação de um campo magnético num ângulo $\theta_{H}$ com relação ao eixo fácil faz a magnetização tender para a direção perpendicular ao campo magnético, mas é impedida pela força de restauração oriunda da anisotropia magnética, com componentes do campo de anisotropia dadas por

$$
H_{A x}^{ \pm}=0, \quad H_{A y}^{ \pm}=-\frac{K_{1}}{M_{0}} \beta^{ \pm}, \quad H_{A z}^{ \pm}=-\frac{K_{2}}{M_{0}} \gamma^{ \pm}
$$

em que $M_{0}$ é o módulo da magnetização. O ângulo $\phi$ entre o eixo fácil e a direção da magnetização depende tanto do ângulo $\theta_{H}$ quanto do módulo do campo magnético, tendo sido calculado por Yosida como ${ }^{21,22}$

$$
\operatorname{tg} 2 \phi=\frac{\operatorname{sen} 2 \theta_{H}}{\cos 2 \theta_{H}-\left(\chi_{\perp}-\chi_{/ /}\right) 2 H^{2} / K_{j}},
$$

em que $K_{j}=K_{1}$ se $K_{2}>K_{1}$, caso contrário $K_{j}=K_{2}$. A frequência de oscilação em função do campo magnético aplicado no plano contendo o eixo fácil pode ser obtida resolvendo-se a equação

$$
\begin{aligned}
& \left(\frac{\omega}{\gamma}\right)^{4}-\left(\frac{\omega}{\gamma}\right)^{2}\left[H^{2}\left(\alpha^{2} \cos ^{2} \varphi+1\right)+c_{2}+c_{1}\left\{\cos ^{2}\left(\varphi-\theta_{H}\right)-2 \operatorname{sen}^{2}\left(\varphi-\theta_{H}\right)\right\}\right]+H^{4} \alpha^{2} \cos ^{2} \varphi- \\
& H^{2}\left[c_{1}\left\{\alpha \cos ^{2} \varphi \cos 2\left(\varphi-\theta_{H}\right)+\alpha \cos \varphi \operatorname{sen} \theta_{H} \operatorname{sen}\left(\varphi-\theta_{H}\right)+\operatorname{sen} \varphi \cos \theta_{H} \operatorname{sen}\left(\varphi-\theta_{H}\right)\right\}+\right. \\
& \left.c_{2}\left(\alpha \cos ^{2} \varphi-\operatorname{sen}^{2} \varphi\right)\right]+c_{1} \cos 2\left(\varphi-\theta_{H}\right)\left[c_{2}-c_{1} \operatorname{sen}^{2}\left(\varphi-\theta_{H}\right)\right]=0 .
\end{aligned}
$$

Essa expressão aplica-se para o campo magnético no plano $x y$. Para o campo aplicado no 
plano $x z$, os subíndices 1 e 2 da equação (3.5) devem ser intercambiados. Nessa expressão, $c_{1}=2 K_{1} / \chi_{\perp}$ e $c_{2}=2 K_{2} / \chi_{\perp}$, com $\chi_{/ /}$e $\chi_{\perp}$ sendo, respectivamente, as susceptibilidades magnéticas paralela e perpendicular ao eixo fácil, obtidas da referência 18 . O fator $\alpha=$ $\left(1-\chi_{/ / /} \chi_{\perp}\right)$ aparece devido à susceptibilidade residual em $5 \mathrm{~K}$. A partir da referência 18 ainda, identificamos a direção dos eixos $a, b$ e $c$ com os eixos $x, y$ e $z$, respectivamente.

Há quatro soluções matemáticas para $\omega / \gamma$ em função de $H$, segundo o modelo dado na equação (3.5), dentre as quais há duas positivas. Estas duas soluções, são dadas a seguir para cada valor de $\theta_{H}$

$$
\begin{aligned}
& \frac{\omega}{\gamma}=\frac{1}{2 \sqrt{2}}\left\{-2 \mathrm{c}_{1}+4 \mathrm{c}_{2}+4 H^{2}+2 \alpha^{2} H^{2}+2 \alpha^{2} H^{2} \cos 2 \varphi+6 \mathrm{c}_{1} \cos \left[2\left(\varphi-\theta_{H}\right)\right] \pm\right. \\
& \sqrt{2}\left[3 \mathrm{c}_{1}^{2}-8 \mathrm{c}_{1} \mathrm{c}_{2}+8 \mathrm{c}_{2}^{2}-8 \alpha \mathrm{c}_{1} H^{2}-4 \alpha^{2} \mathrm{c}_{1} H^{2}+16 \alpha \mathrm{c}_{2} H^{2}+8 \alpha^{2} \mathrm{c}_{2} H^{2}+8 H^{4}-\right. \\
& 8 \alpha^{2} H^{4}+3 \alpha^{4} H^{4}+4 H^{2}\left[-\left(2+2 \alpha+\alpha^{2}\right) \mathrm{c}_{1}+2\left(2+2 \alpha+\alpha^{2}\right) \mathrm{c}_{2}+\alpha^{2}\left(-2+\alpha^{2}\right) H^{2}\right] \cos 2 \varphi+ \\
& \alpha^{4} H^{4} \cos 4 \varphi+8 \alpha \mathrm{c}_{1} H^{2} \cos \left(4 \varphi-2 \theta_{H}\right)+6 \alpha^{2} \mathrm{c}_{1} H^{2} \cos \left(4 \varphi-2 \theta_{H}\right)+ \\
& 4 \mathrm{c}_{1}{ }^{2} \cos \left[2\left(\varphi-\theta_{H}\right)\right]-8 \mathrm{c}_{1} \mathrm{c}_{2} \cos \left[2\left(\varphi-\theta_{H}\right)\right]+16 \mathrm{c}_{1} H^{2} \cos \left[2\left(\varphi-\theta_{H}\right)\right]+ \\
& 24 \alpha \mathrm{c}_{1} H^{2} \cos \left[2\left(\varphi-\theta_{H}\right)\right]+12 \alpha^{2} \mathrm{c}_{1} H^{2} \cos \left[2\left(\varphi-\theta_{H}\right)\right]+\mathrm{c}_{1}{ }^{2} \cos \left[4\left(\varphi-\theta_{H}\right)\right]+ \\
& \left.\left.8 \mathrm{c}_{1} H^{2} \cos 2 \theta_{H}+16 \alpha \mathrm{c}_{1} H^{2} \cos 2 \theta_{H}+6 \alpha^{2} \mathrm{c}_{1} H^{2} \cos 2 \theta_{H}\right]^{1 / 2}\right\}^{1 / 2}
\end{aligned}
$$

e foram utilizadas no ajuste dos dados experimentais.

\subsection{Aplicação da teoria aos dados de $\mathrm{BiMn}_{2} \mathrm{O}_{5}$}

Na estrutura magnética, determinada por Muñoz et al. ${ }^{16}$ a $1.6 \mathrm{~K}$, os sítios de $\mathrm{Mn}^{3+}$ são descritos pela representação $\mathrm{F}_{x}=-3.12 \mu_{B}$ e $\mathrm{C}_{y}=-0.8 \mu_{B}$, e o sítios de $\mathrm{Mn}^{4+}$ pela representação $\mathrm{G}^{\prime}{ }_{x}=2.44 \mu_{B}$ e $\mathrm{A}_{y}^{\prime}=0.6 \mu_{B}$. A partir desse dados, assumimos um modelo de duas sub-redes com mesmo módulo e direção antiparalela correspondendo aos íons de $\mathrm{Mn}^{3+}$ e $\mathrm{Mn}^{4+}$. Os eixos $a, b$ e $c(x, y$ e $z)$ correspondem aos eixos fácil, intermediário e duro, respectivamente, a partir dos dados de susceptibilidade do monocristal. ${ }^{13,18}$

A fim de explicitar os modos de ressonância $\omega$ versus $H$, o campo central das linhas de ressonância da amostra indicados por círculos pretos na Figura 1.7 foram representados em função da frequência na Figura 1.8 .

Na busca por um modo de ressonância antiferromagnética com o campo magnético para- 


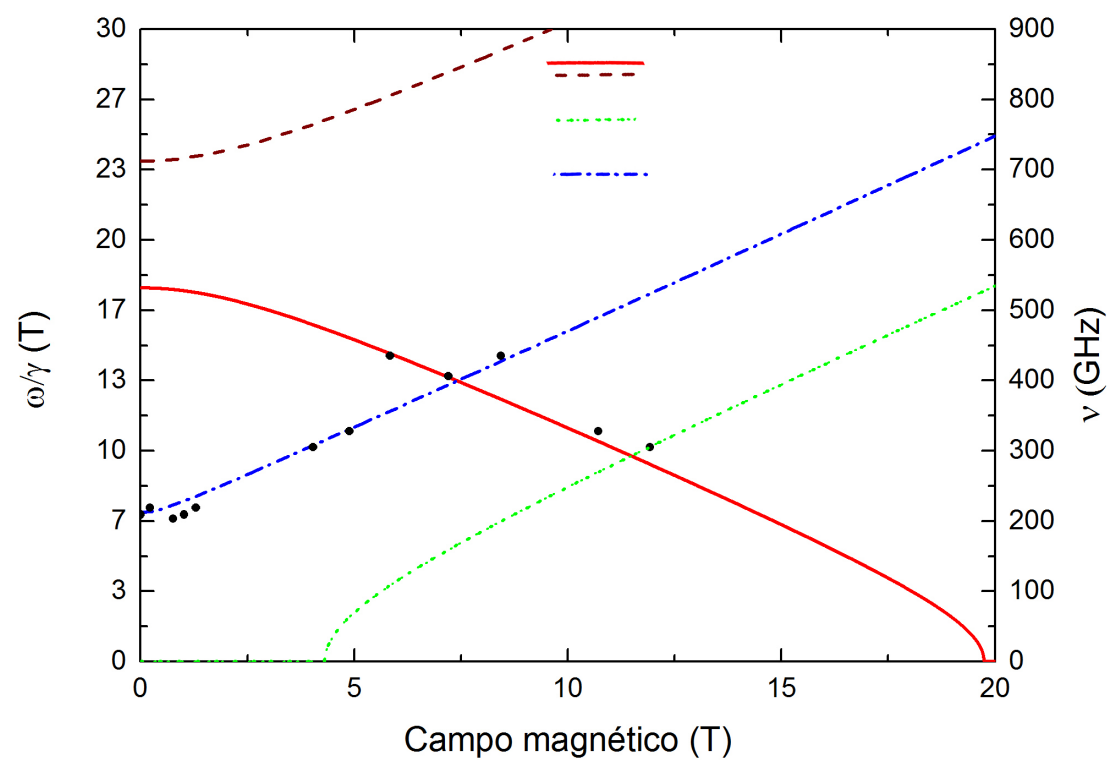

Figura 1.8 - Os pontos mostram a dependência do campo com a frequência da micro-onda das linhas de ressonância observadas nos espectros em múltiplas frequências da figura 1.7. Os modos AFMR obtidos com o modelo de Yosida e Nagamiya para o campo magnético paralelo ao eixo fácil (linha vermelha cheia e marrom tracejada), perpendicular ao eixo fácil (linha verde pontilhada) e fazendo um ângulo de $43^{\circ} \mathrm{com}$ o eixo fácil (linha azul traço-pontilhada) são mostrados. Os parâmetros que melhor ajustam os dados experimentais são $g=2.2, K_{1}=7.0 \times 10^{8}\left(\mathrm{emu} \mathrm{Oe} \mathrm{mol}^{-1}\right)$ e $K_{2}=3.9 \times 10^{8}(\mathrm{emu} \mathrm{Oe}$ $\left.\mathrm{mol}^{-1}\right)$.

Fonte: Elaborada pelo autor.

lelo ao eixo fácil, utilizamos o campo de spin flop ${ }^{\dagger}$ determinado experimentalmente por Kim et al. ${ }^{13}$ em $0.66 \mathrm{~K}$ e $17.5 \mathrm{~K}$ para estimar um campo de spin flop de $19 \mathrm{~T}$ a $5 \mathrm{~K}$. Dado este campo, $K_{1}>K_{2}$ é uma condição necessária para ajustar os dados à equação (3.6). A curva vermelha na figura 1.8 corresponde a este modo paralelo ajustado. A condição $K_{1}>K_{2}$ implica que o modo AFMR do eixo fácil é observado no plano $x z$. A ressonância em mais alto campo a $304.8 \mathrm{GHz}$ que pertence a esse modo é mais larga em relação às outras frequências, sem um centro muito bem definido. Assumimos que essa ressonância seja uma superposição dos modos paralelo e perpendicular (curvas vermelha cheia e verde pontilhada, respectivamente, Figura 1.8), este último sendo aquele para o qual o campo magnético é aplicado na direção $z$. O campo de spin flop de 19 T determina a constante de anisotropia $K_{2}=3.9 \times 10^{8} \mathrm{emu}$ Oe $\mathrm{mol}^{-1}$, que corresponde ao campo no qual $\omega / \gamma$ é igual a zero na Figura 1.8, isto é, o maior campo magnético do modo paralelo. Os modos paralelo e perpendicular da Figura 1.8 foram encontrados a partir da equação (3.6) com $g=2.2$ e $\theta_{H}$ igual a zero e $\pi / 2$, respectivamente.

\footnotetext{
${ }^{\dagger} O$ campo de spin flop corresponde a um valor de campo magnético crítico suficiente para orientar os spins na direção perpendicular à magnetização do eixo fácil. Como foi dito, aplicar um campo magnético na direção paralela à magnetização dá a ela uma tendência a se orientar na direção perpendicular, impedida pela força de restauração oriunda da energia de anisotropia. O campo crítico corresponde ao campo em que a energia de anisotropia é insuficiente para restaurar a orientação da magnetização para o eixo fácil.
} 
A curva em azul foi obtida para $\theta_{H}=\pi / 4.17$ e $K_{1}=7.0 \times 10^{8}$ emu Oe mol ${ }^{-1}$, com o mesmo valor para $g$ e $K_{2}$, e concorda razoavelmente com nove dos pontos experimentais, que possivelmente correspondem a esse modo. Esse modo varia drasticamente com uma mudança de $5 \%$ no valor de $K_{1}$ enquanto os outros modos, identificados como paralelo e perpendicular ao eixo fácil, são insensíveis a essa variação. O valor de $K_{1}$ fixa a posição do modo paralelo de frequências mais altas (curva marrom, Figura 1.8), que estava fora da faixa experimental disponível para medida.

Os modos de ressonância antiferromagnética a $5 \mathrm{~K}$ observados nessa amostra policristalina correspondem àqueles com o campo magnético aplicado no plano $x z$. Três modos foram identificados de acordo com a teoria de Yosida e Nagamiya, a partir do valor experimental para o campo de spin flop: um modo para o campo magnético aplicado paralelo ao eixo fácil eixo $x$; um ponto experimental pertencente a um modo com o campo magnético aplicado na direção perpendicular ao eixo fácil (eixo $z$ ); e um modo com o campo magnético fazendo um ângulo de aproximadamente $43^{\circ}$ com o eixo fácil. Vimos experimentalmente a linha de campo zero deste modo, cuja frequência é de $203 \mathrm{GHz}\left(6.8 \mathrm{~cm}^{-1}\right)$. O modo dos eletromagnons $\ddagger$ em $\mathrm{YMn}_{2} \mathrm{O}_{5}$ foi observado a $7.2 \mathrm{~cm}^{-1}$ a $7 \mathrm{~K}^{23}$. Apesar de terem energia semelhantes, não temos maiores justificativas para sugerir a interação mágnon-fónon como explicação para esse modo. Além disso, eletromagnons não são esperados em fases comensuráveis, em particular em $\mathrm{BiMn}_{2} \mathrm{O}_{5} \cdot{ }^{24}$

As constantes de anisotropia magnética obtidas também podem ser expressas em erg $/ \mathrm{cm}^{3}$. O volume molecular é calculado a partir da expressão

$$
V_{m}=N_{A} V_{\text {cell }} / Z
$$

em que $N_{A}$ é a constante de Avogadro, $Z=4$ é o número de unidades moleculares na célula unitária e $V_{\text {cell }}$ é o volume da célula unitária na fase antiferromagnética de $\mathrm{BiMn}_{2} \mathrm{O}_{5}{ }^{18}$. Sendo assim, $K_{2}=7.0 \times 10^{6} \mathrm{erg} / \mathrm{cm}^{3}$ e $K_{1}=12.5 \times 10^{6} \mathrm{erg} / \mathrm{cm}^{3}$.

A origem microscópica da anisotropia magneto-cristalina é o acoplamento spin-órbita. O mecanismo mais comum e normalmente o mais forte para a anisotropia magnética é a anisotropia de sítio único (single-site anisotropy). ${ }^{25}$ Para $\mathrm{Mn}^{3+}$ alto spin num campo cristalino quadrado-piramidal $\left(\mathrm{S}=2, t_{2 g}^{3} e_{g}^{1}\right)$, o estado $t_{2 g}$ se separa num singleto de energia mais alta e num dubleto levemente separado de energia mais baixa. Para $\mathrm{Mn}^{4+}$ alto spin num campo octaédrico $\left(\mathrm{S}=3 / 2, t_{2 g}^{3}\right)$, o estado fundamental é um singleto orbital ${ }^{6}$. No caso de um singleto

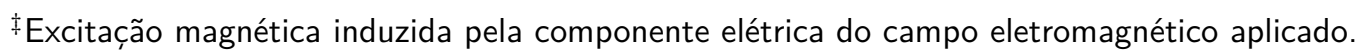


orbital com níveis $t_{2 g}$ semi preenchidos, o acoplamento spin-órbita resulta elementos de matriz em segunda ordem entre o estado fundamental e os níveis $e_{g}$. Nesse caso, a energia de interação pode ser expressa por

$$
K^{\prime} \sim \frac{\lambda^{2}}{\delta E}
$$

em que $\lambda$ é a constante de spin-órbita do íon livre e $\delta E$ é a separação entre os níveis devido ao campo cristalino. Essa situação também é válida para $\circ \mathrm{Mn}^{3+}$ com estado fundamental orbital levemente separado, como discutido por Abragam e Bleaney ${ }^{6}$, que classificaram ambos como íons do tipo A. Para anisotropia magnética axial, a energia de anisotropia de sítio-único pode ser escrita da seguinte forma ${ }^{26}$ :

$$
H_{s u}=-K^{\prime} \sum_{i} S_{x i}^{2}
$$

A constante macroscópica de anisotropia uniaxial $\mathrm{K}$ em $\mathrm{T}=0 \mathrm{~K}$ pode ser escrita em termos da constante microscópica de anisotropia de sítio-único como:

$$
K=K^{\prime} S(S-1 / 2)
$$

Levando em consideração a contribuição de ambos $\mathrm{Mn}^{3+}$ e $\mathrm{Mn}^{4+}$ na equação (3.10), $K=3 K^{\prime}+3 K^{\prime} / 2=9 K^{\prime} / 2$. Escolhendo o valor médio entre $\mathrm{K}_{1}$ e $\mathrm{K}_{2}$ como $\mathrm{K}=9.8 \times 10^{6}$ $\mathrm{erg} / \mathrm{cm}^{3}$ ou $4.6 \mathrm{~cm}^{-1} /$ molécula ( $Z=4$ e volume da célula unitária dado pela referência 18 ), a constante de anisotropia de sítio-único é

$$
K^{\prime}=1.0 \mathrm{~cm}^{-1} / \text { molécula } \text {. }
$$

Usando a equação (3.8), um valor de $\lambda \sim 10^{2} \mathrm{~cm}^{-1}$ implica em $\delta \mathrm{E} \sim 10^{4} \mathrm{~cm}^{-1}$. Esses valores concordam razoavelmente com $\lambda=88 \mathrm{~cm}^{-1}$ e $\lambda=134 \mathrm{~cm}^{-1}$ para $\mathrm{Mn}^{3+}$ e $\mathrm{Mn}^{4+}$, respectivamente, e uma estimativa de separação entre os níveis cristalinos de $10^{4} \mathrm{~cm}^{-1}$ para elétrons $d^{3} .6$ 


\section{Conclusões}

No presente capítulo, demonstramos uma das abordagens possíveis de aplicação da técnica de RPE na fase antiferromagnética de um óxido com propriedades multiferróicas.

Aplicando a teoria fenomenológica de Yosida e Nagamiya ${ }^{21}$, pudemos identificar as ressonâncias em altas frequências e altos campos de uma amostra policristalina de $\mathrm{BiMn}_{2} \mathrm{O}_{5}$ com os modos de ressonância antiferromagnética. Apesar de estarmos lidando com uma amostra em pó, os modos observados correspondem àqueles com o campo magnético aplicado no plano $z y$. A obtenção das constantes de anisotropia magnética macroscópica a partir dos dados experimentais permitiu uma estimativa da constante microscópica de anisotropia magnética, com resultados em boa concordância com outros materiais na literatura. ${ }^{6} \mathrm{~A}$ observação de modos de ressonância antiferromagnética e a determinação da constante de anisotropia dá suporte à sugestão dos resultados de difração de raio- $X$ na literatura, que indicam a magnetoelasticidade como um dos possíveis mecanismos para o surgimento da fase ferroelétrica nesse material. 


\title{
Ludwigita homometálica de ferro, $\mathrm{Fe}_{3} \mathrm{O}_{2} \mathrm{BO}_{3}$
}

\author{
"Às vezes, porém, é mais fácil descobrir \\ uma verdade do que the assinalar o lugar \\ que the cabe." \\ Ferdinand de Saussure
}

\section{Revisão bibliográfica}

A física de materiais com fortes correlações eletrônicas têm sido extensivamente estudada devido à variedade de fenômenos interessantes que estes materiais revelam como, por exemplo, transições metal-isolante, onda de densidade de carga (ordenamento de carga) e spin, coexistência de fases ordenadas e desordenadas, magnetoresistência gigante, supercondutividade a alta temperatura, entre outros, como a multiferroicidade apresentada no capítulo anterior. A descrição da energia de sistemas como metais simples, semicondutores e isolantes usando um campo médio estático é suficiente, em geral. Mas em metais de transição, como ferro, vanádio, manganês e seus óxidos, os elétrons estão sujeitos a uma forte repulsão coulombiana devido ao seu confinamento espacial em orbitais semi-preenchidos do tipo $d$ (ou $f$, no caso das terras raras). Uma discussão mais profunda sobre a complexidade desses sistemas, a física envolvida e seus complicados diagramas de fase está fora do escopo desta tese. No entanto, se for do interesse do leitor, recomenda-se a leitura das referências 12 e 27 , que são revisões interessantes sobre esses sistemas. Recomenda-se também os livros 25 e 28 que tratam dos fenômenos mencionados e toda a física envolvendo sistemas fortemente correlacionados.

O ordenamento de carga é um importante fenômeno que ocorre em manganitas e óxidos de cobre, mas também em óxidos de ferro com valência mista, sendo a transição de Verwey na magnetita um exemplo clássico. ${ }^{30} \mathrm{O}$ comportamento de óxidos de metais de transição isolantes 


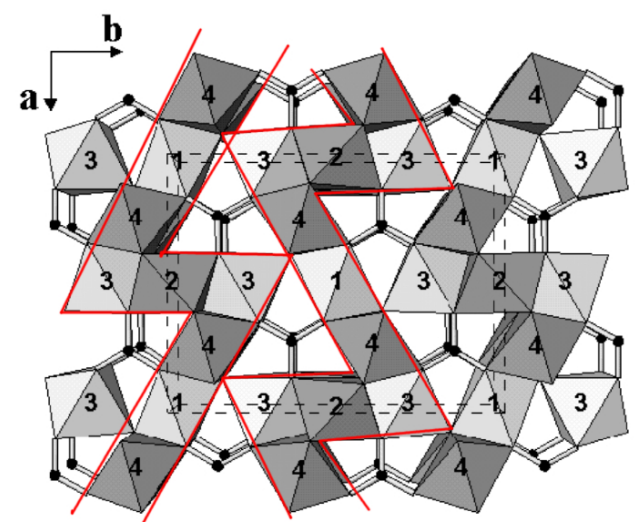

Figura 2.1 - Vista perspectiva da estrutura de $\mathrm{Fe}_{3} \mathrm{O}_{2} \mathrm{BO}_{3}$ projetada no plano perpendicular ao eixo c. As tríades 4-2-4 formam "degraus" de uma "escada de três pernas" ao longo do eixo $c$, sendo que cada perna é dada por uma cadeia de íons 4,2 e 4 ao longo do eixo $c$ (perpendicular ao plano mostrado na figura). As linhas tracejadas indicam os lados $a$ e $b$ da célula unitária e as linhas contínuas vermelhas indicam "paredes" que delimitam estruturas quase bi-dimensionais em zig-zag no plano $a b$.

Fonte: Adaptada de MIR et al. ${ }^{29}$

está relacionado a presença de unidades de baixa dimensão em sua estrutura cristalina. ${ }^{31}$ Algumas famílias de oxiboratos apresentam combinações de correlações eletrônicas fortes e efeitos de baixa dimensão como, por exemplo, a classe de oxiboratos de fórmula molecular $\mathrm{M}_{2}^{\prime 2+} \mathrm{M}^{3+} \mathrm{O}_{2} \mathrm{BO}_{3}\left(\mathrm{M}, \mathrm{M}^{\prime}=\right.$ metal). Essa classe consiste em sistemas isoestruturais ao mineral ludwigita, em que $\mathrm{M}^{\prime}=\mathrm{Mg}$ e $\mathrm{M}=\mathrm{Fe}$. A vonsenita, $\mathrm{Fe}_{3} \mathrm{O}_{2} \mathrm{BO}_{3}$, também chamada na literatura de ludwigita homometálica de ferro, é um desses oxiboratos que se cristaliza num sistema com simetria ortorrômbica, grupo espacial Pbam, com os parâmetros de rede dados por $a=$ $9.462 \AA, b=12.308 \AA$ e $c=3.075 \AA$, à temperatura ambiente. Um esquema da estrutura cristalográfica em temperatura ambiente é mostrado na Figura 2.1.

Seguindo as definições da Figura 2.1, os sítios 1, 2 e 3 são ocupados por íons de $\mathrm{Fe}^{2+}$ e o sítio 4 é ocupado por íons de $\mathrm{Fe}^{3+}$. Enquanto os sítios 1 e 3 são sempre divalentes, o elétron do $\mathrm{Fe}^{2+}$ do sítio Fe2 fica compartilhado dentro de tríade de Fe4-Fe2-Fe4. A valência destes sítios 2 e 4 varia de acordo com a temperatura, enquanto os sítios 1 e 3 são predominantemente divalentes em todas as fases deste material. ${ }^{32}$ As tríades mencionadas são consideradas subestruturas unidimensionais que se repetem infinitamente ao longo do eixo $c$ formando os "degraus" de uma "escada de três pernas" (3LL, sigla do inglês para three-leg ladders), como pode ser visto na Figura 2.2(a). ${ }^{29}$ Todos os sítios estão contidos no centro de octaedros de oxigênio que compartilham arestas, formando paredes em zig-zag numa estrutura quase bi-dimensional no plano $a b$ (ver linhas em vermelho na Figura 2.1) sendo que os sítios 1 e 3 encontram-se no plano $z=1 / 2$ e os sítios 2 e 4 no plano $z=0$. Grupos $\mathrm{BO}_{3}$ trigonais unem os planos. Por volta de $283 \mathrm{~K}$, o composto sofre uma transição estrutural para o grupo 
espacial de menor simetria Pbnm, em que o parâmetro de rede $c$ é dobrado $\left(a^{\prime}=a, b^{\prime}=b\right.$ e $\left.c^{\prime}=2 c\right) .{ }^{33}$ Bordet et al. ${ }^{34}$ observou características dessa duplicação do parâmetro de rede já a 290 K. Essa mudança na estrutura em que os sítios Fe4 se aproximam ou se afastam do sítio Fe2 alternadamente ao longo do eixo $c$ é ilustrada na Figura 2.2, na qual se pode observar que a posição cristalográfica $\mathrm{Fe} 4$ passa a ser distinguida entre $\mathrm{Fe} 4 \mathrm{a}$ ou $\mathrm{Fe} 4 \mathrm{~b}$ de acordo com a distância ao Fe2, compondo uma formação em zig-zag dos íons de $\mathrm{Fe} 2$ nos degraus ao longo das escadas de três pernas. A distância Fe2-Fe4 de $2.79 \AA \AA$ na fase de alta temperatura passa a ser $2.95 \AA ̊$ entre Fe2-Fe4b e $2.61 \AA$ entre Fe2-Fe4a. Assim, essa transição pode ser vista como uma dimerização na tríade, com Fe4a-Fe2 formando o dímero de ferro. A distância entre os íns de ferro ao longo do eixo $c$ é de $3.08 \AA$ e mantém-se aproximadamente a mesma após a transição estrutural.
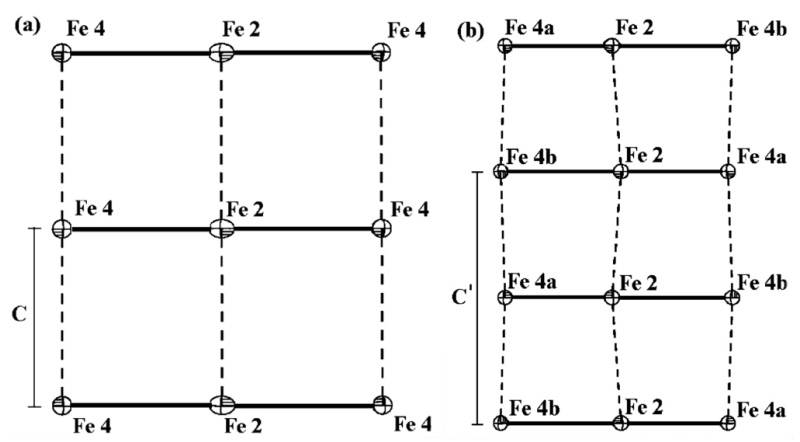

Figura 2.2 - Colunas de tríades (escada) (a) acima e (b) abaixo da transição de fase estrutural. Fonte: MIR et al. ${ }^{29}$

Há duas estruturas 3LL magneticamente não-equivalentes, isto é, não há uma operação de inversão que leva uma estrutura à outra de modo que a projeção de um campo magnético externo aplicado numa dada direção será diferente para cada uma delas. O eixo dos octaedros de oxigênio do centro de cada uma das $3 \mathrm{LL}$ formam um ângulo de $70^{\circ}$ entre si, como pode ser observado na Figura 2.3. Estes octaedros do centro das tríades são aqueles nos quais residem os sítios Fe2.

A dimerização também fica evidente a partir da Figura 2.4, em que se pode observar a aproximação do $\mathrm{Fe} 2$ a um dos Fe4 na tríade. Ainda nessa figura, percebe-se que a valência do Fe4a se aproxima da valência do Fe2 para um valor intermediário, $\sim+2.53$, enquanto a valência do Fe4b tende para um valor mais próximo de +3 , como indicativo da localização do elétron no dímero. A anisotropia no parâmetro de deslocamento atômico*, revelada pelo termo fora da diagonal U12, indica que os pares Fe2-Fe4 existem mesmo na fase de alta

* O parâmetro de deslocamento atômico é dado por um tensor que é diagonal quando a densidade eletrônica está distribuída uniformemente ao redor do sítio, ou seja, quando é isotrópica. Termos fora da diagonal indicam vibração atômica ou deslocamento da nuvem elétronica numa direção preferencial, que nesse caso, corresponde a direção da linha que separa os sítios 2 e 4 . 


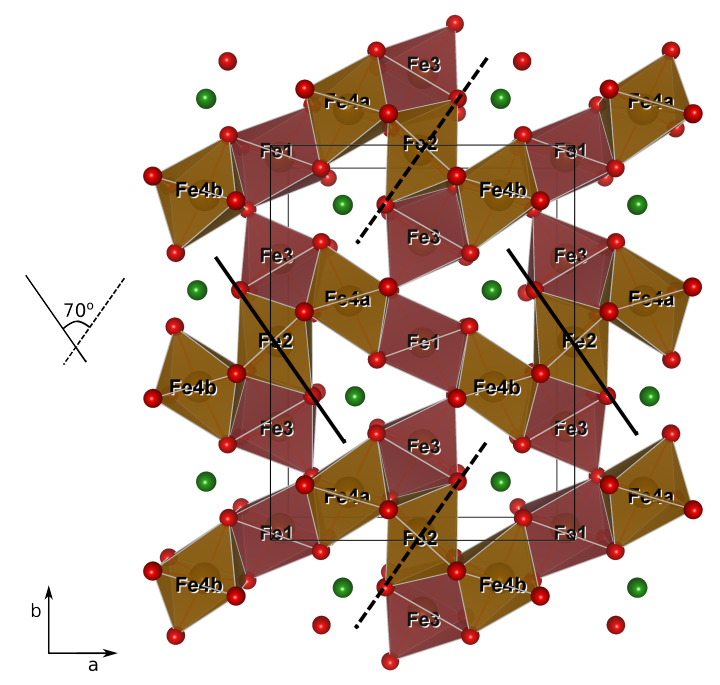

Figura 2.3 - Projeção da estrutura do oxiborato $\mathrm{Fe}_{3} \mathrm{O}_{2} \mathrm{BO}_{3}$ no plano ab evidenciando as duas tríades magneticamente não-equivalentes e o ângulo de $70^{\circ}$ entre os íons de $\mathrm{Fe} 2$ no centro de cada uma delas (linhas contínua e pontilhada).

Fonte: Elaborada pelo autor.

temperatura, mas estão dinamicamente desordenados entre os dois lados do degrau de modo que a transição também pode ser vista como um ordenamento de pares ou dos elétrons que são responsáveis pela existência deles. A diminuição da energia térmica ao resfriar o sistema pode ser a responsável por induzir a localização dos pares Fe2-Fe4. A organização alternada dos dímeros Fe2-Fe4 no eixo $c$ seria um modo de minimizar os efeitos de distorção estrutural induzidos por essa localização. Como pode ser visto ainda nessa figura, a transição ocorre numa larga faixa de temperatura e o valor em que as valências dos íons de ferro saturam não corresponde a um ordenamento de carga completo mesmo a $110 \mathrm{~K}$. Isso tem importantes consequências no comportamento magnético deste material, pois o processo de ordenamento magnético vai ocorrer num contexto dinâmico de desordem de carga, pelo menos dentro das tríades. $^{34}$

Outros óxidos de ferro de valência mista como a warwickita $\mathrm{Fe}_{2} \mathrm{OBO}_{3}$ e a magnetita $\mathrm{Fe}_{3} \mathrm{O}_{2}$ também sofrem uma transição estrutural ortorrômbica-monoclínica causada pela localização de carga, que ocorre a temperaturas bem diferentes das transições de ordem magnética nesses materiais. ${ }^{36}$ Já na ludwigita $\mathrm{Fe}_{3} \mathrm{O}_{2} \mathrm{BO}_{3}$ estudada nesta tese, há três fases magnéticas distintas que ocorrem a temperaturas inferiores à transição estrutural sendo que a temperatura de ordenamento dos ferros nos degraus das escadas é próxima àquela em que a posição dos sítios de Fe2 se estabiliza ao resfriar-se a amostra a partir de temperatura ambiente.

Uma das transições magnéticas observadas ocorre somente na tríade Fe4-Fe2-Fe4 e foi detectada por medidas de espectroscopia Mössbauer ${ }^{32}$ a $112 \mathrm{~K}$, também observada por calor 


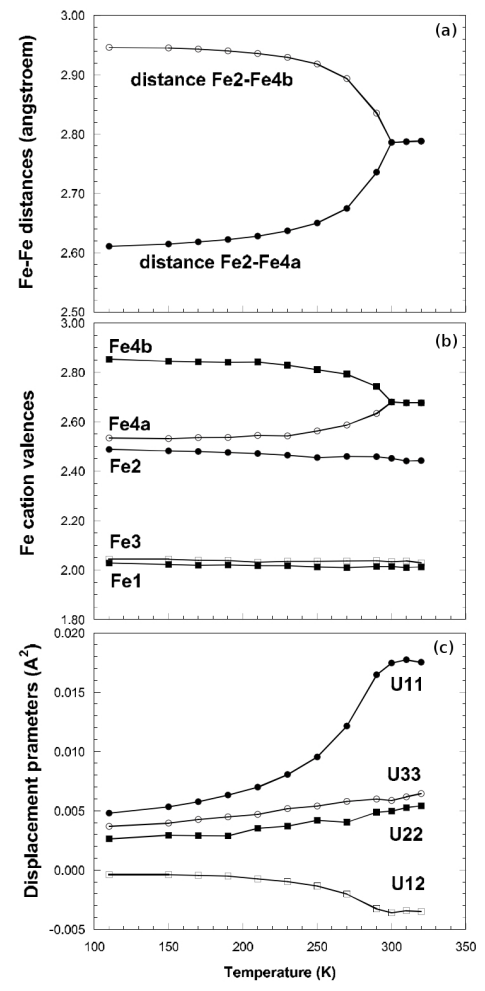

Figura 2.4 - Ordenamento de carga e formação do par de cátions de ferro em $\mathrm{Fe}_{3} \mathrm{O}_{2} \mathrm{BO}_{3}$. (a) Distâncias Fe-Fe dentro dos degraus Fe4-Fe2-Fe4 nas escadas. (b) Valências dos íons de ferro calculadas pelo método da soma das valências de ligação. ${ }^{35}$ (c) Parâmetro de deslocamento atômico para o Fe2.

Fonte: BORDET et al. ${ }^{34}$

específico ${ }^{30}$ e confirmada por medidas de difração de nêutrons. ${ }^{34}$ Essa transição corresponde ao ordenamento antiferromagnético dos momentos magnéticos dos sítios $\mathrm{Fe} 2$ e Fe4 nas escadas ao longo do eixo $c$. Os momentos nos sítios Fe1 e Fe3 permanecem desordenados até 70 $\mathrm{K}$, temperatura na qual se ordenam ferromagneticamente ao longo do eixo $c$ numa direção perpendicular aos momentos nos sítios das tríades. Sendo assim, pode-se dividir os sistema em duas sub-redes magnéticas: os momentos nos sítios 2 e 4 formando uma delas e os momentos nos sítios 1 e 3 formando a outra. O acoplamento magnético entre essas duas sub-redes é muito fraco com a coexistência de antiferromagnetismo e paramagnetismo entre $112 \mathrm{~K}$ e $70 \mathrm{~K}$. O alinhamento perpendicular dos momentos nas duas sub-redes ordenadas é postulado como consequência da frustração entre elas. ${ }^{37}$ Esse acoplamento ferromagnético dos sítios de fora da tríade ao longo do eixo $c$ a $70 \mathrm{~K}$ pode ser visto como uma transição de maior intensidade observada no calor específico, enquanto a transição nas tríades a $112 \mathrm{~K}$ é menos acentuada nesta medida cujo gráfico está reproduzido na Figura 2.5. Esse resultado consolida o caráter termodinâmico da transição a $112 \mathrm{~K}$, já que ela não é detectada em medidas macroscópicas de susceptibilidade e magnetização. O caráter constante do calor específico, $C / T=\gamma$, indicado pela linha pontilhada na Figura 2.5 , com um valor de $\gamma=773 \mathrm{~m} \mathrm{~J} / \mathrm{molK}^{2}$, 
típico de metais fortemente correlacionados como férmions pesados ${ }^{\dagger}$ foi atribuído ao forte acoplamento dos graus de liberdade eletrônico, estrutural e magnético do elétron extra (vindo do $\mathrm{Fe} 2$ ) na tríade. A contribuição do tipo $C=B T^{2}$ abaixo da temperatura de transição de $70 \mathrm{~K}$ é atribuída a dispersão bidimensional de magnons antiferromagnéticos propagando-se dentro das paredes. ${ }^{30}$ Entre $70 \mathrm{~K}$ e $40 \mathrm{~K}$, a amostra apresenta um ferromagnetismo fraco com um campo coercitivo alto $(9 \mathrm{kOe}$ a $50 \mathrm{~K}) .{ }^{39}$ Abaixo de $40 \mathrm{~K}$, a histerese não é mais observada e todos os spins do sistema estão ordenados na chamada fase antiferromagnética tridimensional. Ainda é controverso este estado, já que nenhuma evidência dessa transição a $40 \mathrm{~K}$ é observada nas medidas de difração de nêutrons, mas a medida de Mössbauer parece indicar a localização do elétron extra no sítio 2. Apesar de o arranjo a baixa temperatura ser denominado antiferromagnético pela ausência de magnetização, o momento magnético total não é nulo, tendo sido determinado como $0.52 \mu_{B}$ por átomo de ferro a $5 \mathrm{~K}$ na referência 37 e $0.79 \mu_{B}$ por átomo de ferro a $10 \mathrm{~K}$ na referência 34 .

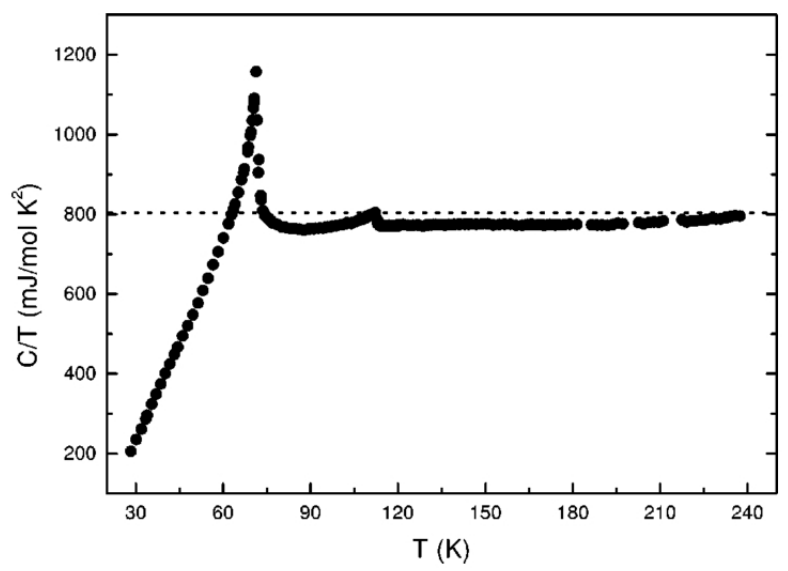

Figura 2.5 - Calor específico da ludwigita homometálica $\mathrm{Fe}_{3} \mathrm{O}_{2} \mathrm{BO}_{3}, \mathrm{C} / \mathrm{T}$ em função da temperatura. A linha pontilhada é referência para evidenciar o comportamento constante de $\mathrm{C} / \mathrm{T}$.

Fonte: FERNANDES et al. ${ }^{30}$

Não é incomum que um óxido de ferro tenha sub-estruturas independentes compostas por íons de ferro dentro de sua rede. A magnetita é um exemplo em que há duas sub-redes de ferro sendo que apenas uma delas é relevante para o ordenamento de carga. ${ }^{10}$ Assim como na ludwigita $\mathrm{Fe}_{3} \mathrm{O}_{2} \mathrm{BO}_{3}$, na manganita de estrutura peroviskita $\operatorname{Pr}_{0.6} \mathrm{Ca}_{0.4} \mathrm{MnO}_{3}$ o ordenamento de carga acontece bem acima da temperatura de Neél $\left(\mathrm{T}_{C O}=235 \mathrm{~K}>\mathrm{T}_{N}=160 \mathrm{~K}\right)$ mas as correlações magnéticas para ambos os materiais persistem até a temperatura de ordenamento de carga. ${ }^{40}$ Swinnea and Steinfink ${ }^{41}$ sugeriram com base em análise de espectros de Mössbauer, que as distâncias inter-atômicas da ordem de $2.8 \AA$ nas tríades Fe4-Fe2-Fe4 resultam numa sobreposição dos orbitais que dá origem a um hopping eletrônico tal que, num dado

\footnotetext{
${ }^{\dagger}$ Para um metal típico com o cobre, $\gamma=0.69 \mathrm{~mJ} / \mathrm{mol} \mathrm{K}^{2} .{ }^{38}$
} 
instante, um par de íons de ferro tem um estado de valência intermediária e o Fe4 restante é trivalente. Esse estado de valência intermediária é associado à transferência de carga e à deslocalização eletrônica. Ou seja, o primeiro trabalho de Mössbauer publicado sobre a ludwigita de ferro já sugeria que a tríade podia ser separada num dímero mais um $\mathrm{Fe}^{3+}{ }^{41} \mathrm{O}$ valor de $2.3 \mu_{B}$ encontrado para os momentos dos cátions de ferro na tríade é muito menor que o esperado de $5 \mu_{B}$ para $\mathrm{Fe}^{3+}$ e $4 \mu_{B}$ para $\mathrm{Fe}^{2+}$, sugerindo que a localização eletrônica é incompleta mesmo nas fases ordenadas magneticamente. ${ }^{34} \mathrm{O}$ refinamento da estrutura magnética dos dados de difração de nêutrons na referência mencionada foram sempre obtidos considerando cada sítio numa estrutura comensurável, mas seria interessante considerar essa estrutura como um sítio para o dímero e um sítio para o ferro que sobra ao invés de três sítios 4-2-4. As medidas de transporte indicam que a resistividade aumenta com a diminuição da temperatura, com uma temperatura de ativação $\mathrm{T}_{C O}=220 \mathrm{~K}$, sendo que por volta da temperatura de ordem dos sítios da tríade, $110 \mathrm{~K}$, atinge uma espécie de patamar que possui uma pequena inclinação de acordo com a história térmica do material. Esse comportamento a $110 \mathrm{~K}$ coincide com o fim do processo de dimerização. ${ }^{42}$ Apesar de ordem de longo alcance ser evidenciada abaixo de $110 \mathrm{~K}$, considerável espalhamento magnético dinâmico também é observado pelas medidas de difração de nêutrons, indicando a existência de correlações magnéticas fortes desde temperatura ambiente.

Dumas et al. ${ }^{43}$ publicaram resultados de RPE em banda $X$ tanto em pó como em monocristais de $\mathrm{Fe}_{3} \mathrm{O}_{2} \mathrm{BO}_{3}$, sendo que os espectros foram primeiramente atribuídos a um $\mathrm{Fe}^{2+}$ e posteriormente a um $\mathrm{Fe}^{3+} .{ }^{43,44}$ Esses dados no monocristal foram apresentados com uma variação angular apenas em um plano que contém o eixo $c$ e a temperaturas abaixo de 150 $\mathrm{K}$, sem justificar a origem da anisotropia nos espectros. Segundo os dados de espectroscopia Mössbauer, a multiplicidade de spin dos centros de $\mathrm{Fe}^{2+}$ e $\mathrm{Fe}^{3+}$ são respectivamente 2 e 5/2. ${ }^{32}$ Centros paramagnéticos de Fe spin 2 são conhecidos na literatura como EPR silent, ou seja, não apresentam sinal de RPE em banda X. Centros paramagnéticos de Fe spin 5/2 podem apresentar diversas características, algumas das quais serão discutidas ao longo da apresentação desta tese.

Essa variedade de efeitos e transições levaram as seguintes questões pontuadas na referência 45, que até o momento ainda não foram totalmente esclarecidas: (a) Quais fatores eletrônicos causam a ocorrência de duas sub-redes de spin fracamente interagentes? (b) A transição antiferromagnética ocorre na sub-rede das tríades Fe4-Fe2-Fe4. Como, então, tríades adjacentes interagem para dar origem a um ordenamento antiferromagnético tridimensional? (c) Por que esse ordenamento tridimensional das escadas a $112 \mathrm{~K}$ não é visto pelas medidas de susceptibilidade? (d) Qual a razão da largura de linha de RPE crescer gradualmente com 
o resfriamento da amostra, como apontado no estudo 43 ?

Diante do exposto e motivados pela existência do sinal de RPE e a complexidade do sistema em questão, decidiu-se por aprofundar o entendimento dos espectros de ressonância dessa amostra num estudo mais completo e cuidadoso em banda $X$ e banda $Q$ para uma ampla faixa de temperaturas e com o cristal orientado em três planos ortogonais. Desse modo, pretende-se contribuir para a compreensão das propriedades apresentadas por este material.

\section{Material e Métodos}

\subsection{Material}

Amostras monocristalinas de $\mathrm{Fe}_{3} \mathrm{O}_{2} \mathrm{BO}_{3}$ foram obtidas numa colaboração com o Prof. Dr. João Carlos Fernandes e Prof. Dr. Mucio Continentino do Instituto de Física da Universidade Federal Fluminense. O cristal utilizado nas medidas está mostrado na Figura 2.6. Como a estrutura cristalina do material é ortorrômbica, mas a inspeção visual das faces do cristal na figura revela que elas não são ortogonais entre si, a projeção dos planos do cristal no referencial do laboratório torna-se não trivial.

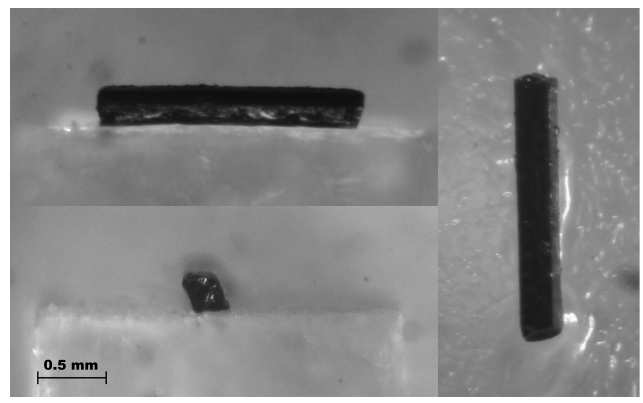

(a)

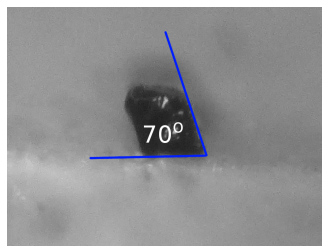

(b)

Figura 2.6 - (a) Fotografias do cristal de $\mathrm{Fe}_{3} \mathrm{O}_{2} \mathrm{BO}_{3}$ obtidas por estereomicroscópio em três planos distintos. (b) Ângulo entre as faces do cristal no plano $a b$.

Fonte: Elaborada pelo autor.

As medidas no monocristal foram feitas nos planos mostrados na foto da Figura 2.6 e a correspondência dos eixos $x, y$ e $z$ do referencial do laboratório não é diretamente a dos eixos $a, b$ e $c$ do cristal. Entretanto, a direção longitudinal (mais comprida) do cristal em forma de agulha corresponde supostamente ao eixo c e vamos adotar como sendo o eixo z no referencial do laboratório. ${ }^{43}$ Esta equivalência entre o eixo comprido e o eixo $c$ foi verificada por medidas de raio-X do cristal, uma vez que a referência citada em questão faz essa afirmação sem provas 
e nenhum outro trabalho sugere a equivalência do hábito de crescimento com o eixo cristalino. Na Figura 2.7, o sistema está descrito a partir do referencial do laboratório. Para garantir a ortogonalidade no referencial do laboratório, a amostra está apoiada sobre um cristal cúbico de $\mathrm{KCl}$, que não possui sinal de RPE e é utilizado como suporte, juntamente com um bastão de quartzo, nas medidas do monocristal de $\mathrm{Fe}_{3} \mathrm{O}_{2} \mathrm{BO}_{3}$.

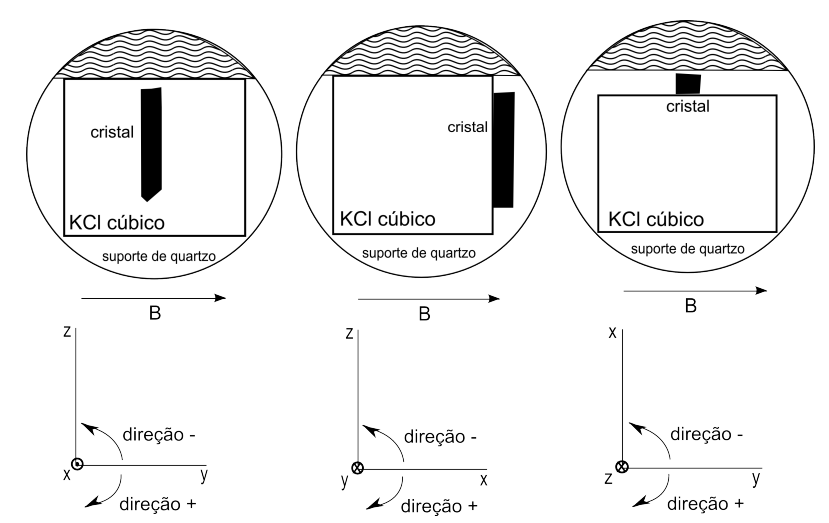

Figura 2.7 - Orientação do cristal de $\mathrm{Fe}_{3} \mathrm{O}_{2} \mathrm{BO}_{3}$ utilizada nas medidas orientadas, descrita no referencial do laboratório.

Fonte: Elaborada pelo autor.

Os experimentos em função da temperatura foram feitos aguardando-se de 3 a 5 minutos para estabilização térmica antes de iniciar cada medida. Uma série de experimentos foram realizados:

- medidas de um conjunto de cristais pulverizados em almofariz de ágata;

- medidas do cristal em banda $X$ e banda $Q$ em temperatura ambiente variando a orientação da amostra a cada 5 graus em relação ao campo magnético para cada plano;

- medidas de variação angular no plano xy do cristal em banda X para algumas temperaturas;

- medidas do cristal em banda X em função da temperatura com o campo magnético na direção de maior separação das linhas do espectro de RPE (direção $x$ ou $y$ ) e no eixo $z$;

- medidas de saturação do sinal de RPE (banda X em função da potência da micro-onda.)

A visualização estrutural bem como a elaboração de figuras relacionadas a estrutura desta amostra foram feitas no software VESTA ${ }^{46}$.

Monocristais da ludwigita heterometálica $\mathrm{FeCO}_{2} \mathrm{O}_{2} \mathrm{BO}_{3}$ e da ludwigita homometálica de cobalto, $\mathrm{Co}_{3} \mathrm{O}_{2} \mathrm{BO}_{3}$, obtidas na mesma colaboração, foram medidas em banda $\mathrm{X}$ entre $4 \mathrm{~K} \mathrm{e}$ $300 \mathrm{~K}$ e em banda $\mathrm{Q}$ à temperatura ambiente mas não apresentaram sinal de RPE. 


\subsection{Métodos}

\subsubsection{Ressonância paramagnética eletrônica}

Dois equipamentos foram utilizados para a aquisição dos espectros de RPE: um Varian modelo E109 e um Bruker modelo E-580. Para medidas em banda $X(9.5 \mathrm{GHz})$, em ambos os espectrômetros, temos a disposição um criostato Oxford para medidas entre $4 \mathrm{~K}$ e 300 $\mathrm{K}$ usando uma cavidade retangular operando no modo $\mathrm{TE}_{102}$ para as medidas em modo onda contínua. Uma ponte de banda Q (35 GHz) com uma cavidade cilíndrica operando no modo $\mathrm{TE}_{011}$ pode ser adaptada ao Varian para medidas à temperatura ambiente e em função da orientação da amostra em relação ao campo magnético estático aplicado. Para as medidas em função da orientação da amostra em relação ao campo em banda $X$ contamos com um goniômetro eletrônico controlado remotamente via software para o Bruker e um goniômetro manual para o Varian. Para variação angular em banda $Q$, utilizamos a base giratória do eletroímã Varian. Os detalhes técnicos e a teoria envolvida na técnica de RPE estão consolidados e são extensivamente discutidos na literatura ${ }^{2,4-8}$, de modo que apenas o necessário para a explicação dos resultados foi mencionado ao longo do texto.

\subsubsection{Análise dos resultados}

\section{a) Formas de linha}

A forma do espectro de absorção e seus parâmetros são um conjunto de informações valioso a respeito das interações locais em materiais que apresentam um sinal de RPE. O campo magnético efetivo local num centro absorvedor depende do excesso positivo ou negativo de seus vizinhos mais próximos com spins alinhados na direção positiva do campo estático externo $B_{0}$; assume-se que os spins através da amostra estejam aleatoriamente alinhados paralela ou anti-paralelamente a $B_{0}$ e no limite de grandes números de vizinhos ao redor de cada centro absorvedor, esse excesso se distribui entre os núcleos absorvedores de acordo com uma função gaussiana. ${ }^{47}$ Portanto, a forma gaussiana está relacionada à homogeneidade do campo magnético local causado pela interação dipolar. Uma linha lorentziana está relacionada com centros sujeitos à interação de troca, em que os spins vizinhos possuem uma orientação mais definida com relação ao campo ex- 
terno. Apesar de este modelo ser uma simplificação, ele consiste de uma imagem física interessante para justificar o aparecimento da forma de linha gaussiana ou lorentziana num centro paramagnético típico de materiais estudados via RPE, ou seja, materiais com centros paramagnéticos de concentração diluída na estrutura. Em alguns casos, a linha pode ser uma convolução entre uma linha lorentziana e uma linha gaussiana, conhecida como função Voigt. Em geral, uma aproximação dada pela combinação linear de uma curva gaussiana e uma lorentziana é usada no lugar da convolução das duas, e esse perfil é conhecido como pseudo-Voigt. Seguindo a lógica simples apresentada acima, um espectro com uma forma voigtiana (ou pseudo-voigtiana) corresponderia àquele em que os dois fenômenos discutidos (interação dipolar e interação de troca) são da mesma ordem de modo que nenhum deles é predominante sobre o outro. ${ }^{7}$ A derivada da pseudo-voigtiana é dada por

$Y^{\prime}=-r \frac{2 A w}{\pi} \frac{8 x-8 x_{c}}{\left[4\left(x-x_{c}\right)^{2}+w^{2}\right]^{2}}-(1-r) \frac{4 A \ln (2)}{\pi / 4 \ln (2)} \frac{2 x-2 x_{c}}{w^{3}} \exp \left(-\left[4 \ln (2)\left(x-x_{c}\right)^{2}\right] / w^{2}\right)$,

que corresponde à soma direta da derivada da gaussiana e da derivada da lorentziana de mesma largura $w$, campo central $x_{c}$, intensidade (área) $A$ e coeficiente $r$. Se $r=1$ a função corresponde à uma lorentziana. Caso $r=0$, a função é uma gaussiana.

b) RPE em monocristais: anisotropia da interação Zeeman e determinação do tensor $g$

A forma do espectro de RPE no estado sólido depende da orientação relativa do campo magnético aplicado $(\vec{B})$ com respeito à orientação do centro paramagnético e da simetria do sítio em que ele está. Isto é, a condição de ressonância é dependente da orientação da amostra em relação ao campo magnético, na forma ${ }^{4}$

$$
h v=\mu_{B} g(\theta, \phi) B
$$

em que $\theta$ e $\phi$ se referem aos ângulos polares da direção do campo magnético aplicado no sistema dos eixos principais do tensor $\mathbf{g}$ molecular. Sendo assim, o Hamiltoniano Zeeman toma uma forma mais completa para conter todas as possíveis orientações de $g$ :

$$
\mathscr{H}=\mu_{B} \mathbf{S} \cdot \mathbf{g} \cdot \mathbf{B},
$$


em que $\mu_{B}$ é o magneton de Bohr, $\mathbf{S}=\left(S_{x}, S_{y}, S_{z}\right)$ é o vetor dos operadores de spin e $\mathbf{g}$ uma matriz e não mais um fator representado por uma quantidade escalar. É importante manter em mente que o campo real sentido pelo spin não é oriundo somente do campo magnético aplicado mas também de um campo local causado por interações como a interação dipolar e com o campo cristalino. Ou seja, o campo total ao qual o centro está sujeito é, na verdade, um campo efetivo e o tensor calculado corresponde também a um tensor $\mathbf{g}_{\text {eff }}$ efetivo. Por simplicidade de notação, usaremos apenas $\mathbf{g}$.

Os termos dos tensores $\mathbf{g}$ dos centros ressonantes no monocristal estudado foram obtidos a partir dos campos centrais $x_{c}\left(H_{0}\right)$ das linhas ajustadas. Os espectros foram coletados para várias orientações da amostra em relação ao campo magnético aplicado em cada um dos três planos ortogonais no referencial do laboratório $x y z$. Esses eixos representam um referencial arbitrário para o cristal montado na cavidade de RPE. Em geral, esse sistema é escolhido por razões práticas e os espectros são obtidos pela rotação sistemática do cristal (ou do eletroímã) em torno dele. No nosso caso, escolheu-se o referencial arbitrário como os eixos perpendiculares de um cristal cúbico de $\mathrm{KCl}$, fazendo o eixo $c$ (eixo longo do cristal) coincidir com o eixo $z$ do referencial do laboratório. Nessa escolha conveniente, a superfície apoiada do cristal de ludwigita (Figura 2.6) coincidiu com o eixo de um dos octaedros de oxigênio do ferro central da tríade, que por sua vez coincidiu com o plano diagonal aos eixos $a b$ do cristal, como mostrado no capítulo de resultados. O tensor resultante será diagonal se o conjunto ortogonal $x y z$ coincidir com o referencial molecular, isto é, se eles forem os eixos principais. Se esse não for o caso, pode-se fazer um acerto dos dados corrigindo o ângulo em que os eixos principais estão deslocados ou então diagonalizar posteriormente. A determinação do tensor $\mathbf{g}$ foi feita ajustando os dados experimentais de $g^{2}$ e obtendo a matriz gg, que é uma matriz simétrica, não diagonal e com seis elementos independentes $(g g)_{i j}$ no referencial arbitrário. Diagonalizar essa matriz corresponde a realizar uma rotação dos eixos $x y z$ para coincidir com o referencial dos eixos principais. Os elementos de gg foram obtidos rodando-se a amostra nos planos $x z\left(\phi=0^{\circ}\right), y z\left(\phi=90^{\circ}\right)$ e $x y\left(\theta=90^{\circ}\right)$. Após manipulação da equação (2.3), obtem-se o seguinte conjunto de expressões ${ }^{2,4}$ a seguir, a partir das quais ajustamos os dados experimentais e determinamos $(g g)_{i j}$.

$$
\begin{aligned}
g^{2}\left(\theta, 0^{\circ}\right) & =(g g)_{x x} \operatorname{sen}^{2} \theta+2(g g)_{x z} \operatorname{sen} \theta \cos \theta+(g g)_{z z} \cos ^{2} \theta, \\
g^{2}\left(\theta, 90^{\circ}\right) & =(g g)_{y y} \operatorname{sen}^{2} \theta+2(g g)_{y z} \operatorname{sen} \theta \cos \theta+(g g)_{z z} \cos ^{2} \theta, \\
g^{2}\left(90^{\circ}, \phi\right) & =(g g)_{x x} \operatorname{sen}^{2} \phi+2(g g)_{x y} \operatorname{sen} \phi \cos \phi+(g g)_{z z} \cos ^{2} \phi .
\end{aligned}
$$


É interessante observar nas expressões acima que os parâmetros $(g g)_{x x},(g g)_{y y}$ e $(g g)_{z z}$ são obtidos duas vezes e servem como confirmação para a qualidade da medida.

Uma apresentação mais detalhada da anisotropia considerada a partir da interação Zeeman efetiva está apresentada em vários textos sobre RPE, entre eles no capítulo 4 da referência 2.

\section{Resultados e discussão}

\subsection{Determinação da orientação do cristal $\mathrm{Fe}_{3} \mathrm{O}_{2} \mathrm{BO}_{3}$}

A estrutura da fase cristalina do composto $\mathrm{Fe}_{3} \mathrm{O}_{2} \mathrm{BO}_{3}$ foi obtida em um difratômetro Enraf-Nonius Kappa-CCD usando radiação $\operatorname{MoK} \alpha(0.71073 \AA)$ monocromada por grafite. Para o refinamento da célula unitária, utilizou-se o software Collect and Scalepack ${ }^{48}$. A representação gráfica foi preparada com o software Mercury ${ }^{49}$. Desse modo, a direção mais alongada do cristal foi confirmada como paralela ao eixo $c$ e, portanto, paralela ao eixo $z$ escolhido no referencial do laboratório. Como mencionado, Dumas et al. ${ }^{43}$ foi o único a fazer essa afirmação porém sem mencionar a maneira como determinou essa equivalência entre o hábito de crescimento do cristal e os eixos cristalinos. Na Figura 2.8, encontra-se uma fotografia do cristal obtida via difração de raios-X com a direção dos eixos indicados, $a=$ 9.445(5), $b=12.277(0)$ e $c=3.070(0)$ e $\alpha=\beta=\gamma=90^{\circ}$.

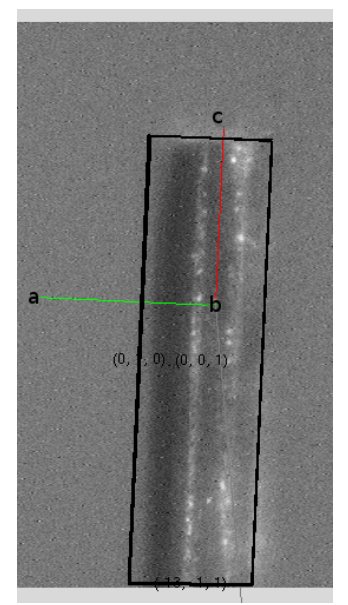

Figura 2.8 - Micrografia ótica do monocristal de $\mathrm{Fe}_{3} \mathrm{O}_{2} \mathrm{BO}_{3}$ indicando os eixos cristalinos obtidos por difração de raios-X. O eixo $c$ pode ser visto ao longa da direção mais alongada do cristal em forma de agulha.

Fonte: Elaborada pelo autor. 


\subsection{Variação angular do cristal e análise de $g_{e f f}$}

Os espectros de ressonância paramagnética eletrônica da variação angular do cristal em relação ao campo magnético à temperatura ambiente no plano perpendicular ao eixo $c$, plano $x y$, bem como nos planos $z x$ e zy em banda $X$ e em banda $Q$ são exibidos na Figura 2.9.
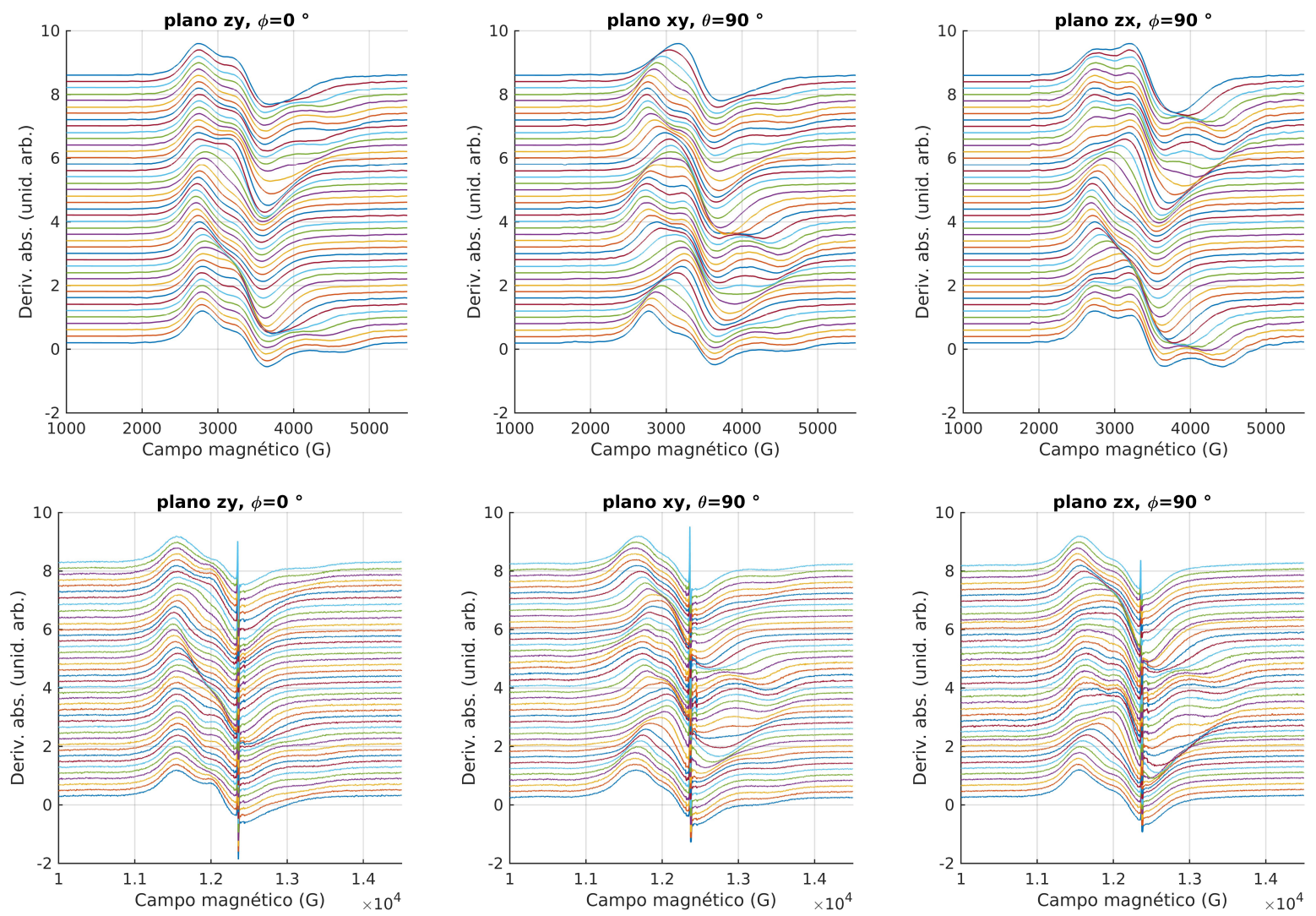

Figura 2.9 - Espectros de RPE da amostra $\mathrm{Fe}_{3} \mathrm{O}_{2} \mathrm{BO}_{3}$ obtidos a partir da variação angular do cristal em relação ao campo magnético à temperatura ambiente no plano perpendicular ao eixo $c$, plano $x y$, bem como nos planos $z x$ e $z y$ em banda $X$ (superior) e em banda $Q$ (inferior). Observe que a faixa de varredura do campo em banda $X$ e banda $Q$ é a mesma. O sinal estreito nos espectros em banda $Q$ corresponde a um marcador com $\mathrm{Cr}^{3+}$.

Fonte: Elaborada pelo autor.

A região de campo mostrada nesses gráficos está limitada àquela em que sinais de absorção foram observados, isto é, nenhuma ressonância foi vista fora dessa região. A varredura angular está diferente em cada banda devido a razões experimentais, ou seja, o suporte de montagem da amostra para a cavidade de banda $Q$ e banda $X$ são diferentes, no primeiro giramos 0 magneto e no segundo giramos a amostra através do goniômetro. No entanto, o resultado não se altera, pois fazemos o casamento dos dados de acordo com o desenho da orientação no experimento. Ou seja, as direções $x, y$ e $z$ são as mesmas nas duas medidas. Esse procedimento 
de casamento entre os dois conjuntos de dados fica mais claro nos gráficos da variação angular do campo central $\left(g_{e f f}\right)$ na figura 2.10 .
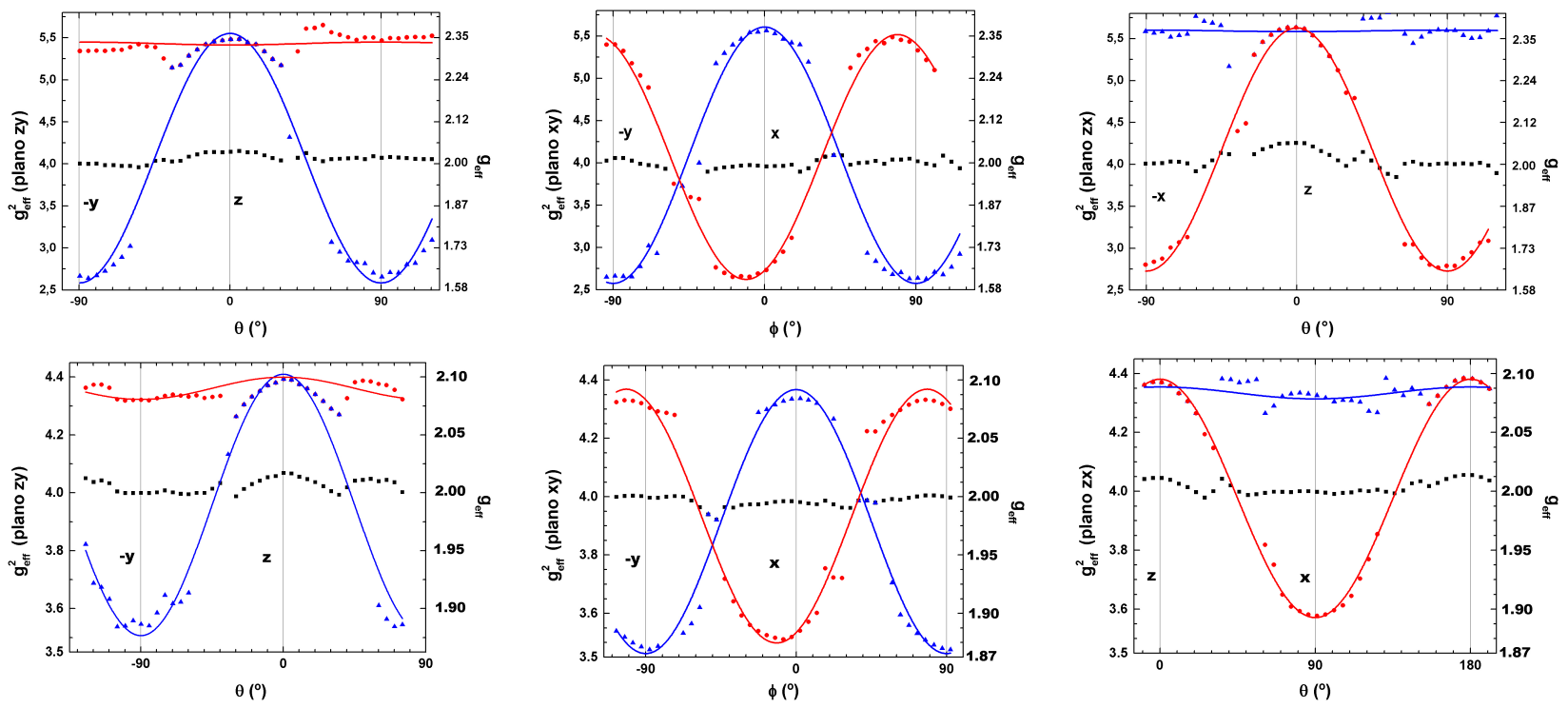

Figura 2.10 - Variação angular dos campos de ressonância convertidos para $g_{\text {eff }}^{2}$ em banda X (fileira superior) e $Q$ (fileira inferior) obtidos à temperatura ambiente para cada orientação nos planos $z y, x y$ e $z x$. É possível identificar dois conjuntos, I (triângulos azuis) e II (círculos vermelhos), anisotrópicos angularmente deslocados. Uma linha isotrópica em torno de g 2 também é observada e assinalada como conjunto III (quadrados pretos). As linhas cheias correspondem ao ajuste de $g^{2}(\theta, \phi)$ da expressão (2.4).

Fonte: Elaborada pelo autor.

Para compreender o significado e a informação contida nesses espectros de linhas sobrepostas e com largura entre $500 \mathrm{G}$ e $1000 \mathrm{G}$, um ajuste para cada orientação foi realizado com uma composição de três linhas. Esse número foi escolhido com base em uma inspeção visual desses dados. Os ajustes foram obtidos a partir da expressão (2.1), deixando os parâmetros variarem livremente para reduzir o erro mínimo quadrático, assumindo que os espectros pudessem ser tanto compostos por linhas lorentzianas, gaussianas ou uma combinação de ambas, neste caso, de acordo com o valor de $r$ ajustado. Uma das três linhas é quase isotrópica e o parâmetro $r$ converge para um valor médio de 0.5 , tanto para banda $\mathrm{X}$ quanto para banda Q. Já as outras duas linhas são anisotrópicas e $r$ converge a 0 para o menor erro, ou seja, exclusivamente gaussianas em ambas as frequências para todas as direções. Nas direções em que as linhas são mais separadas (eixo $x$ e eixo $y$ ) e no entorno delas, a área das linhas anisotrópicas convergem para o mesmo valor. Na figura 2.10 são mostrados os valores ajustados para o campo ressonante dos espectros, transformados em $g_{e f f}$, em função do ângulo do campo magnético em relação a amostra nos planos $z y, x y$ e $z x$. Num primeiro momento, identificamos qualitativamente a presença de duas espécies ressonantes magneticamente não-equivalentes que estão representadas por triângulos azuis (espécie I) e círculos vermelhos (espécie II). Essa 
classificação foi feita primeiro no plano $x y$, que é o plano no qual as linhas tem maior variação angular. O conjunto I tem o valor máximo de $g^{2}$ num ângulo próximo a que o conjunto II tem o valor mínimo. Este comportamento facilita a identificação dos conjuntos I e II nos planos restantes. As linhas cheias nos gráficos dessa figura correspondem ao resultado do ajuste de $g_{\text {eff }}^{2}(\theta, \phi)$ usando as expressões da anisotropia Zeeman, (2.4), em ambas as bandas. $\mathrm{O}$ conjunto III, de quadrados pretos, corresponde a linha quase isotrópica.

Os tensores (gg) para cada espécie e cada banda determinados a partir dos ajustes são mostrados no apêndice $A$. Considerando o resultado desses ajustes e o fato de as linhas do conjunto I e II terem a mesma área, determinou-se quantitativamente que as duas espécies identificadas correspondem ao mesmo centro deslocado angularmente de $70^{\circ} \mathrm{em}$ torno do eixo $z$, ou seja, no plano $a b$. Os valores principais de $g_{\text {eff }}$ são

$$
\begin{aligned}
& \mathbf{g}_{\text {eff }}^{X}=[2.39 \pm 0.02,1.57 \pm 0.04,2.36 \pm 0.01] \\
& \mathbf{g}_{\text {eff }}^{Q}=[2.10 \pm 0.01,1.86 \pm 0.01,2.09 \pm 0.01]
\end{aligned}
$$

A principal fonte de erro é a imprecisão na determinação do campo central devido a sobreposição $\ddagger$ das linhas largas no espectro. A diferença no valor de $g_{\text {eff }}$ entre banda $\mathrm{X}$ e banda $Q$ será discutida ao longo do texto. O ângulo encontrado é identificado quando analisamos a projeção da estrutura no plano $a b$, Figura 2.3, e corresponde a separação angular entre os eixos dos octaedros de oxigênio que contêm o sítio 2 no centro dos degraus das $3 \mathrm{LL}$, ou seja, corresponde a rotação que leva uma tríade na outra no plano $a b$. Esse cálculo também elucida por completo a configuração do cristal: a face apoiada do cristal sobre o suporte cúbico de $\mathrm{KCl}$ é paralela ao eixo do octaedro de oxigênio do ferro central das tríades que coincide com o eixo diagonal do plano $a b$ (110), veja Figura 2.6(b).

Os quatro sítios distintos de ferro na estrutura da ludwigita possuem simetria octaédrica e são alto spin como definido pelas medidas de Mössbauer ${ }^{32}$, isto é, $S_{A}=5 / 2$ e $S_{B}=2$ para os $\mathrm{Fe}^{3+}$ e $\mathrm{Fe}^{2+}$, respectivamente. Para que uma espécie seja alto spin em simetria octaédrica, a energia do campo cristalino $\sim 10 D q \S$ deve ser menor que a repulsão eletrônica (princípio da exclusão de Pauli) em cada orbital. Vamos discutir as possibilidades para cada caso:

a) $\quad \mathrm{Fe}^{2+}$ alto spin é conhecido como silencioso em RPE nas frequências de $9 \mathrm{GHz}$ e 35

\footnotetext{
${ }_{\ddagger}^{\ddagger}$ Essa sobreposição está ilustrada para o plano $a b$ em banda $\mathrm{X}$ no apêndice $\mathrm{B}$.

$\S$ Lembrando que $D$ é o termo de separação de campo nulo na hamiltoniana de spin e $q$ a carga eletrônica e que essa $(\sim 10 D q)$ é a separação entre os estados $t_{2 g}$ e $e_{g}$ que acomodam três orbitais $\left(\mathrm{d}_{x y}, \mathrm{~d}_{z y}\right.$ e $\left.\mathrm{d}_{z x}\right)$ e dois orbitais $\left(\mathrm{d}_{z^{2}}\right.$ e $\left.\mathrm{d}_{y^{2}-x^{2}}\right)$, respectivamente. Esse quadro representa um íon do grupo $3 \mathrm{~d}$ isolado num campo octaédrico e, portanto, é uma descrição aproximada para o nosso caso.
} 
GHz. Uma contribuição muito forte de campo cristalino resultaria num centro baixo spin com spin nulo e, obviamente, sem sinal de RPE. Os casos descritos de sinal de RPE em banda $\mathrm{X}$ para $\mathrm{Fe}^{2+}$ estão relacionados à situação do limite da interação Zeeman fraca, ou seja, uma separação de campo zero $D>>g \mu_{B} B .{ }^{6}$ De fato, Tinkham ${ }^{50}$ demonstrou experimentalmente um valor de $g=8.97 \pm 0.02$ em íons de ferro(II) diluídos numa rede de fluoreto de zinco $\mathrm{ZnF}_{2}$ a baixa temperatura, na qual esse limite é aplicável. Como a amostra $\mathrm{Fe}_{3} \mathrm{O}_{2} \mathrm{BO}_{3}$ não apresenta nenhum sinal detectável em campos mais baixos, excluímos a possibilidade de que o sinal venha do $\mathrm{Fe}^{2+}$.

b) Para o $\mathrm{Fe}^{3+}$, uma separação de campo zero muito grande oriunda do campo cristalino tornaria a espécie num centro de baixo spin com spin $1 / 2$, que resultaria em sinal de RPE isotrópico ou anisotrópico em torno de $\mathrm{g}=2$. Entretanto, essa possibilidade é refutada pela medida de Mössbauer e pelo fato de $g_{\text {eff }}$ ser diferente em banda X e banda $\mathrm{Q}$. Com um campo cristalino intermediário, $\mathrm{Fe}^{3+}$ com spin $5 / 2$ poderia ser observado com $g$ em torno de 2 e uma anisotropia que não excede 1 a $2 \%{ }^{6,51}$ Como o fator $g$ do conjunto III quase isotrópico é o mesmo nas duas bandas, a explicação para esse sinal pode ser o $\mathrm{Fe}^{3+}$ "isolado" do dímero na tríade, com spin 5/2. Resta-nos interpretar o sinal anisotrópico. Uma separação de campo nulo grande oriunda de outros fenômenos, como interação dipolar ou de troca, isotrópica $(E=0)$ ou anisotrópica $(E \neq 0)$, resulta num esquema de níveis de energia consolidado e amplamente utilizado para $\mathrm{Fe}^{3+}$ alto spin, com absorção em $\mathrm{g} \perp=6$ e $\mathrm{g} \|=2$ para $\mathrm{E}=0$ e variando conforme $\lambda=E / D$ como mostra o gráfico da figura 2.11. É possível perceber que, para qualquer valor dessa razão, o campo ressonante dos espectros deveria variar entre valores mais baixos de campo ( $g$ mais alto), caso estivéssemos nessa situação. Ou seja, as linhas anisotrópicas no nosso experimento dificilmente seriam explicadas como oriundas de um estado puro $\mathrm{Fe}^{3+}$ alto spin.

Dadas as evidências experimentais, na literatura, da formação de um dímero alternadamente ao longo do eixo $c$ nos degraus da $3 \mathrm{LL}$ e a relação estrutural da variação angular com a orientação dos degraus que contém o dímero, vamos considerar a possibilidade de o sinal ser oriundo do sistema $\mathrm{Fe}^{3+}-\mathrm{Fe}^{2+}$ ou $(\mathrm{Fe}-\mathrm{Fe})^{5+}$ ou ainda $\mathrm{Fe}^{2.5+}-\mathrm{Fe}^{2.5+}$, no qual consideraremos a presença de dois efeitos: a interação de troca e a interação de troca dupla. 


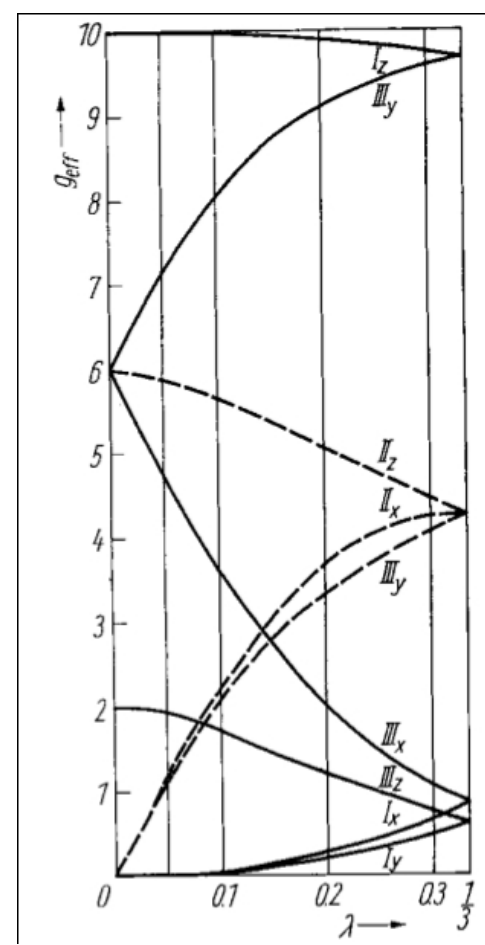

Figura 2.11 - Valores principais do tensor $\mathbf{g}$ para um sistema de spin $S=5 / 2$ com altos valores de separação de campo zero $D$ em função de $\lambda=E / D$.

Fonte: SHCHERBAKOVA; ISTOMIN ${ }^{52}$

A interação de troca isotrópica é dada por

$$
\hat{\mathscr{H}}=-J\left(\mathbf{S}_{A} \cdot \mathbf{S}_{B}\right)
$$

em que a constante de troca $J>0$ corresponde a um sistema ferromagneticamente acoplado e $J<0$ a um sistema antiferromagneticamente acoplado. Os autovalores desse Hamiltoniano podem ser determinados abrindo-se o quadrado $\mathbf{S}^{2}=\left(\mathbf{S}_{A}+\mathbf{S}_{B}\right)^{2}=\mathbf{S}_{A}^{2}+2 \mathbf{S}_{A} \cdot \mathbf{S}_{B}+\mathbf{S}_{B}^{2}$ de modo que

$$
\hat{\mathscr{H}}=-\frac{J}{2}\left(\mathbf{S}^{2}-\mathbf{S}_{A}^{2}-\mathbf{S}_{B}^{2}\right)
$$

que tem autovalores

$$
E_{t}\left(S_{0}\right)=-\frac{J}{2}\left(S_{0}\left(S_{0}+1\right)-S_{A}\left(S_{A}+1\right)-S_{B}\left(S_{B}-1\right)\right)
$$

\footnotetext{
IA interação de troca anisotrópica é da ordem de $(\Delta g / g)^{2}$ vezes a troca isotrópica, em que $\Delta g$ é o efeito da interação spin-órbita. Ou seja, quando o efeito da interação spin-órbita é pequeno, a interação de troca anisotrópica é um efeito de segunda ordem e pode ser desprezado. ${ }^{6}$
} 
em que vamos omitir o termo constante $\frac{J}{2}\left(S_{A}\left(S_{A}+1\right)+S_{B}\left(S_{B}-1\right)\right)$, pois estamos interessados na separação entre os níveis e não no valor absoluto da energia, resultando em

$$
E_{t}\left(S_{0}\right)=-\frac{J}{2} S_{0}\left(S_{0}+1\right)
$$

em que $S_{0}=\left|S_{A}+S_{B}\right|,\left|S_{A}+S_{B}\right|-1, \ldots,\left|S_{A}-S_{B}\right|$. A interação de troca entre $S_{A}=5 / 2$ e $S_{B}=2$, resulta num sistema de spin total 9/2. Duas situações podem advir: i) se a interação for ferromagnética $J>0$, o estado fundamental é $S_{0}=9 / 2$; ii) se a interação for antiferromagnética $J<0$, o estado fundamental é $\mathrm{S}_{0}=1 / 2$. A natureza ferro ou antiferromagnética da interação pode ser determinada pelas regras de Goodenough-Kanamori. ${ }^{25}$ No nosso caso, teríamos uma interação antiferromagnética de acordo com a regra $90^{\circ} \mathrm{M}-\mathrm{O}-\mathrm{M}$ (metal-oxigênio-metal) para a interação de supertroca. ${ }^{37}$ Essa interação antiferromagnética também é sugerida pelo valor menor que o esperado para o momento magnético nos sítios, como mencionado na revisão bibliográfica. Os níveis de energia desse sistema, estão representados no esquema da figura 2.12.

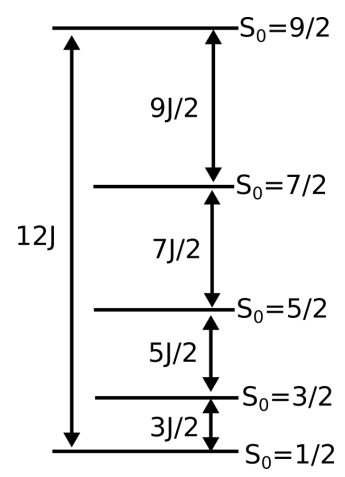

Figura 2.12 - Esquema de energia para uma interação de troca isotrópica entre dois spins, $S_{A}=5 / 2$ e $S_{B}=2$, com $J<0$.

Fonte: Elaborada pelo autor.

As medidas de difração de nêutrons detectaram correlação eletrônica desde temperatura ambiente. ${ }^{34}$ Essa correlação pode estar relacionada ao dímero e ao fato de a interação entre eles ser forte o bastante para mantê-los acoplados a alta temperatura mesmo enquanto ordem de longo alcance não tenha se formado. A abordagem do dímero como uma unidade magnética "dura" também é confirmada por simulação com DFT. ${ }^{36}$ As ressonâncias observadas em torno de $\mathrm{g}=2$ e a ausência de qualquer sinal em campos mais baixos confirmam a presença de um estado ligado com spin efetivo $1 / 2$ coerente com a estrutura descrita. Como a intensidade pico-a-pico do sinal é pequena para o monocristal, mediu-se a amostra policristalina que tem um sinal mais intenso e confirmou-se que nenhum sinal é observado para campos fora da faixa estudada. Clusters de ferro-enxofre em que dímeros de ferro com valência mista e estado 
fundamental antiferromagnético têm a mesma característica. ${ }^{53}$

Até o momento, portanto, vimos que a variação angular no plano $a b$ de duas linhas simétricas de mesma área deslocadas de $70^{\circ}$ corresponderia à separação angular entre as duas tríades na estrutura. Entretanto, esse modelo em que a ressonância tem origem no dímero em seu estado fundamental $S_{0}=1 / 2$ não contempla o fato de existir um $g$ efetivo dependente da frequência, isto é, o fator $g$ é diferente para banda $X$ e banda $Q$. A observação dos espectros mostra que a diferença $\Delta H$ entre o campo de ressonância máximo $H_{0, \max }$ e mínimo $H_{0, \min }$ é praticamente o mesmo na variação angular nas duas frequências nos três planos, ou seja,

$$
\Delta H^{X, Q}=H_{0, \text { max }}^{X, Q}-H_{0, \text { min }}^{X, Q} \simeq 1800 G
$$

Essa equivalência de separação em campo entre as bandas corresponde a uma variação simétrica e de sinais opostos no fator $g$, isto é,

$$
\Delta g=\left|g_{x, y, z}^{Q}-g_{x, y, z}^{X}\right| \simeq 0.28 \pm 0.01
$$

de modo que

$$
\begin{gathered}
g_{x, z}^{Q}=g_{x, z}^{X}-\Delta g, \\
g_{y}^{Q}=g_{y}^{X}+\Delta g .
\end{gathered}
$$

Um modo de entender essa questão, seria pensar num possível campo interno e anisotrópico. Vejamos: nas direções $x$ e $z$, que identificamos como perpendicular ao eixo molecular do dímero, o valor de $g$ efetivo diminui de $\Delta g$ em banda $Q$. Em termos de campo, isso significa que o campo magnético externo aplicado necessário para absorção da micro-onda foi maior que o esperado. Nessas direções, portanto, podemos pensar que o campo induzido interno diminuiu. Na direção y ocorre o oposto, o valor de $g$ aumenta de $\Delta g$ em banda $Q$. Então, o campo magnético externo aplicado para ressonância é menor que o esperado indicando um aumento do campo interno nessa direção. Vemos que a existência de um campo magnético interno e anisotrópico, proporcional ao campo externo aplicado, justificaria a mudança em $g$ entre os dois experimentos de RPE.

Outro modo de entender essa questão, é pensar na existência de um termo independente da frequência na hamiltoniana de spin, na forma de uma separação de campo zero. Basicamente, ocorre que, se a separação entre os níveis de energia independe da frequência num termo 
do tipo separação de campo zero, ela será tão mais relevante quanto menor for a frequência utilizada no experimento.

Dada a configuração eletrônica no dímero, esse termo pode ser oriundo da competição entre a interação de troca e uma interação de troca dupla dentro do dímero, como será apresentado a seguir.

Em sistemas de valência mista, a interação de troca dupla ( $D E$, do inglês, double exchange) via orbitais $p$ do oxigênio ligante pode ter um papel importante. Anderson e Hasegawa ${ }^{54}$ calcularam a contribuição da integral de transferência de carga na energia de um sistema com um elétron saltando entre dois íons (hopping) como $\|$

$$
E_{t d}\left(S_{0}\right)= \pm b \frac{\left(S_{0}+1 / 2\right)}{(2 S+1)}
$$

em que $S$ é o valor do spin no sítio que contém o elétron extra e $S_{0}$ pode assumir valores entre $1 / 2$ e $2 S+1 / 2$. A interpretação física dessa expressão é que "a integral de transferência $b$ efetiva entre os dois estados possíveis para o elétron é reduzida pela razão $\left(S_{0}+1 / 2\right) /(2 S+1)$, e os auto-estados são essencialmente combinações simétricas e antissimétricas dos orbitais localizados com o spin eletrônico paralelo a $\mathbf{S}_{A}$ ou $\mathbf{S}_{B}$, respectivamente". ${ }^{54}$ A consequência mais significativa da contribuição deste termo na energia do sistema é que, para cada valor de $S_{0}$, há dois estados, não um, distribuídos simetricamente em torno de uma energia média. O mecanismo de interação de troca dupla foi introduzido, historicamente, para explicar o acoplamento ferromagnético em certas dopagens nas manganitas. ${ }^{25}$ Para explicar a condutividade em amostras reais de magnetita, os elétrons participando do processo de hopping são considerados num modelo de troca dupla em que estão localizados exclusivamente no par $\mathrm{Fe}^{3+}-\mathrm{Fe}^{2+}$, e não como pertencentes a uma banda de condução 3D ou participando de um processo de transferência eletrônica deslocalizado na rede. ${ }^{55}$ Aqui, invocaremos o mesmo mecanismo para explicar a separação do estado fundamental $1 / 2$ da interação de troca em dois níveis simetricamente dispostos uma vez que claramente o dímero está estruturalmente caracterizado pelas medidas de Mössbauer e raio-X. Para elucidar a competição das duas interações, vamos escrever a energia do dímero como a soma das interações de troca e de troca dupla, respectivamente equações (3.6) e (3.11):

\footnotetext{
"No trabalho citado, há um termo aditivo adicional, $-J_{\text {hund }} S$, na expressão da energia que está relacionado à interação de troca entre o spin do elétron de hopping e o spin dos elétrons restantes localizados em cada sítio interagente, isto é, à interação de troca intra-atômica. Este termo, no entanto, é só uma constante aditiva na energia, cujo sinal é imaterial e pode ser omitido. ${ }^{54}$ Fisicamente, estamos no caso em que $J_{\text {hund }} \gg b$, isto é, o acoplamento entre o spin dos íons no dímero e o spin do elétron extra é muito grande de modo que este elétron está localizado no dímero.
} 


$$
E\left(S_{0}\right)=E_{t}\left(S_{0}\right)+E_{t d}\left(S_{0}\right)=-\frac{J}{2} S_{0}\left(S_{0}+1\right) \pm b \frac{\left(S_{0}+1 / 2\right)}{(2 S+1)}
$$

Para um dímero $\mathrm{d}^{5}-\mathrm{d}^{6}$, como é o caso do $\mathrm{Fe}^{3+}-\mathrm{Fe}^{2+}$, temos $S_{0}=1 / 2,3 / 2, \ldots, 9 / 2$ e $S=2$. Na figura 2.13, encontra-se um diagrama de $E\left(S_{0}\right) /|J|$ em função de $b /|J|$, exemplificando a correlação existente entre o estado fundamental e a razão entre a integral de transferência e a interação de troca, $b /|J|$, para este dímero. ${ }^{56}$

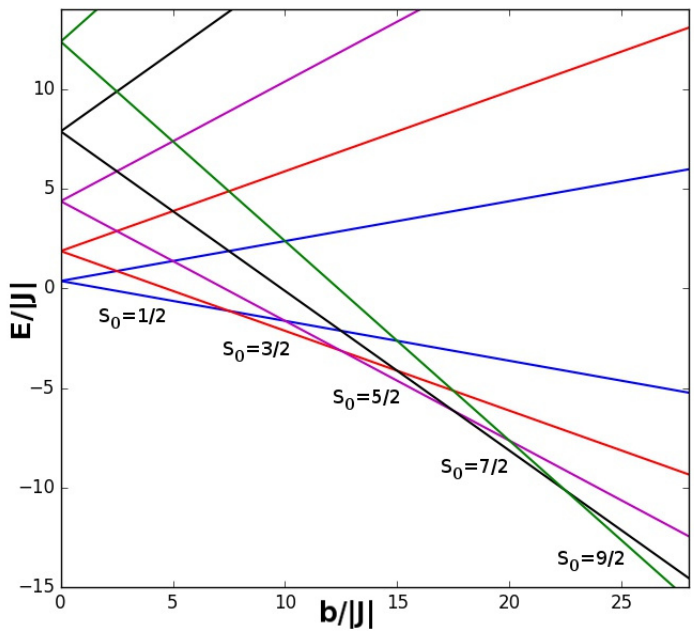

(a)

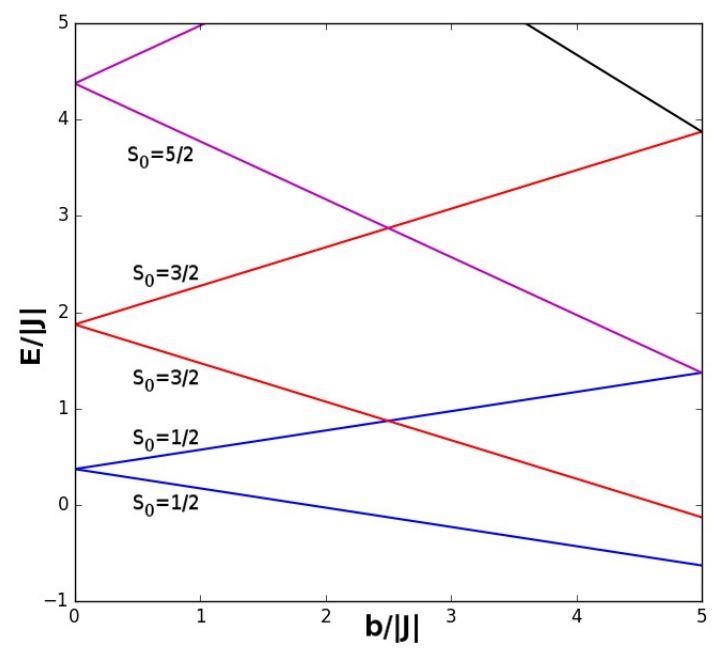

(b)

Figura 2.13 - (a) Diagrama de correlação entre a energia de um dímero de valência mista e a razão $b /|J|$, em que $b$ é energia de transferência de carga (hopping) e $J$ é a constante da interação de troca isotrópica, Equação (3.12). Nesse diagrama, a interação de troca é antiferromagnética, isto é, $J<0$. (b) Detalhe para $b /|J|<5$.

Fonte: Elaborada pelo autor.

Pode-se observar ainda na Figura 2.13, que o sistema terá o estado fundamental $S_{0}$ ferromagnético $\left(S_{0}=9 / 2\right)$ para $b>20 J$ e antiferromagnético $\left(S_{0}=9 / 2\right)$ para $b<7 J$. A diferença básica entre o estado antiferromagnético num sistema em que somente a interação de troca tem um papel e na presença da interação de troca dupla é que, na última, existem dois estados $S_{0}=1 / 2$ separados por $2 b / 5$. Sendo assim, a interação de troca dupla tem efeito análogo a uma separação de campo zero entre os dois estados $S_{0}=1 / 2$.

Para visualizar essa situação, soma-se a interação Zeeman à energia da expressão (3.12) e obtém-se o diagrama de energia em função do campo magnético da figura 2.14. 


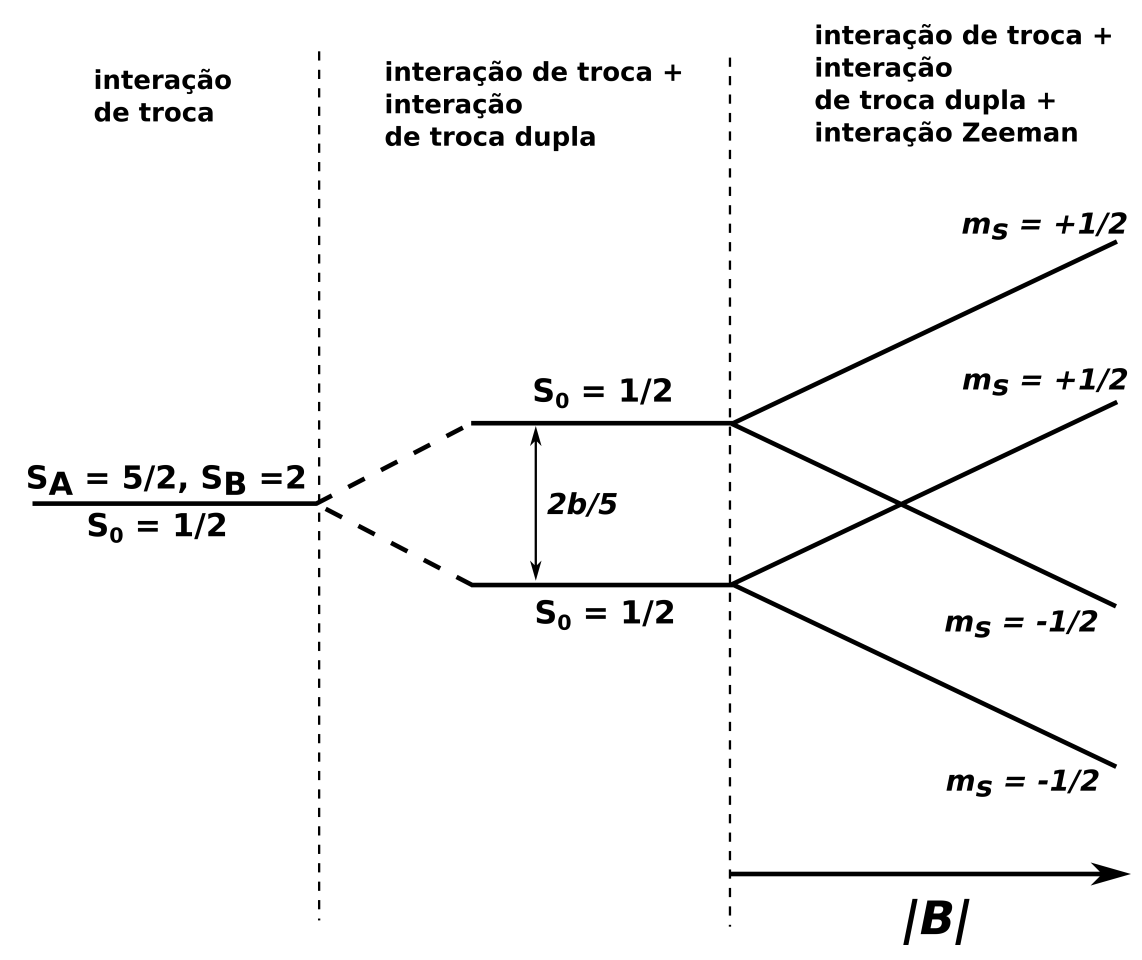

Figura 2.14 - Estado fundamental da interação de troca no dímero $\mathrm{Fe}^{3+}-\mathrm{Fe}^{2+}, S_{A}=5 / 2$ e $S_{B}=2$, respectivamente, modificado pela presença da interação de troca dupla e sujeito a um campo magnético.

Fonte: Elaborada pelo autor.

Dado esse esquema de energia, dois casos são possíveis para se interpretar a diferença observada em $g$ efetivo.

- $\quad$ Caso A:

Ajustando-se adequadamente o valor de $b$ para $0.21 \mathrm{~cm}^{-1}$, obtém-se a separação em campo entre as transições indicadas pelas linhas verdes na Figura 2.15 como $1800 \mathrm{G}$, que equivale a separação em campo observada experimentalmente nas duas frequências medidas.

O valor da constante de troca isotrópica $J$ não altera a diferença de energia entre os níveis dos estados $S_{0}$ sob ação do campo magnético, mas sua relação com $b$ determina quem será o estado fundamental, de modo que a observação do sinal em torno de $g=2$ indica $|J| \gg 0.21 \mathrm{~cm}^{-1}$. As transições em verde estão sujeitas a uma anisotropia em $b$, enquanto que as transições em azul e vermelho podem ser anisotrópicas desde que haja uma anisotropia em $g$ causada por campo cristalino, campo dipolar ou interação de troca, como no caso do $\mathrm{Fe}(\mathrm{III})$ baixo spin em porfirinas e do $\mathrm{Cu}(\mathrm{II})$ em $\mathrm{Cu}_{2} \mathrm{Cl}^{57,58}$ A linha do centro corresponde às transições entre os níveis do mesmo dubleto e estão 


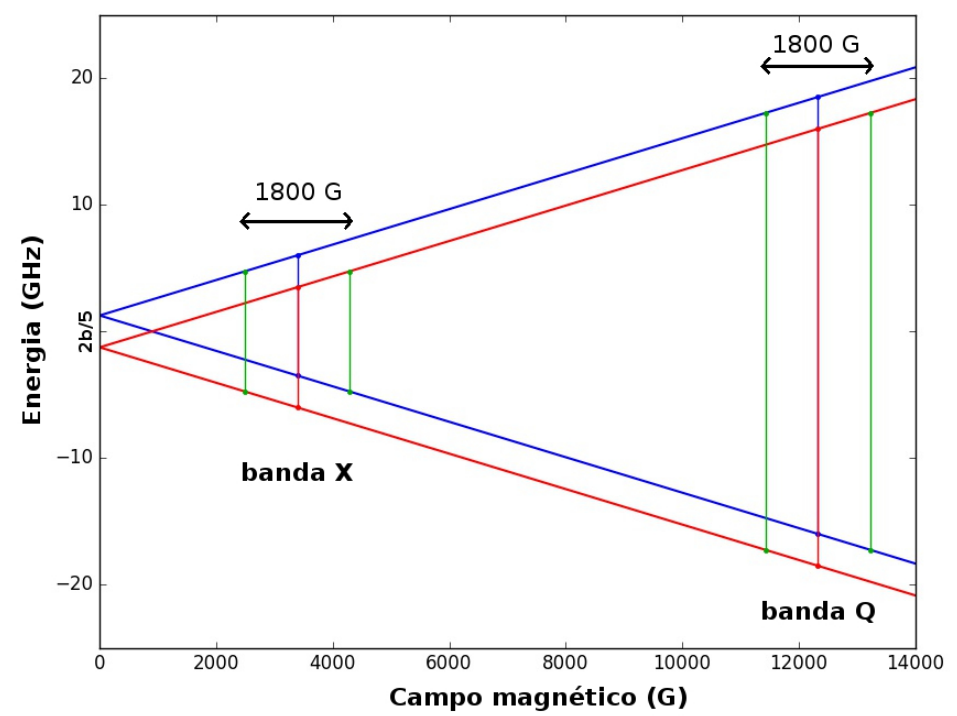

Figura 2.15 - Diagrama de níveis de energia em escala e transições que obedecem a regra de seleção $\Delta m= \pm 1$ em banda $\mathrm{X}$ e banda $\mathrm{Q}$ para o dímero em questão.

Fonte: Elaborada pelo autor.

sujeitas a anisotropia no fator $g$ real que deve se manter a mesma nas duas bandas.

A origem da anisotropia em $b$ vem do fato de o hopping ser maior na sobreposição dos orbitais $\mathrm{p}$-d ao longo da ligação $\mathrm{Fe}-\mathrm{O}\left(b_{p-d \sigma}\right)$ e menor na direção perpendicular $\left(b_{p-d \pi}\right){ }^{25}$

O uso desse modelo explica o número de linhas observadas e a diferença entre as bandas, desde que haja algum mecanismo de troca entre as duas orientações de tríades resultando em ressonâncias num campo médio, ou seja, uma interação de troca inter-dímeros. Isto é, os conjuntos I, II e III identificados previamente são um único conjunto com parâmetros promediados. Esse efeito de colapso via interação de troca é tipicamente observado em dímeros de cobre e o aparato matemático que o justifica já está amplamente discutido na literatura. 9,59,60

A partir da interpretação dos espectros como transições num sistema sujeito a interação de troca dupla, o ajuste dos espectros incluindo uma linha adicional que poderia ter origem no $\mathrm{Fe}^{3+}$ "isolado" do dímero na tríade às três consideradas inicialmente não deve ser descartada, uma vez que o ajuste é tão bom quanto o ajuste feito excluindo-se essa linha adicional. Na figura 2.10, nota-se que os eixos $x$ e $y$ correspondem às direções em que as linhas estão mais separadas, ou seja, em que os espectros possuem a maior resolução. Por essa razão, escolhemos a direção y para fazer esse ajuste mais cuidadoso. No resultado da figura 2.14(b), nota-se que a linha central referente ao dímero deve ter o dobro da área das linhas das extremidades se considerarmos que todas as transições tem a mesma probabilidade de ocorrer. Vincular a área nessas proporções, usando três linhas referentes ao dímero e uma linha referente ao $\mathrm{Fe}^{3+}$ que não faz parte 
do dímero na tríade para ajustar os espectros na direção $y$ tanto em banda $\mathrm{X}$ quanto em banda $Q$ resulta no ajuste que pode ser visto na Figura 2.16, ou seja, o presente ajuste inclui a possibilidade de que a absorção da micro-onda ocorra tanto pelo $\mathrm{Fe}^{3+}$ alto spin como pelos dímeros $\mathrm{Fe}^{3+}{ }_{-} \mathrm{Fe}^{2+}$ nas tríades. $\mathrm{O}$ melhor ajuste em cada banda corresponde aquele em que a linha isotrópica do $\mathrm{Fe}^{3+}$ também tem área dobrada: como a linha é isotrópica, a contribuição deste sítio em cada tríade ocorre no mesmo campo, resultando nessa proporção de 2:1 em relação aos sinais anisotrópicos de campo mais alto e mais baixo.

O problema nessa explicação em assumir que transição entre os estados $S_{0}=1 / 2$ ocorra de maneira direta através da regra de seleção $\Delta m= \pm 1$ em primeira ordem está relacionado a variação angular nos três planos apresentados. A existência de três linhas no espectro e a separação em campo é satisfatoriamente aplicável no plano $x y$, mas mesmo uma anisotropia em $b$ não é suficiente para explicar a variação angular nos outros dois planos de forma coerente nas duas frequências estudadas. Além disso, o deslocamento de $70^{\circ}$ entre a linhas também não é contemplado por esta abordagem em que os conjuntos I, II e III sejam oriundos do colapso dos dois dímeros. Para resolver esse problema, faz-se necessário partir da hamiltoniana de spin para entender de maneira mais fundamental como a transição entre esses níveis ocorre.

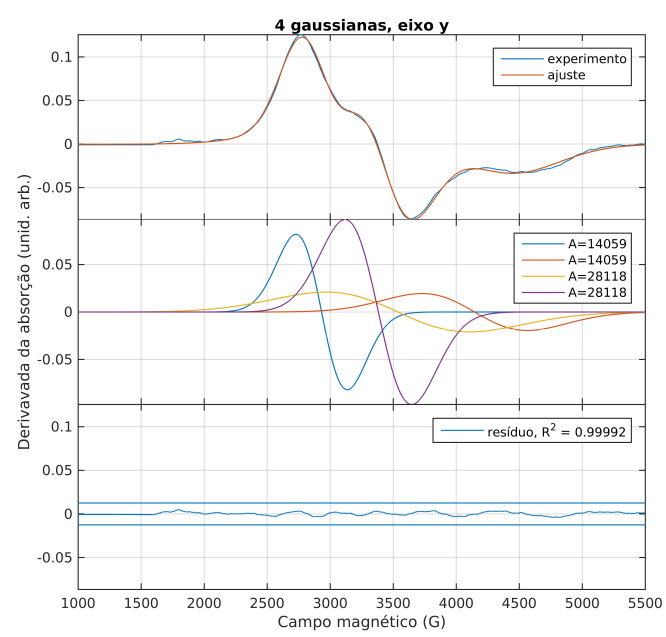

(a)

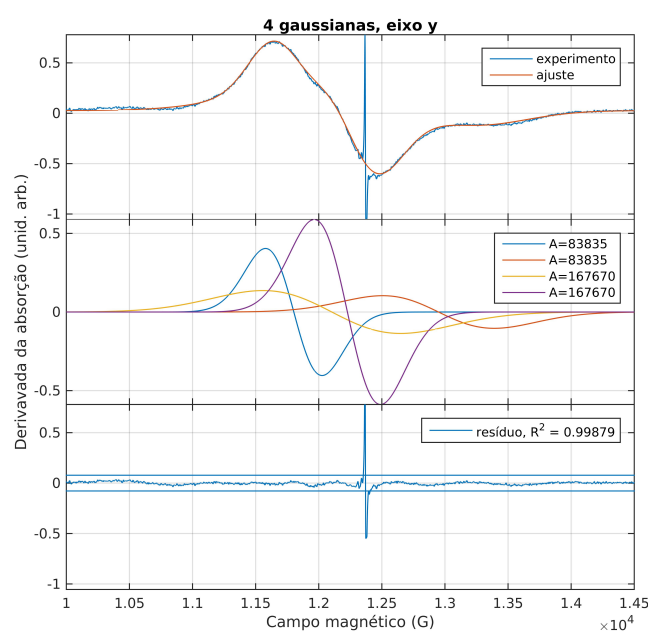

(b)

Figura 2.16 - Simulação do espectro de RPE em (a) banda X e (b) banda Q com o campo magnético aplicado ao longo do eixo $y$, utilizando quatro linhas gaussianas. Fonte: Elaborada pelo autor. 
- $\quad$ Caso B:

A separação de $2 b / 5$ entre os dois estados $S_{0}=1 / 2$ é análoga a que existe em sistemas com separação de campo zero, nos quais as transições são computadas com base em aproximações obtidas a partir de teoria de perturbação. Um exemplo é o $\mathrm{Cr}^{3+} \mathrm{com}$ spin $3 / 2$ na esmeralda. Neste centro paramagnético com simetria axial, o dubleto $\pm 3 / 2$ está separado do dubleto $\pm 1 / 2$ por uma energia de $2 D$. O valor de $g$ efetivo, calculado a partir de uma aproximação em segunda ordem da hamiltoniana de spin, apresenta uma dependência com a frequência que é do tipo $g_{e f} \propto g\left[1 \pm(h v / 2 D)^{2}\right]=g[1 \pm \Delta g]$ para $D>>h v$, em que $v$ é a frequência da micro-onda utilizada no experimento. ${ }^{61}$ Para o dímero na ludwigita, as interações em questão são de natureza distinta, mas é uma situação análoga na qual a separação de campo zero ocorre entre dois dubletos $\pm 1 / 2$ como mostrado na Figura 2.14. Vimos que o comportamento de $g_{e f}$ depende de um termo do tipo $\Delta g$ que varia com a frequência assim como no $\mathrm{Cr}^{3+}$. Nesse caso, precisamos assumir que $2 b / 5 \gg h v$, de modo que a mesma condição de uma separação de campo nulo bem maior que a frequência do experimento seja válida. Para ter uma ideia da ordem de grandeza, a aproximação para o $\mathrm{Cr}^{3+}$ já é válida para $D>4 h v$ entre banda $\mathrm{L}\left(h v=0.044 \mathrm{~cm}^{-1}\right)$ e banda $\mathrm{X}\left(h v\right.$ é $\left.0.31 \mathrm{~cm}^{-1}\right)$ como mostrado na referência ${ }^{62}$. No caso estudado aqui, em que usamos banda $\mathrm{X}$ e banda $\mathrm{Q}\left(1.2 \mathrm{~cm}^{-1}\right)$, temos que $b>3$ $\mathrm{cm}^{-1}$ seria suficiente para a validade da aproximação em que $g_{e f} \propto g[1 \pm \Delta g]$. Desde que $b \gg J$, não há nenhum limite para o valor de $b$, sendo que isto não constitui uma falha na interpretação.

Considerando esse caso, os conjuntos I e II continuam correspondendo cada um a um dímero da estrutura, coerente com a interpretação dos dados utilizando a anisotropia Zeeman. O cálculo mais detalhado das transições considerando a hamiltoniana de spin e esse modelo perturbativo será objeto de estudo para trabalhos futuros.

\subsection{Variação angular no plano $a b$ em função da temperatura}

Na figura 2.17 é mostrado o comportamento da variação angular no plano $x y$ em algumas temperaturas entre $295 \mathrm{~K}$ e $5 \mathrm{~K}$. Como a largura da linha aumenta com a diminuição da temperatura, a sobreposição das linhas é maior. Entretanto é possível perceber uma variação semelhante àquela à temperatura ambiente com duas diferenças: i) o valor médio do campo ressonante cai (ou $g_{\text {eff }}$ aumenta), indicando um aumento do campo interno devido ao 
ordenamento magnético, sobretudo abaixo de $110 \mathrm{~K}$, em que se estabelece ordem de longo alcance nas tríades; ii) a separação entre o campo de ressonância mais alto e mais baixo (ou a diferença entre o maior e o menor $g_{e f f}$ ) aumenta, o que configura uma variação sutil no valor da interação de troca dupla $b$ de acordo com as interpretações apresentadas acima, em que $b$ determina a separação entre o campo central dos sinais anisotrópicos.

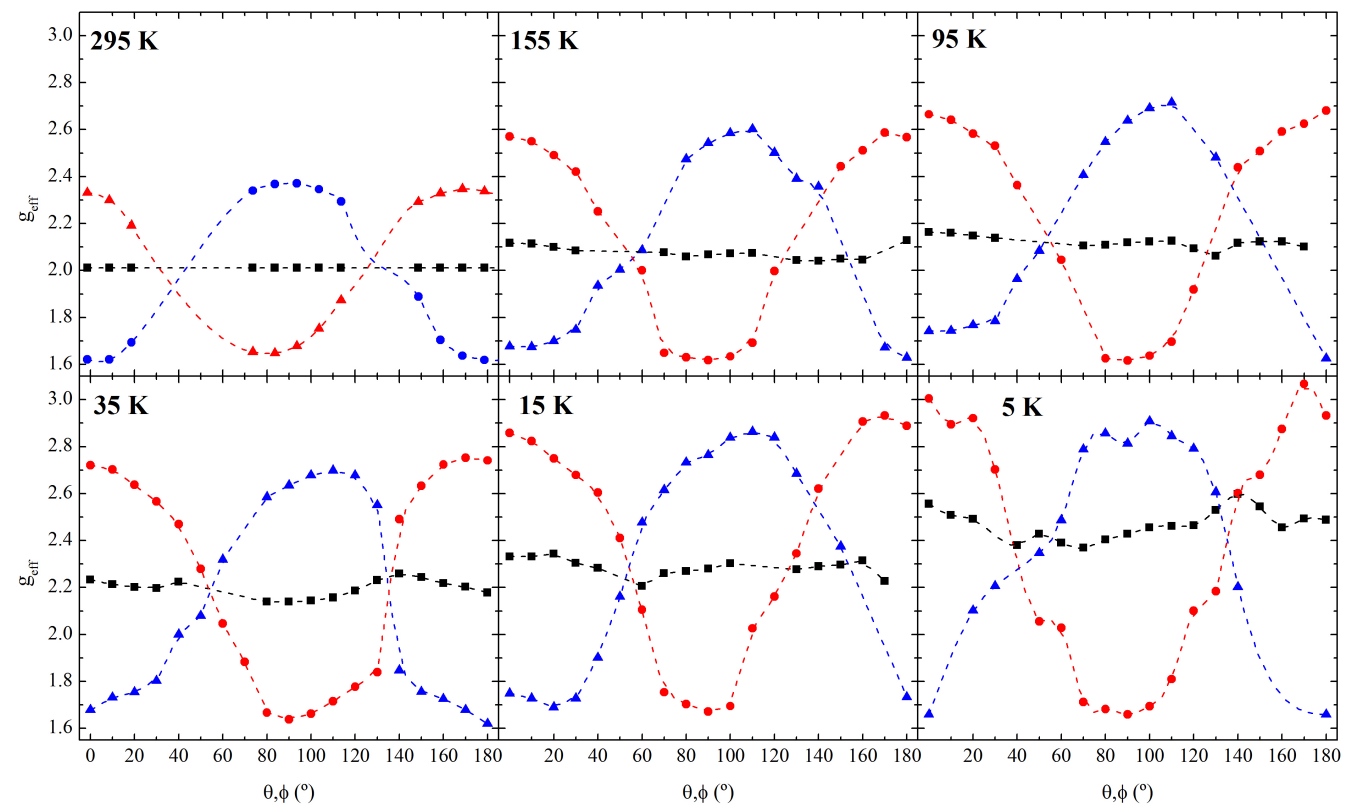

Figura 2.17 - Variação angular, $g_{e f f}(\theta, \phi)$, obtida em banda $\mathrm{X}$ para o cristal $\mathrm{Fe}_{3} \mathrm{O}_{2} \mathrm{BO}_{3}$ no plano $x y(a b)$ para algumas temperaturas. As linhas tracejadas são apenas guias para os olhos.

Fonte: Elaborada pelo autor.

As mesmas observações podem ser feitas a partir dos valores de $g_{\text {eff }}$ em função da temperatura para o campo aplicado na direção $y$, Figura 2.19(c), em que o maior $g_{e f}$ aumenta e o menor diminui ligeiramente até $150 \mathrm{~K}$. Para a integral de transferência de carga variar, a sobreposição dos orbitais dos íons de ferro compondo o dímero e do oxigênio ligante precisa ter variado. De fato, os dados de raio $X$ do cristal mostram que a distância entre os ferros do dímero só se estabiliza por volta de $150 \mathrm{~K}$, assim como o parâmetro de deslocamento atômico. ${ }^{34} \mathrm{~A}$ variação dessa distância está associada à transição estrutural $P b a m \rightarrow P b m n, \mathrm{e}$ a mudança no valor de $g$ também pode estar relacionada a essa distorção da rede. A distorção na estrutura também pode afetar a constante de troca de modo que a diminuição do ângulo $\mathrm{Fe}^{3+}-\mathrm{O}-\mathrm{Fe}^{2+}$ e da distância do oxigênio à linha que separa os dois ferros no dímero aumenta o valor de $J{ }^{25}$ Essa deve ser a razão para a condutividade cair com a queda da temperatura ${ }^{42}$, pois com a queda da energia térmica na rede, a interação antiferromagnética começa a ser dominante e o hopping energeticamente desfavorável, isto é, a relação entre $J$ e $b$ muda. Os dados a $5 \mathrm{~K}, 15 \mathrm{~K}$ e $35 \mathrm{~K}$ correspondem a faixa de temperatura na qual a amostra está na fase antiferromagnética (ou possivelmente ferrimagnética) com o momento magnético de 
todos os sítios de ferro orientados no plano $a b$. Os dados a $95 \mathrm{~K}$ correspondem à fase em que os sítios 2 e 4 da 3LL estão antiferromagneticamente ordenados mas os sítios 1 e 3 ( $\mathrm{Fe}^{2+}$ fora da tríade) não estão. Os dados a $155 \mathrm{~K}$ correspondem a fase em que a dimerização já ocorreu mas não há ordem magnética de longo alcance. Os dados a temperatura ambiente (295 K) correspondem à temperatura em que a dimerização já começou mas também não há ordem magnética de longo alcance. A observação do dímero em todas as fases magnéticas do material está de acordo com a sugestão de desordem eletrônica a baixa temperatura e também com a sugestão de correlação eletrônica a alta temperatura mencionadas na seção 1 deste capítulo.

\subsection{Curva de saturação do sinal de RPE}

Na Figura 2.18, encontram-se as curvas de saturação em temperatura ambiente e a 5 K para o cristal da ludwigita de ferro. Consideremos a expressão da potência absorvida na cavidade no experimento de RPE

$$
P_{a}(\omega)=\frac{\pi}{\mu_{0}} \frac{B_{1}^{2}}{\left(1+\gamma_{e}^{2} B_{1}^{2} \tau_{1} \tau_{2}\right)^{1 / 2}} \omega \omega_{B} \chi^{0} Y
$$

em que $B_{1}$ corresponde ao campo magnético oscilante (micro-onda), $\gamma_{e}$ ao fator giromagnético do elétron, $\tau_{1}$ ao tempo de relaxação spin-rede, $\tau_{2}$ ao tempo de relaxação spin-spin, $\mu_{0}$ à permeabilidade magnética no vácuo, $\omega_{B}$ à frequência de Larmor, $\chi^{0}$ à susceptibilidade estática e $Y$ à função de forma da linha. A saturação do sinal de absorção é determinada pelo produto $\gamma_{e}^{2} B_{1}^{2} \tau_{1} \tau_{2}$ no denominador da equação (3.13). Se este termo é suficientemente pequeno, a potência absorvida (área do sinal de RPE) é diretamente proporcional à raiz quadrada da potência da micro-onda (ou seja, a $B_{1}$ ). Se $\gamma_{e}^{2} B_{1}^{2} \tau_{1} \tau_{2} \gg 1$ este termo não pode ser desprezado e ocorre a saturação do sinal, ou seja, a potência absorvida perde a linearidade $\operatorname{com} B_{1}^{2}$. Isso pode ser observado aumentando-se a potência da micro-onda na amostra.

No nosso caso, como pode ser visto na Figura 2.18(d), o aumento da potência não leva à saturação do sinal nem a $295 \mathrm{~K}$, nem a $5 \mathrm{~K}$, indicando que o produto $\tau_{1} \tau_{2}$ é muito pequeno. A baixas temperaturas, $\tau_{1}$ pode crescer drasticamente para paramagnetos típicos, de modo que o sinal de RPE geralmente satura. ${ }^{2}$ Sendo assim, o tempo de relaxação $\tau_{2}$ deve ser suficientemente pequeno a ponto de dominar a relaxação no dímero. Esse comportamento pode ser atribuído à presença de estados deslocalizados ou parcialmente localizados, que têm tempo de relaxação muito pequeno comparado a momentos localizados, isto é, o tempo de 
relaxação $\tau_{2}$ pequeno pode ser atribuído à correlação eletrônica no dímero, seja ela atribuída tanto a desordem de carga quanto a interação de troca.

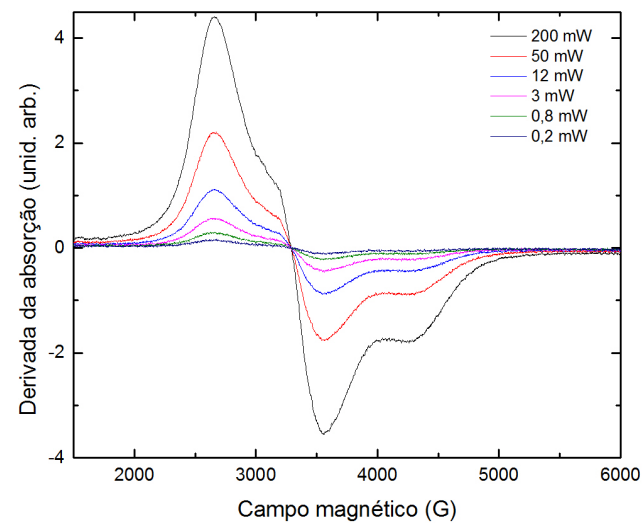

(a)

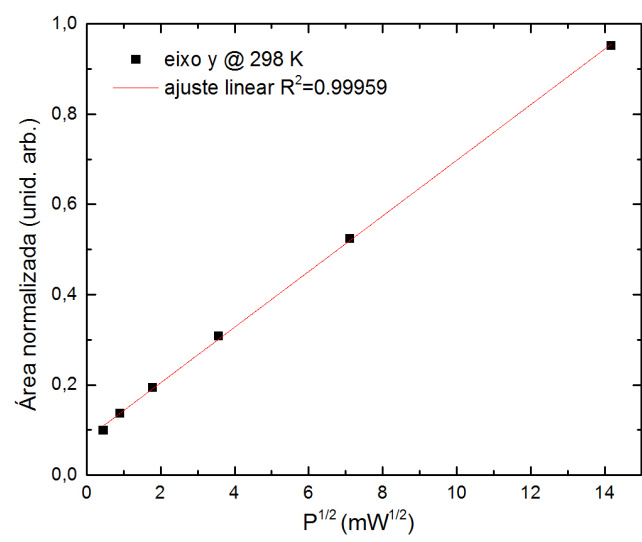

(c)

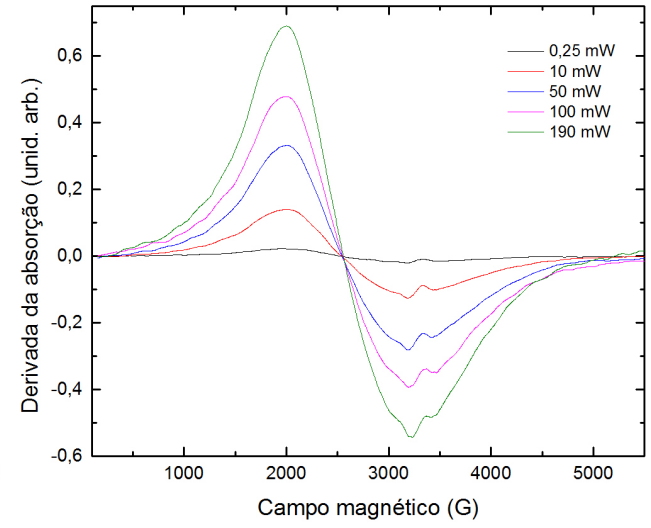

(b)

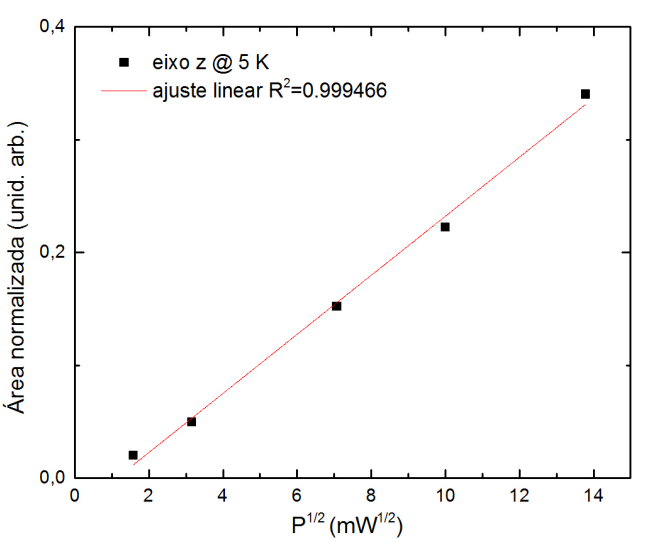

(d)

Figura 2.18 - Variação da potência da micro-onda para o monocristal de $\mathrm{Fe}_{3} \mathrm{O}_{2} \mathrm{BO}_{3}$ à temperatura ambiente e a $5 \mathrm{~K}$ (resfriada com o campo ligado) em banda $\mathrm{X}$.

Fonte: Elaborada pelo autor.

\subsection{Variação térmica com campo orientado ao longo dos eixos $z$ e $y$}

O comportamento do tempo de relaxação evidenciado pela medida de saturação e justificado pela correlação eletrônica no dímero também é observado no comportamento da largura de linha em função da temperatura, como será mostrado a seguir. De modo geral, duas contribuições podem ser levadas em consideração na largura de linha de um sinal de RPE:

$$
\Delta H \propto \frac{1}{\tau_{1}}+\frac{1}{\tau_{2}} .
$$


Nota-se a partir da Figura 2.19(d), que a largura aumenta com a diminuição da temperatura, indicando a diminuição do tempo de relaxação dominante, $\tau_{2}$, de acordo com a expressão (3.14) acima, para todas as linhas e direções medidas.

Outra evidência experimental de que o sinal se trata de transições relacionadas a estados ligados e não centros paramagnéticos isolados, impurezas ou vacâncias é obtida a partir da medida da área do sinal de RPE em função da temperatura da amostra com o campo magnético orientado ao longo dos eixos $z(c)$ e $y$. Na figura 2.19(b), percebe-se claramente um comportamento do tipo Curie-Weiss em temperatura mais altas para o recíproco da área dos espectros medidos no eixo $c$, ou seja, perpendicular ao plano em que os momentos se orientam na fase ordenada, com $\Theta \simeq-400 \mathrm{~K}$. O mesmo valor para a constante de Curie-Weiss foi estimado na referência 32, na qual evidência de correlações bem acima da temperatura de Néel da tríade também são mencionadas.

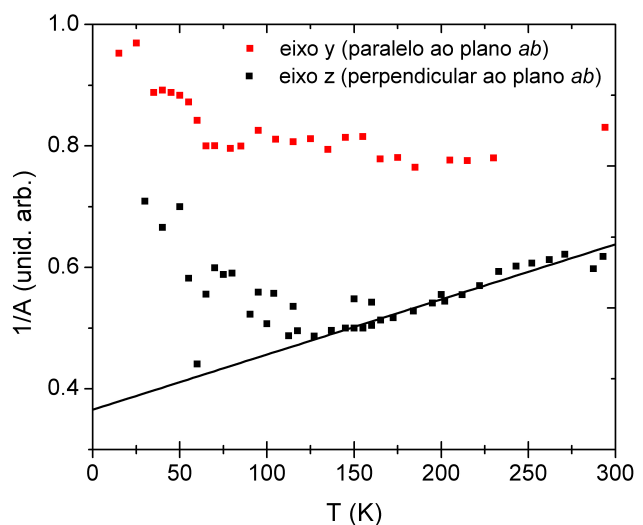

(a)

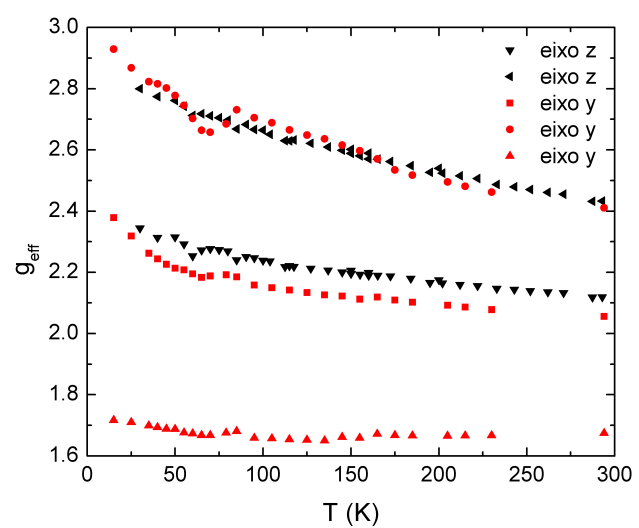

(c)

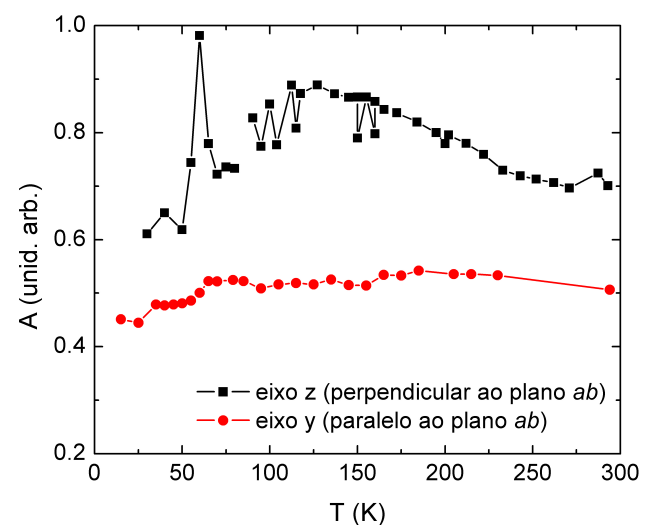

(b)

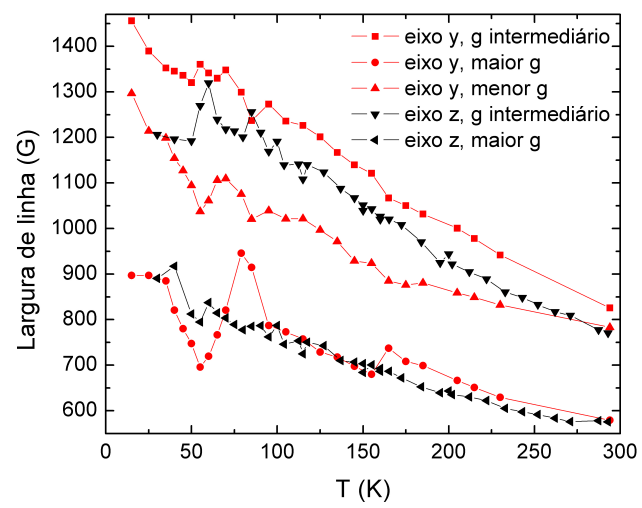

(d)

Figura 2.19 - (a) Recíproco da área (1/A), (b) área, (c) $g_{\text {eff }}$ e (d) largura de linha do sinal de RPE em função da temperatura para o campo magnético aplicado na direção paralela e perpendicular ao plano $a b$.

Fonte: Elaborada pelo autor.

Já para a medida paralela ao plano $a b$, a área do sinal é praticamente constante de 300 
$\mathrm{K}$ até $65 \mathrm{~K}$, temperatura na qual a área começa a cair, coincidindo com a temperatura de ordem magnética de todos os sítios da ludwigita. Nesta mesma temperatura de $65 \mathrm{~K}$, um máximo local na área da medida no eixo $z$ também é observado. Embora o comportamento em função da temperatura possa ser comparado entre as medidas nas duas direções, o valor absoluto não constitui um parâmetro comparativo, pois a medida não foi feita utilizando um padrão e garantindo controle de todas as variáveis para uma medida de RPE quantitativa.

Dado que uma interação dipolar entre os sítios de ferro do dímero possa influenciar tanto na anisotropia quanto na largura de linha, usamos um modelo de dipolos de cargas pontuais para estimar seu valor. O campo magnético em um ponto distante $r$ do seu vizinho mais próximo pode ser estimado por $^{38}$

$$
B_{d} \simeq \mu / r^{3}
$$

Considerando $\mu \sim \mu_{B}$ para o elétron deslocalizado na tríade e a distância entre os sítios 2 e $4 r=0.278816 \mathrm{~nm}$, temos $B_{d} \simeq 430 \mathrm{G}$, que é da mesma ordem da largura de linha em temperatura ambiente.

\subsection{Medidas a baixa temperatura}

Os resultados para o espectros de RPE em banda $X$ a baixas temperaturas $(<20 \mathrm{~K})$ apresentam um comportamento ainda não muito bem compreendido. Por exemplo, como pode ser observado na Figura 2.20, o espectro a $4 \mathrm{~K}$ é dependente das condições de congelamento da amostra. Diminuir a temperatura com o campo magnético ligado (FC, da sigla em inglês para field cooling) favorece o aparecimento de uma estrutura não existente no sinal quando a temperatura é reduzida com o campo magnético desligado (ZFC, zero field cooling). As medidas foram repetidas 4 vezes e também foram feitas apenas com o tubo de quartzo e o porta-amostra para garantir que o efeito observado não era causado por nenhum fator externo à amostra.

Na Figura 2.21 encontram-se os espectros em função da orientação do campo magnético e uma variação térmica entre $4.5 \mathrm{~K}$ e $21 \mathrm{~K}$ após resfriamento com campo ligado (FC). Nota-se que a linha em torno de 8000 G é anisotrópica com relação a orientação do campo magnético aplicado, enquanto a linha em campo mais baixo é dominada pela contribuição isotrópica do sinal observado nessa região de campo. Esse comportamento será avaliado em trabalhos futuros. 


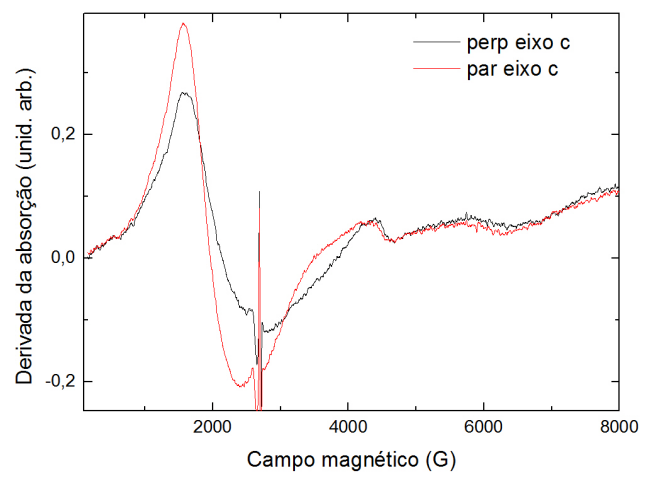

(a)

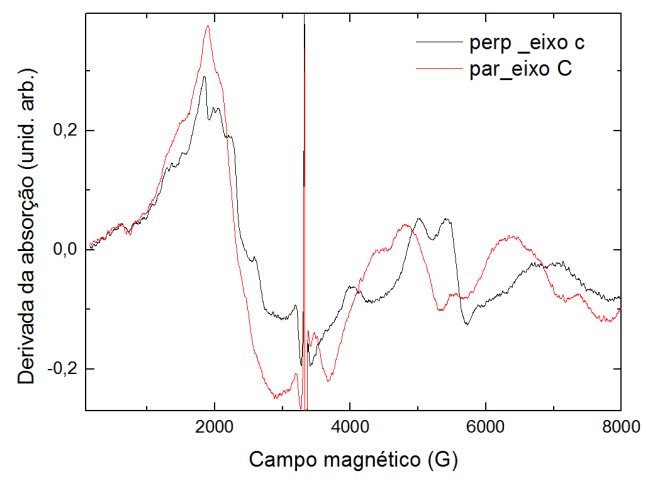

(b)

Figura 2.20 - Medidas em função da orientação do cristal em relação ao campo magnético a $4 \mathrm{~K}$ com (a) ZFC e (b) FC. A linha fina em torno de $3200 \mathrm{G}$ é uma impureza do tubo que foi usado nesta medida.

Fonte: Elaborada pelo autor.

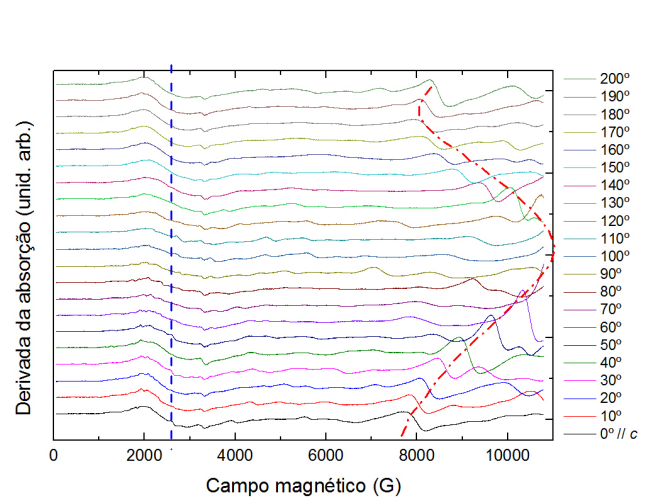

(a)

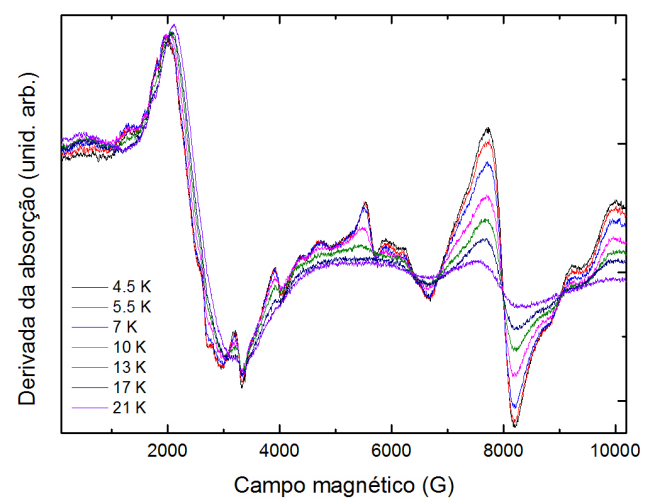

(b)

Figura 2.21 - Variação angular no eixo $z$ a $4 \mathrm{~K}$ e em função da temperatura para a linha de mais alto campo, após ZFC.

Fonte: Elaborada pelo autor.

\subsection{Considerações sobre o dímero}

Monocristais da ludwigita heterometálica $\mathrm{FeCO}_{2} \mathrm{O}_{2} \mathrm{BO}_{3}$ e da ludwigita homometálica de cobalto, $\mathrm{Co}_{3} \mathrm{O}_{2} \mathrm{BO}_{3}$, foram medidas mas não apresentaram sinal de RPE em nenhuma temperatura medida na faixa de $4 \mathrm{~K}$ a $300 \mathrm{~K}$, tanto em banda $\mathrm{X}$ quanto em banda $\mathrm{Q}$. Apesar da equivalência estrutural em temperatura ambiente, ambas as amostras possuem características elétricas e magnéticas diferentes do composto $\mathrm{Fe}_{3} \mathrm{O}_{2} \mathrm{BO}_{3}$. Não há informações sobre uma transição estrutural na ludwigita heterometálica de Fe-Co na literatura. Na ludwigita homometálica de cobalto não ocorre transição estrutural (dimerização) e as interações presentes são predominantemente ferromagnéticas. ${ }^{42,63} \mathrm{Na}$ ludwigita homometálica de ferro, a configuração eletrônica é tal que há três $\mathrm{Fe}^{3+}$ com spin $5 / 2$ compartilhando um elétron. No caso do sistema 
com cobalto, os íons de $\mathrm{Co}^{3+}$ compartilhando o elétron possuem spin 2 . O íon de ferro com spin $5 / 2$ possui um orbital $d$ semi-preenchido com momento orbital $L=0$, que é associado com anisotropia magnética pequena e acoplamento fraco à rede devido a ausência de interação spin-órbita. Esse fato sugere que a transição de dimerização tem origem puramente eletrônica de modo que para o cobalto, o acoplamento com a rede age em detrimento da transição estrutural. Além disso, a amostra de cobalto apresenta uma única transição magnética na qual todos os sítios se ordenam simultaneamente. ${ }^{64}$ Sendo assim, a dimerização e a desordem de carga no dímero de ferro parecem ter um importante papel em todos os efeitos na ludwigita de ferro. De fato, as características do sinal de RPE e sua observação em toda a faixa de temperatura estudada são evidências desse fato. Além disso, se uma interação de troca dupla predominante sobre a interação de troca, $t \gg J$, é sugerida como explicação para o ferromagnetismo observado na ludwigita de cobalto, a ausência de sinal de RPE pode estar relacionada a um estado fundamental com alto spin, como se pode observar na Figura 2.13(a), que não necessariamente tem sinal de RPE em frequências de banda $X$ e banda $Q$.

Medidas de RPE em banda $X$ e banda $Q$ em amostras policristalinas de $\mathrm{La}_{(1-x)} \mathrm{Ca}_{x} \mathrm{MnO}_{(3+\delta)}$ apresentam uma linha larga em torno de $\mathrm{g}=2$ desde altas temperaturas. ${ }^{65}$ Esses compostos também apresentam valência mista, neste caso, íons de $\mathrm{Mn}^{3+}$ e $\mathrm{Mn}^{4+}$ com multiplicidade de spin respectivamente $S=2$ e $S=3 / 2$, ambos raramente observados por RPE em temperatura ambiente. Oseroff et al. ${ }^{65}$ sugere que, na manganita mencionada, o sinal pode ser originado de polarons magnéticos, aglomerados de spins, ou seja, alguma forma de ordenamento de curto alcance entre portadores spin-polarizados. Analogamente, pudemos associar o sinal observado a um estado ligado, refutando que o sinal observado na amostra $\mathrm{Fe}_{3} \mathrm{O}_{2} \mathrm{BO}_{3}$ seja exclusivamente dos elétrons d do ferro III em campo octaédrico com interação dipolar e menos provavelmente dos íons de $\mathrm{Fe}^{2+}(\mathrm{S}=2)$. Demonstramos que, de fato, a correlação eletrônica existe e é responsável pelo sinal de RPE inclusive na fase com ordem de longo alcance. Há apenas um elétron por tríade sendo compartilhado, tornando a verificação da interação de troca dupla mais fácil do que nas manganitas em que a dopagem é imprecisa e as amostras são instáveis causando problemas de reprodutibilidade.

Sobre a competição entre as duas interações intra-dímeros, de troca e de troca dupla: o resultado final das interações no dímero indica um estado fundamental antiferromagnético mas há uma integral de transferência de carga $b$ pequena em relação a $J$. Uma interpretação possível é que, em certos dímeros, o elétron está no sítio 2 e em outros no sítio 4a, de modo que a deslocalização observada nas técnicas de Mössbauer ${ }^{32}$ e calculadas a partir da estrutura 66 esteja mais relacionada à carga média dos sítios e ao ordenamento de carga do que de fato ao hopping dentro das tríades consideradas individualmente. Entretanto, a condutividade neste 
material é explicada pelo hopping, de modo que mesmo pequeno, ele evidentemente ocorre. Nas manganitas, o significado físico de um $b$ pequeno é que o spin dos sítios localizados não precisam necessariamente ser ferromagnéticos para que o elétron possa saltar entre eles. Pode ser suficiente que haja uma inclinação (canting) nas subredes antiferromagnéticas. Algum hopping é, então, permitido ao elétron deslocalizado, mas toda a energia da interação de troca não é perdida imediatamente. Portanto, com baixas dopagens, espera-se a formação de um estado antiferromagnético inclinado (canted) e é somente em amostras com maior concentração de eletróns móveis que o material se torna de fato ferromagnético. ${ }^{25}$ Como a resistividade da ludwigita é muito grande, estamos no caso semelhante ao de baixas dopagens nas manganitas.

\section{Conclusões}

Neste capítulo, os resultados de medidas de ressonância paramagnética eletrônica na ludwigita homometálica de ferro $\mathrm{Fe}_{3} \mathrm{O}_{2} \mathrm{BO}_{3}$ foram apresentados. Os dados de variação angular em banda $X$ e banda $Q$ são condizentes com a existência de um estado dimérico $\mathrm{Fe}^{3+}{ }_{-} \mathrm{Fe}^{2+}$ previsto na literatura. Mostrou-se que o dímero está acoplado antiferromagneticamente e propôs-se que a diferença no valor de $g$ efetivo entre as duas frequências estudadas pode ser explicado pela interação de troca dupla.

Duas possibilidades foram consideradas para explicar os resultados: no primeiro caso, considera-se a existência de um único conjunto de linhas no espectro oriundo do colapso entre as duas orientações dos dois dímeros não-equivalentes na estrutura. Nesse caso, o valor da integral de transferência $b$ foi estimado como $0.21 \mathrm{~cm}^{-1}(b \sim h v)$. No segundo caso, considerou-se cada linha do espectro originada de um dos dois dímeros não-equivalentes. Para explicar a variação de $g$ em função da frequência, estimou-se que $b>3 \mathrm{~cm}^{-1}$. Nas duas situações expostas, a condição da constante de troca $J \gg b$ deve ser satisfeita. Um modelo definitivo que possa explicar os resultados de RPE realizados nesse trabalho implica num cálculo mais elaborado levando em conta todos os termos que possam influir na hamiltoniana de spin.

Outra evidência do dímero foi obtida a partir das medidas de saturação do sinal de RPE, que indicam a existência de fortes correlações eletrônicas, com a relaxação dominada pelo tempo de relaxação spin-spin $\tau_{2}$, desde alta temperatura. A variação da largura de linha em função da temperatura corrobora com esta interpretação. Não só a largura de linha, mas 
também os outros parâmetros obtidos a partir do ajuste das linhas nos espectros em função da temperatura, como o fator $g$ e a área do sinal de RPE, apresentam variações nas mesmas temperaturas de ordenamento magnético reportadas na literatura para este material.

\section{Perspectivas}

Em trabalhos futuros, pretende-se encontrar um modelo que seja suficiente para simular o comportamento da variação angular nos três planos e nas diferentes frequências de modo a determinar inequivocamente a anisotropia das linhas observadas. Além disso, medidas em altos campos magnéticos e em múltiplas frequências podem ser úteis tanto pela possibilidade de se observar fenômenos de ressonância antiferromagnética quanto para observação do $\mathrm{Fe}^{+2}$ alto spin silencioso nas frequências medidas neste trabalho. Medidas de anisotropia magnética utilizando uma balança de torsão também podem trazer informações sobre o campo interno, que precisa ser analisado para considerar ou descartar que seja a causa da dependência em frequência do valor de $g_{\text {eff }}$. 


\title{
Polianilinas dopadas com plastificantes
}

\author{
"A lógica de um pensamento é o \\ conjunto das crises que ele atravessa. \\ Assemelha-se mais a uma cadeia \\ vulcânica do que a um sistema tranquilo \\ e próximo do equilíbrio." \\ Gilles Deleuze
}

\section{Revisão bibliográfica}

Polianilinas (PANI), entre outros polímeros condutores, têm sido extensivamente estudadas desde os anos 1980, após Heeger, MacDiarmid e Shirakawa descobrirem a possibilidade de incrementar a condutividade do poliacetileno em até 12 vezes mediante dopagem em temperatura ambiente, em $1977 .{ }^{67} \mathrm{O}$ campo de pesquisa em polímeros condutores é atraente não somente devido ao interesse fundamental na dopagem e nas transições metal-isolante induzidas por dopagem como também com respeito a físico-química deles no seu estado semicondutor não dopado, interessante para a construção de dispositivos eletrônicos "plásticos" 68 . Através da concentração de dopantes, as propriedades óticas e eletrônicas de polímeros condutores podem ser controladas numa ampla faixa correspondente àquelas de metais até isolantes. Além do efeito nas propriedades elétricas, a dopagem desses materiais pode ocasionar o aparecimento de ordenamentos magnéticos cuja origem tem sido discutida e investigada e está intimamente ligada ao mecanismo de condução. ${ }^{69}$

A classe de polímeros condutores é formada por materiais cujas cadeias tem duplas ligações $\mathrm{C}=\mathrm{C}$ conjugadas, separadas por ligações simples. Alguns exemplos são mostrados na Figura 3.1. A ligação dupla, do tipo $\pi$, na qual orbitais de carbono estão hibridizados na configuração $\mathrm{sp}^{2}$ e se sobrepõem ao longo da estrutura, acarreta uma deslocalização eletrônica ao longo da cadeia polimérica. Essa deslocalização oferece um "caminho" para a mobilidade de carga ao 
longo na estrutura do polímero. ${ }^{68}$

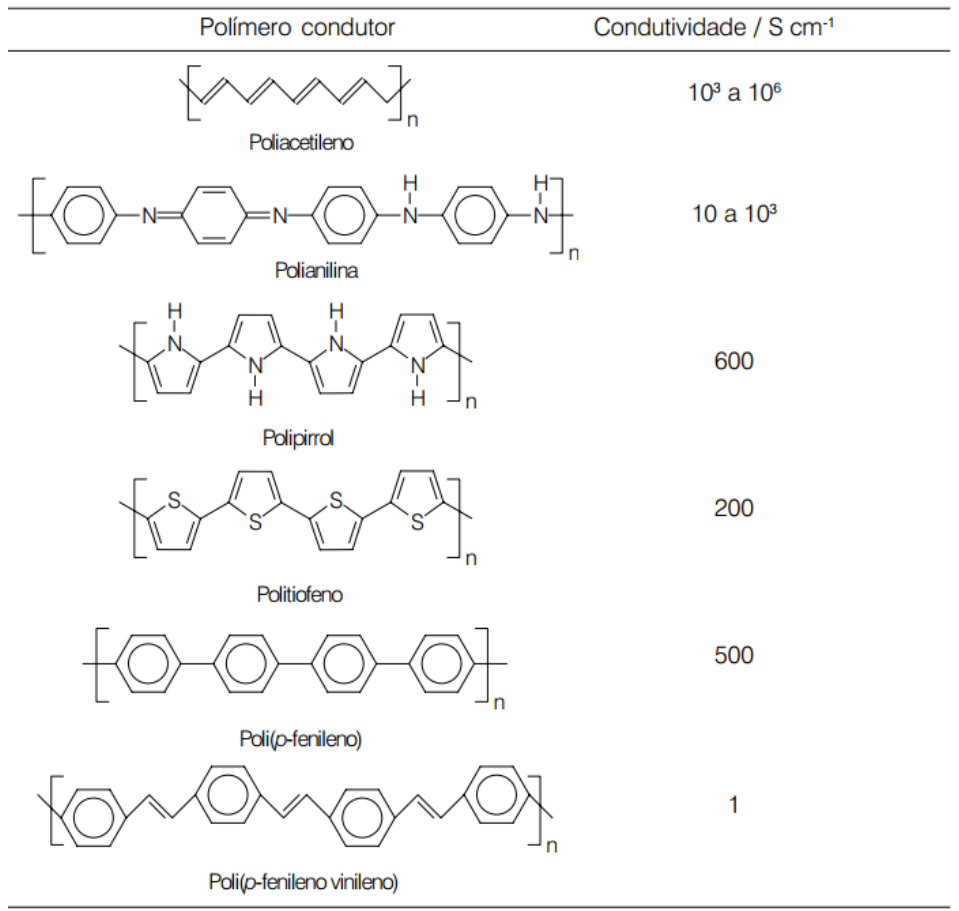

Figura 3.1 - Estrutura dos principais polímeros intrinsecamente condutores.

Fonte: FAEZ et al. ${ }^{69}$

A estrutura eletrônica de polímeros conjugados foi descrita por Su, Schrieffer e Heeger (SSH) $\left(1979^{70}\right.$ e $\left.1980^{71}\right)$ em termos de um modelo tight-binding quase unidimensional em que elétrons $\pi$ são acoplados por distorções na estrutura do polímero por interações elétron-fônon. Essas distorções podem ser interpretadas como a redistribuição de elétrons $\pi$, que polarizam a cadeia polimérica apenas localmente, produzindo uma modificação de curto alcance na distribuição espacial dos átomos. Um dos radicais formados neste processo é chamado de pólaron, e consiste num férmion de carga $\mathrm{q}= \pm e$ e spin $\mathrm{s}=1 / 2$. O pólaron positivo (negativo) pode ser visto como um radical catiônico (aniônico), uma quase-partícula formada por uma única carga eletrônica "vestida" com a relaxação geométrica local do comprimento das ligações químicas na cadeia do polímero (distribuição espacial dos átomos). Dois pólarons ligados pela sobreposição de distorções na rede formam bipólarons, ou seja, o bipólaron pode ser visto como dois pólarons ligados por uma combinação de atração coulombiana e de distorção compartilhada. ${ }^{68}$

Cálculos teóricos sugerem que pólarons sejam instáveis com respeito ao pareamento de seus spins e a formação de um bipólaron duplamente carregado de spin nulo. ${ }^{72,73}$ No entanto, o aparecimento de uma linha de RPE para polímeros condutores sugere o uso do conceito de bandas de pólarons ferro- e antiferromagneticamente acoplados e bipólarons com diferen- 
tes estados de spin singleto, $S=0$, ou tripleto, $S=1$, para explicar tanto o comportamento ferromagnético quanto a dependência da magnetização com o campo magnético observados em pastilhas prensadas de polímeros condutores, a saber poli(3-metiltiofeno) e polipirrol. ${ }^{74}$ Também para a PANI-CSA e suas blendas, evidência de comportamento antiferromagnético foi observado. ${ }^{75}$ Bussac e Zuppiroli ${ }^{76}$ calcularam estados singleto e tripleto para um bipólaron dentro de um modelo de deformação adiabática contínua incluindo repulsões coulombianas de curto alcance entre elétrons e a atração entre os íons dopantes. Kahol et al. ${ }^{77-79}$ aplicaram este modelo na análise de dados de susceptibilidade magnética em vários polímeros condutores e foram os primeiros a apontar a importância de levar a interação de troca em consideração na análise de dados magnéticos em polímeros condutores. Um modelo de clusters de pólarons também foi proposto por Zuppiroli et al. ${ }^{80}$ para explicar evidências de correlação entre pólarons observadas em dados de magnetoresistência. Vemos que ainda há alguma controvérsia a respeito dos defeitos mais estáveis em polímeros condutores, daí a importância de acumular-se informações a respeito das propriedades e fenômenos observados nesses materiais.

Particularmente, o interesse na classe das polianilinas está relacionado ao fato da matériaprima (monômero) ser barata, da reação de polimerização ser simples e de alta performance e de elas terem alta estabilidade. A PANI ocorre em diferentes estados de oxidação, sendo que a forma esmeraldina, $50 \%$ oxidada, corresponde à mais estável. Tanto essa forma quanto alguns outros estados de oxidação são mostrados na Figura 3.2. As polianilinas se tornam condutoras via dois métodos possíveis: oxidação (química ou eletroquímica) da base leucoesmeraldina ou protonação (isto é, sem que ocorra alteração do número de elétrons associados à cadeia polimérica) da base esmeraldina usando química de ácidos e bases. ${ }^{68}$ Como a inserção de contra-íons (para neutralidade de carga) é necessária, a polianilina condutora é um sal (um policátion com um ânion por unidade repetidora). A protonação dos nitrogênios da imina é o mecanismo envolvido na mudança drástica das propriedades eletrônicas na esmeraldina, de isolante para metal. Atualmente é aceito que a protonação distorce localmente as ligações químicas na cadeia de forma a confinar a carga positiva em excesso, formando os polarons / bipolarons. Devido ao alto peso molecular, a processabilidade das polianilinas em dispositivos eletrônicos ou objetos úteis foi um desafio mas muito progresso já foi atingido. Na última década, por exemplo, Dufour et al. ${ }^{81}$ reportou uma série de polianilinas dopadas com diésters de ácido sulfosuccínico (plastificante) apresentando propriedades controláveis pelo tipo de dopante e boa flexibilidade mecânica.

Essas polianilinas protonadas com plastificantes constituem, portanto, uma interessante classe de polímeros condutores, combinando razoável estabilidade e boas propriedades mecânicas. ${ }^{81}$ Estudos em filmes automontados dessas polianilinas dopadas com plastificantes 


Salado de oxidação

Figura 3.2 - Principais estados de oxidação da polianilina: leucoesmeraldina, esmeraldina (isolante e condutora) e pernigranilina.

Fonte: FAEZ et al. ${ }^{69}$

revelaram que, nesses sistemas, uma transição metal-semicondutor ocorre, sendo que abaixo da temperatura de transição, a interação predominante é antiferromagnética como, por exemplo, na (PANI-DEHESSA $)_{0.5}{ }^{82}$ Estudos por calor específico da polianilina plastificada com outro dopante (PANI-DB3EPSA) 0.5 revelaram que, quando o campo magnético é nulo, não existe ordenamento antiferromagnético; porém, o ordenamento antiferromagnético para um campo aplicado de $3.3 \mathrm{kOe}$ pode ser observado tanto no calor específico quanto por RPE. ${ }^{83}$ Esse comportamento sugere que os pólarons de spin $1 / 2$ abaixo da transição metal-isolante podem ser modelados por um sistema de dímeros de spin 1.

Recentes estudos de RPE com filmes de polianilina dopada com outro plastificante (PANIDDoESSA) 0.5 para diferentes direções do campo magnético aplicado, no plano do filme e perpendicular a esse, permitiram estimar a interação intradímero e interdímero e observar evidências de ferromagnetismo fraco com o vetor de Dzyaloshinskii-Moriya* orientado predominantemente no plano do filme. ${ }^{84}$

Neste capítulo, apresentamos medidas de RPE em mais dois compostos dessa série de polianilinas dopadas com plastificantes, apontando as evidências da localização dos portadores na cadeia bem como do acoplamento via interação de troca entre os pólarons.

*O vetor de Dzyaloshinskii-Moriya é o termo $\mathbf{D}$ na expressão do hamiltoniano de interação de troca anisotrópica anti-simétrica $\mathscr{H}_{D M}=\mathbf{D} \cdot\left[\mathbf{S}_{\mathbf{i}} \times \mathbf{S}_{\mathbf{j}}\right]$, responsável pelo "canting" dos spins que resulta no ferromagnetismo fraco. 


\section{Material e Métodos}

\subsection{Material}

Os filmes automontados de polianilina (PANI) dopada com plastificantes são obtidos numa colaboração com o Dr. David Djurado do CEA, Grenoble, França. Detalhes da síntese do filme estudado podem ser encontrados na referência. ${ }^{81}$ Todos os membros desta família de compostos de PANI dopada com plastificante tem uma estrutura claramente estabelecida: um tipo lamelar de organização da estrutura na qual fileiras de cadeias poliméricas estão separadas por ânions dopantes regular e alternadamente distribuídos perpendicularmente ao longo do eixo das cadeias de polianilina. ${ }^{85}$

Medidas foram realizadas nos filmes (espessura $\mathrm{d}=35 \mu \mathrm{m}$ ) auto montados de polianilina protonada com 1,2-di(n-dodecil) éster de ácido 1,2-benzenodicarboxílico (PANI-DDoEPSA $)_{0.5}$ e protonada com di-2-butoxi-2-ethoxi-etil éster de ácido sulfosuccínico (PANI-DB3ESSA) 0.5 . A estrutura molecular da forma do sal esmeraldina (forma condutora) da polianilina e o dopante plastificante está na Figura 3.3.

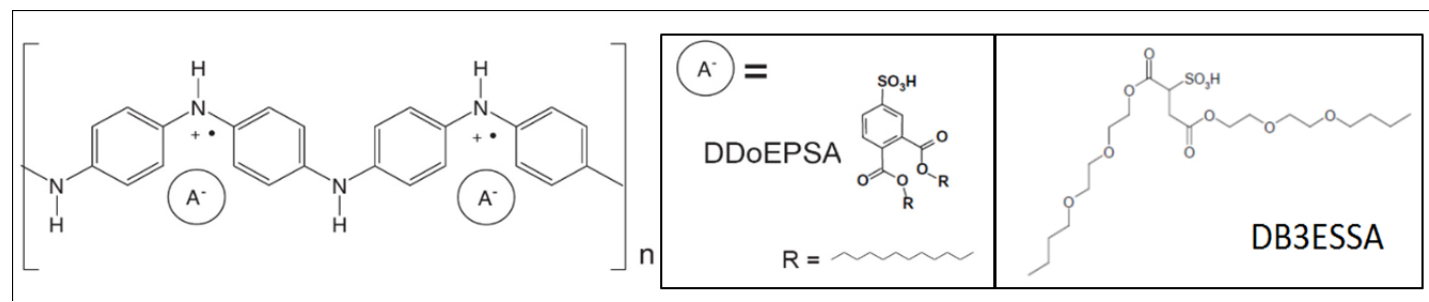

Figura 3.3 - Forma do sal esmeraldina (forma condutora) da polianilina e o dopante plastificante das amostras estudadas. O par $+\bullet$ indica a localização dos pólarons na cadeia da PANI.

Fonte: SNIECHOWSKI et al. ${ }^{85}$; DUFOUR et al. ${ }^{86}$

As medidas foram realizadas em duas diferentes configurações, isto é, com o campo magnético orientado paralela e perpendicularmente ao plano dos filmes que estão encapsulados em tubo de quartzo de 1.0 mm de diâmetro interno, em atmosfera de argônio (Figura 3.4).

A amostra (PANI-DDoEPSA) 0.5 foi submetida a três séries de medidas $M 1, M 2$ e $M 3$ realizadas sob as mesmas condições experimentais na mesma amostra. A amostra (PANIDB3ESSA $)_{0.5}$ foi submetida a quatro séries de medidas, realizadas sob as mesmas condições experimentais na mesma amostra: 1) espectros obtidos durante a diminuição da temperatura, com campo magnético ligado (descida FC, field cooling); 2) espectros obtidos durante o aumento da temperatura após diminuir a temperatura com o campo ligado (FC); 3) mesmo 
que 1 ; 4) espectros obtidos durante o aumento da temperatura, após resfriar a amostra com o campo magnético desligado (ZFC, zero field cooling).

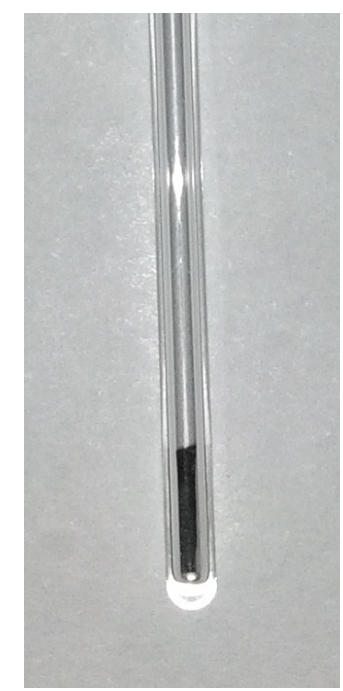

Figura 3.4 - Amostra encapsulada de (PANI-DDoEPSA) 0.5 .

Fonte: Elaborada pelo autor.

Um marcador de $\mathrm{Cr}^{3+}$ foi utilizado para aferição precisa do fator g. Óleo mineral foi utilizado para melhorar o contato térmico entre o tubo que contém a amostra e o tubo padrão de RPE (5 mm) usado na cavidade e aguardou-se de 3 a 5 minutos para estabilização da temperatura a cada medida.

\subsection{Métodos}

\subsubsection{Ressonância paramagnética eletrônica}

Dois equipamentos foram utilizados para a aquisição dos espectros de RPE: um Varian modelo E109 e um Bruker modelo E-580. Para medidas em banda X $(9.5 \mathrm{GHz})$ em ambos os espectrômetros temos a disposição um criostato Oxford para medidas entre $4 \mathrm{~K}$ e $300 \mathrm{~K}$ usando uma cavidade retangular operando no modo $\mathrm{TE}_{102}$ para as medidas em modo onda contínua. Para as medidas em função da orientação da amostra em relação ao campo em banda $\mathrm{X}$ contamos com um goniômetro eletrônico controlado remotamente via software para o Bruker e um goniômetro manual para o Varian. 


\subsubsection{Formas de linha}

Formas de linhas lorentzianas são comumente utilizadas para o ajuste dos dados de RPE. A função de Lorentz aparece da solução das equações de Bloch, porém vários mecanismos são utilizados na descrição do comportamento dos espectros de ressonância, como, por exemplo, o alargamento e a assimetria das linhas devido à condutividade elétrica, polarização de spins, interação dipolar, etc. A intensidade ou área do sinal de absorção é uma medida do número líquido de spins na amostra e proporcional a susceptibilidade magnética. ${ }^{7}$

A derivada da absorção da lorentziana pode ser dada pela seguinte expressão

$$
Y_{L}^{\prime}=\frac{-2 a x}{\left(1+x^{2}\right)^{2}}
$$

em que $x=\frac{H-H_{0}}{\frac{1}{2} \Delta H_{1 / 2}}, H_{0}$ é o campo magnético estático, $\Delta H_{1 / 2}$ é a largura de linha e $a=2 y_{m}^{\prime}$ onde $y_{m}^{\prime}$ é a amplitude da derivada.

A linha de ressonância para elétrons de condução em metais é bem descrita pela teoria de Dyson. ${ }^{87}$ A linha dysoniana geral é descrita como uma função de dois parâmetros, $\lambda=d / \delta$ (em que $d$ é a espessura da amostra e $\delta$ é o skin depth do campo de microondas e $R=\left(T_{D} / T_{2}\right)^{1 / 2}$ (em que $T_{D}$ é o tempo de difusão dos spins através do skin depth e $T_{2}$ é o tempo de relaxação do spin). No limite de amostras finas da teoria de Dyson, quando o skin depth é da ordem da espessura da amostra $d<$ or $\sim \delta$, a linha dysoniana é função somente de $\lambda$ e pode ser ajustada como uma combinação de lorentzianas de absorção e dispersão ${ }^{88}$

$$
Y_{D}^{\prime}=\frac{-2 a x+a d\left(1-x^{2}\right)}{\left(1+x^{2}\right)^{2}}
$$

em que $x$ e $a$ estão definidos para a equação 2.1 e $d$ é o coeficiente de dispersão.

A contribuição dispersiva causa uma assimetria na linha que é relacionada à condutividade a.c. segundo a equação

$$
\delta=\sqrt{2 / \mu \omega \sigma}
$$

onde $\omega$ é a frequência da microonda, $\mu=\mu_{0}$ a permeabilidade magnética no vácuo e

$$
\sigma=\frac{2 \lambda^{2}}{d^{2} \omega \mu}
$$


a condutividade elétrica no plano. A razão A/B pode ser extraída do espectro de RPE como mostrado na figura 3.5(a) e a condutividade elétrica na frequência da microonda pode ser calculada a partir da equação 2.4 através da relação entre $\lambda$ e $A / B$, figura 3.5(b).
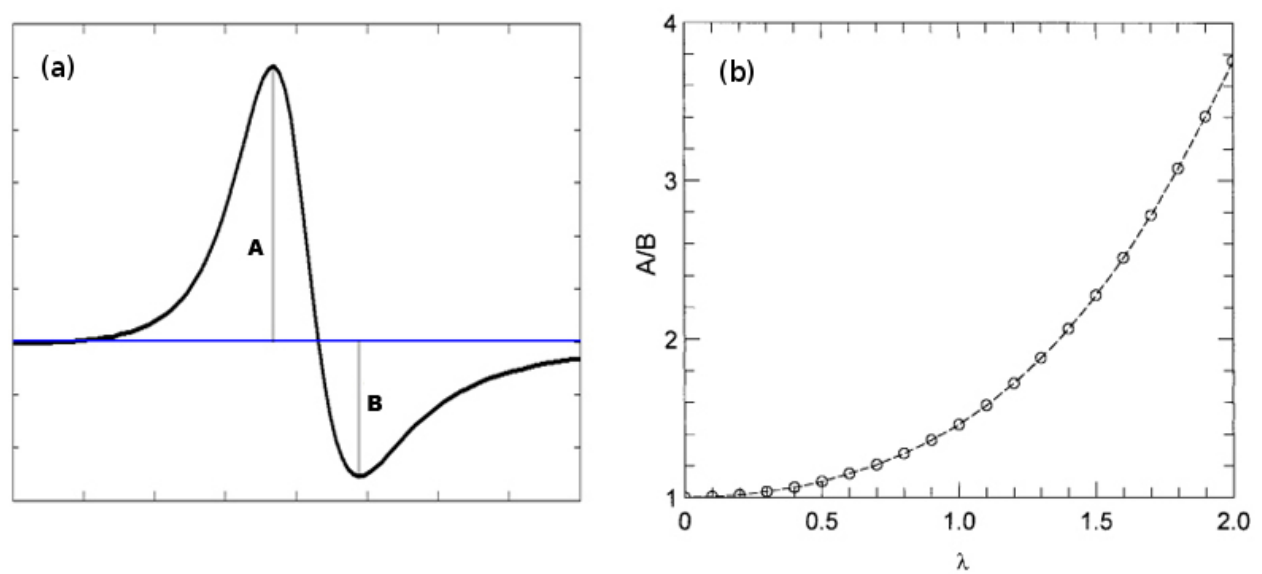

Figura 3.5 - (a) Exemplo de uma linha assimétrica de RPE. (b) Curva teórica de $A / B$ versus $\lambda$ baseada na teoria de Dyson no limite $d \leq \delta$.

Fonte (a): Elaborada pelo autor.

Fonte (b): WALMSLEY. ${ }^{88}$

\section{Resultados e discussão}

\section{1 (PANI-DDoEPSA) 0.5}

Exemplos de espectros em função da temperatura e uma simulação da linha experimental com uma dysoniana são mostrados na Figura 3.6. As medidas foram realizadas em duas orientações, com o campo magnético aplicado paralela e perpendicularmente a superfície do filme. Entretanto, como o comportamento do espectro foi aproximadamente isotrópico, apresentamos os resultados de apenas um dos conjuntos de medida, a saber, com o campo aplicado perpendicularmente a superfície do filme.

O comportamento do sinal de RPE a $4 \mathrm{~K}$ em função da raiz quadrada da potência da micro-onda para o filme (PANI-DDoEPSA) 0.5 é mostrado na Figura 3.7. É possível observar que o sinal não satura ${ }^{\dagger}$ pelo menos até $16 \mathrm{~mW}$. Tomamos o cuidado de não submeter a amostra a potência muito alta para evitar aquecimento e consequente amorfização do filme. Com base nesta medida, uma potência de $1.0 \mathrm{~mW}$ foi escolhida para obtenção dos espectros em função 

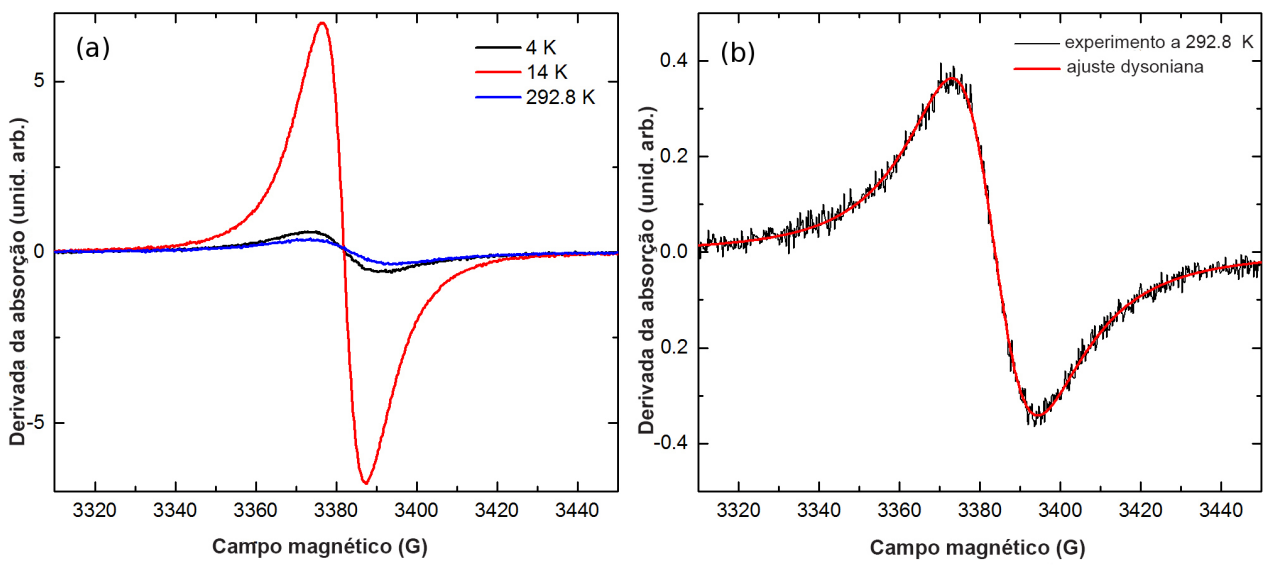

Figura 3.6 - (a) Exemplo do espectro de RPE para (PANI-DDoEPSA) 0.5 a $4 \mathrm{~K}, 14 \mathrm{~K}$ e temperatura ambiente. (b) Exemplo de um ajuste do espectro experimental obtido à temperatura ambiente usando uma linha dysoniana.

Fonte: Elaborada pelo autor.

da temperatura.

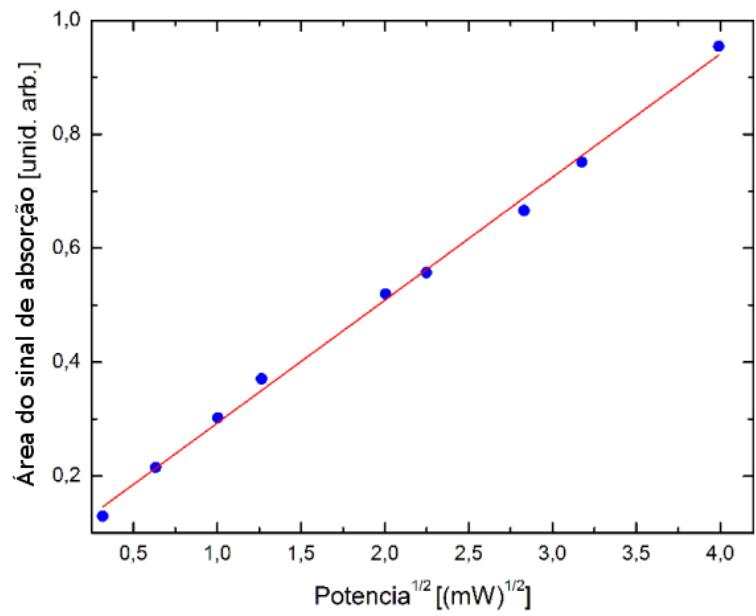

Figura 3.7 - Área do sinal de RPE em função da raiz quadrada da potência para a amostra (PANIDDoEPSA $)_{0.5}$

Fonte: Elaborada pelo autor.

A área do sinal de absorção (Figura 3.8(a)) é aproximadamente constante (susceptibilidade de Pauli) entre temperatura ambiente e $90 \mathrm{~K}$ para todos os conjuntos de medidas M1, M2 e M3, indicando absorção por portadores deslocalizados, comportamento tipicamente metálico. Em 90 K, o aumento da área indica o início da localização dos portadores, sugerindo uma transição do estado metálico para um estado semicondutor. A transição de portadores deslocalizados para portadores localizados também é observada em dados de UV-Vis e condutividade nessa amostra. ${ }^{89}$ Esse tipo de transição em polímeros condutores em geral é extensivamente discutida na referência 90 .

Apesar de ocorrer em diferentes temperaturas para cada conjunto de medidas ( $M 1, M 2$ 
e M3), um máximo na área sempre foi observado. Esse comportamento da área em função da temperatura na região de temperatura em que se observa o estado localizado pode ser modelado como dois pólarons de spin $1 / 2$ acoplados via interação de troca formando um dímero de spin total 1, como discutido na referência 84. A existência do máximo indica a população do estado triplete $(S=1)$ no modelo de dímeros de spin $1 / 2$ interagentes. A diminuição no valor da área após o máximo indica a despopulação deste estado e foi associada ao acoplamento antiferromagnético. A seguir, um breve detalhamento dessa questão é apresentado.
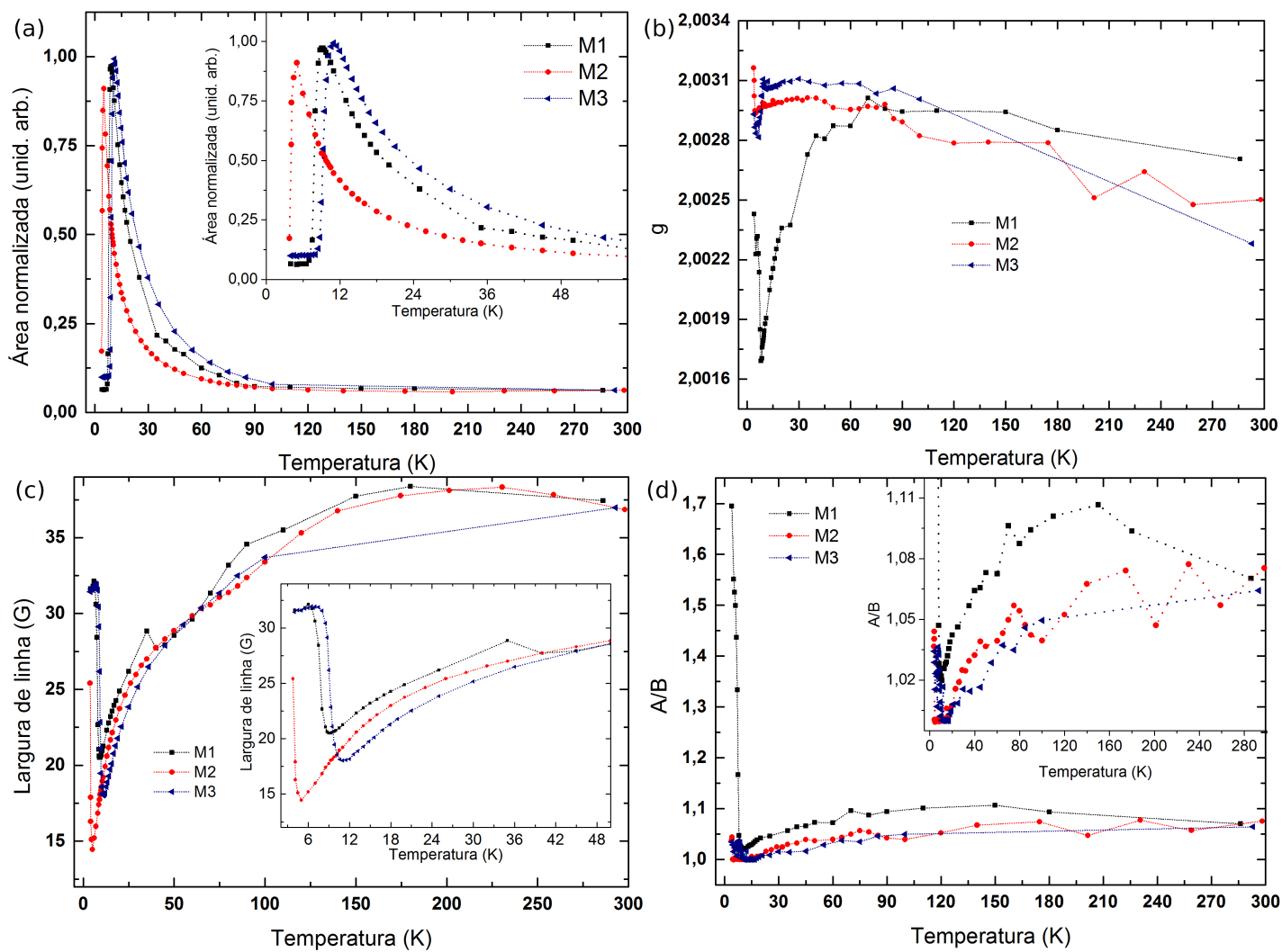

Figura 3.8 - Parâmetros da linha dysoniana utilizada para ajuste dos espectros experimentais do filme de (PANI-DDoEPSA $)_{0.5}$ medidos em função da temperatura com o campo magnético aplicado na direção perpendicular em relação a superfície do filme. (a) Área do sinal. (b) fator $g$. (c) Largura da linha. (d) Razão de assimetria $A / B$. As medidas M1, M2 e M3 correspondem a três medidas realizadas sob as mesmas condições experimentais na mesma amostra.

Fonte: Elaborada pelo autor.

A expressão da susceptibilidade magnética para um dímero $S_{1}=S_{2}=1 / 2$ é dada por ${ }^{6}$

$$
\chi=\frac{2 N_{A} g_{e}^{2} \mu_{B}^{2}}{k T[3+\exp (-J / k T)]},
$$

em que $N_{A}$ é o número de Avogadro, $g_{e}$ é o fator $g$ eletrônico, $\mu_{B}$ é o magneton de Bohr, $k$ é a constante de Boltzmann e $J$ é a constante de troca. Essa expressão é derivada na mecânica 
estatística através da distribuição de Boltzmann e corresponde a despopulação dos $(2 \mathrm{~S}+1)$ estados excitados (tripleto) no dímero de spins $1 / 2$ interagentes. ${ }^{91}$ Uma interação antiferromagnética no dímero, $J<0$, indica o estado singleto $(S=0)$ como estado fundamental da interação. A forma geral dessa expressão no caso $J<0$ é semelhante ao resultado apresentado da variação da área com a temperatura (Figura 3.8(a)), também com um máximo característico. No entanto, o ajuste não fica muito bom. A principal razão parece ser a largura muito estreita do pico. A presença de interação inter-dímeros pode ser a razão e um modelo que ajuste corretamente os dados é motivação e uma sugestão para trabalhos futuros.

A interação antiferromagnética também é evidenciada pelo estreitamento da linha, exchange narrowing ${ }^{\ddagger}$.

A razão de assimetria $A / B$ dos espectros em função da temperatura é mostrada na Figura 3.6. Numa situação em que quase todos os sinais de RPE são devidos a uma linha dysoniana, assume-se que a penetração da micro-onda é a de uma onda plana incidente num filme condutor com o campo elétrico no plano do filme, sendo o skin depth governado pela condutividade no plano (equação (2.3)). Da relação entre a assimetria da linha $(A / B)$ e $\lambda$ extraído da Figura 3.5(b) juntamente com a espessura $d$ da amostra usou-se a expressão (2.4) para estimar a condutividade da micro-onda no plano em temperatura ambiente como $20 \mathrm{~S} / \mathrm{cm}$. Esse valor é da mesma ordem de grandeza da condutividade dc de $79 \mathrm{~S} / \mathrm{cm}$ para essa amostra à temperatura ambiente. ${ }^{92}$ Podemos observar que a razão $A / B$ e consequentemente a condutividade da micro-onda no plano diminui com a queda da temperatura, seguindo o mesmo padrão que a condutividade dc em outras polianilinas dessa classe. ${ }^{89,93}$

Vimos no capítulo anterior, que duas contribuições podem ser levadas em consideração na largura de linha de um sinal de RPE:

$$
\Delta H \propto\left(\frac{1}{T_{1}}+\frac{1}{T_{2}}\right) .
$$

$T_{1}$ corresponde ao tempo de relaxação spin-rede e $T_{2}$, ao tempo de relaxação spin-spin. $\mathrm{O}$ tempo de relaxação spin-rede é dominante em altas temperaturas. Pelo mecanismo de Elliot da relaxação da rede via acoplamento spin-órbita ${ }^{94}, T_{1}$ está associado ao espalhamento devido a inversão dos spins que por sua vez é proporcional ao tempo de relaxação $\tau_{R}$ característico da resistividade elétrica $\left(\rho \propto \frac{1}{\tau_{R}}\right)$ na direção do campo magnético aplicado. Portanto, espera-

\footnotetext{
${ }^{\ddagger}$ A interação spin-spin acontece via dois mecanismos: interação dipolar e interação de troca. A direção do campo local sobre os centros paramagnéticos devido a interação dipolar é aleatória, uma vez que os centros ao redor tem momentos magnéticos apontando em diferentes direções, causando um alargamento na linha. A interação de troca tende a orientar a direção dos spins diminuindo essa aleatoriedade. Desse modo, o espectro tende a ficar mais estreito num fenômeno conhecido com exchange narrowing.
} 
se que a largura da linha na região de temperatura em que a amostra possui portadores deslocalizados seja proporcional a resistividade. De fato, o comportamento da largura de linha em alta temperatura é semelhante ao comportamento de $A / B$ que por sua vez está de acordo com a variação térmica da condutividade como mencionado no parágrafo anterior.

Diferentemente do que foi observado em amostras com maior organização estrutural, como a PANI-DDoESSA ${ }^{84}$, nenhuma anisotropia é detectada quando a superfície do filme está orientada na direção paralela ou perpendicular ao campo magnético aplicado.

\section{2 (PANI-DB3ESSA) 0.5}

Exemplos de espectros em função da temperatura e uma simulação da linha experimental com uma dysoniana são mostradas na Figura 3.9. Como descrito na seção experimental, utilizamos uma soma de uma lorentziana de absorção e de dispersão. Porém como a linha é quase simétrica, a componente dispersiva é muito pequena e foi desprezada.
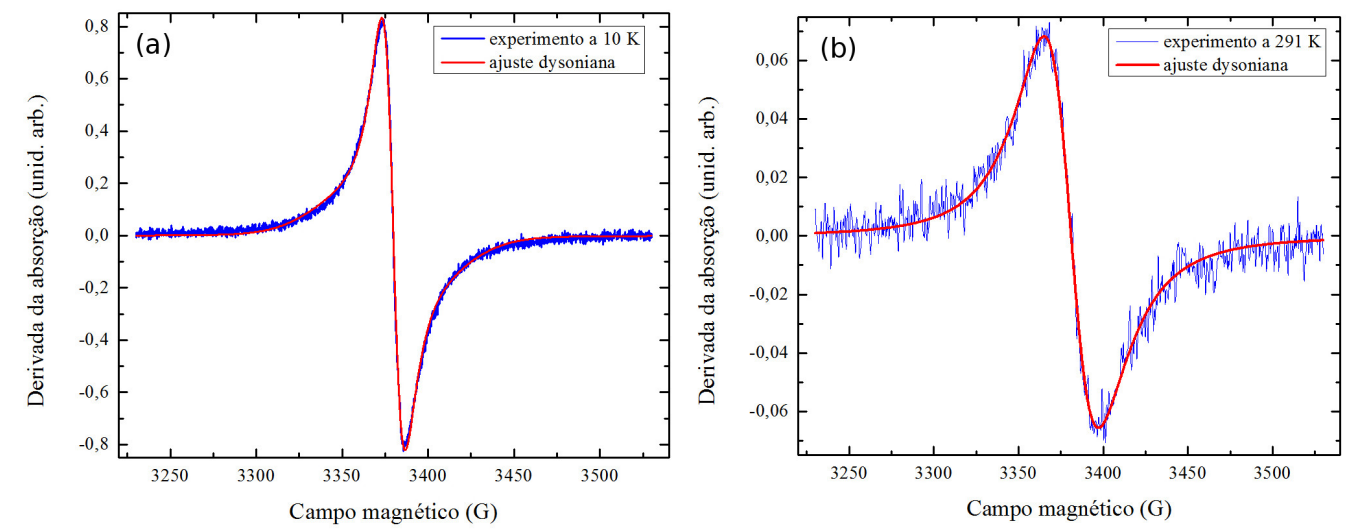

Figura 3.9 - Exemplo do espectro de RPE e ajuste para (PANI-DB3ESSA) 0.5 a (a) $10 \mathrm{~K}$ e (b) temperatura ambiente.

Fonte: Elaborada pelo autor.

As medidas de variação térmica em banda $X$ foram obtidas com $1 \mathrm{~mW}$ de potência, para garantir que o experimento ocorresse na região linear da curva de saturação em baixa temperatura, Figura 3.10. As medidas foram realizadas em duas orientações, com o campo magnético aplicado paralela e perpendicularmente a superfície do filme. Entretanto, como o comportamento do espectro foi isotrópico, apresentamos os resultados de apenas um dos conjuntos de medida, a saber, com o campo aplicado perpendicularmente a superfície do filme.

O comportamento dos parâmetros dos espectros da amostra (PANI-DB3ESSA) $0.5 \mathrm{em}$ função da temperatura variou para temperaturas mais baixas independentemente da repetição 

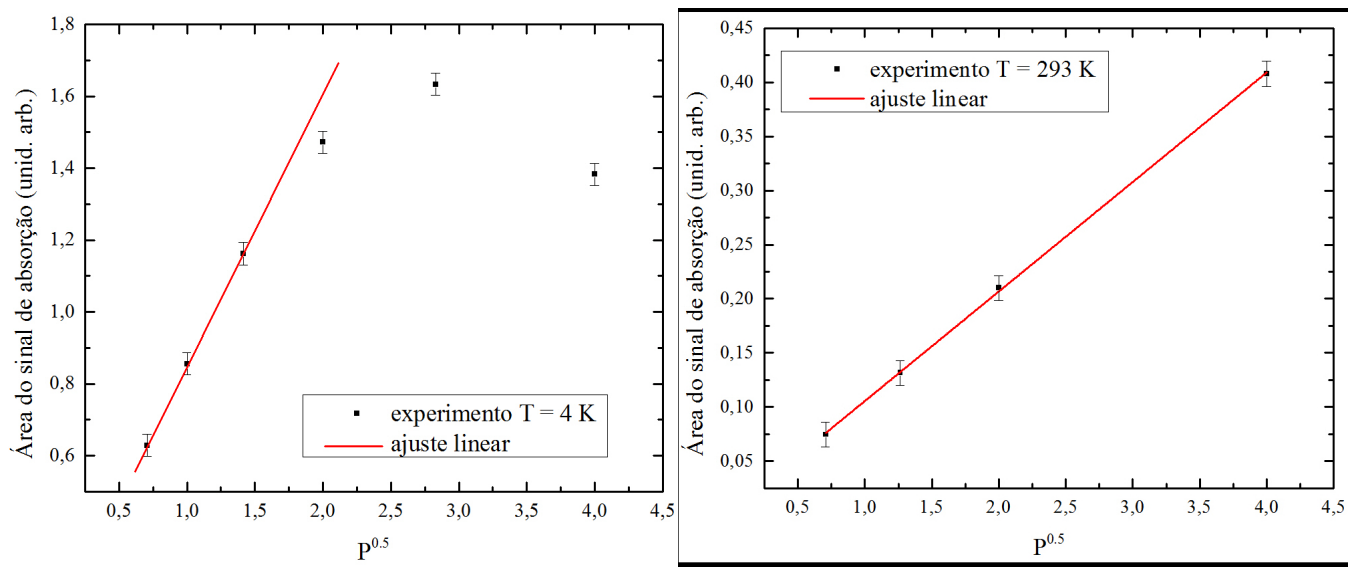

Figura 3.10 - Variação com a potência em banda $X$ para temperatura ambiente e $4 \mathrm{~K}$ do filme de (PANI-DB3ESSA $)_{0.5}$.

Fonte: Elaborada pelo autor.

controlada de resfriamento e campo magnético aplicado (FC ou ZFC). A área do sinal de absorção, o fator $g$ e a largura de linha são mostrados em detalhe para baixa temperatura na Figura 3.11. Podemos observar a existência ou não do máximo bem como o deslocamento do mesmo dependendo da medida.

Foi observado na (PANI-DDoEPSA $)_{0.5}$ e (PANI-DDoESSA $)_{0.5}$ que a área do sinal de absorção é aproximadamente constante entre temperatura ambiente e $85 \mathrm{~K}$ para todas as medidas, indicando absorção por portadores deslocalizados, comportamento tipicamente metálico. Já na (PANI-DB3ESSA) 0.5 , a área é aproximadamente constante até $100 \mathrm{~K}$, porém observamos uma pequena inclinação na curva que liga os pontos entre temperatura ambiente e $150 \mathrm{~K}$. Chauvet et al. ${ }^{95}$ sugere que essa tendência de crescimento da susceptibilidade com a temperatura está relacionada com bipolarons termicamente excitados no estado tripleto. A estabilização do bipolaron vem do balanço de energia entre o ganho de energia elástica devido a relaxação da cadeia, a repulsão coulombiana entre as duas cargas e a atração coulombiana com os centros dopantes. Quando os centros estão próximos uns dos outros, um bipolaron convencional com energia $J_{0}$ é formado; se eles estão muito distantes, os dois polarons se mantem isolados; para uma separação intermediária, um bipolaron fracamente ligado com uma integral de troca dependendo exponencialmente da distância $d, J(d)$, é estabilizado. ${ }^{95}$ De acordo com este modelo, a área do sinal de RPE tem a forma

$$
I(T)=\frac{C}{T}+A T^{\alpha}
$$

em que o primeiro termo corresponde ao paramagnetismo de Curie e o segundo termo ao tripleto termicamente excitado do bipolaron. Na Figura 3.12, vemos que a contribuição para a susceptibilidade da despopulação do estado tripleto do bipolaron (curva azul) é predominante 


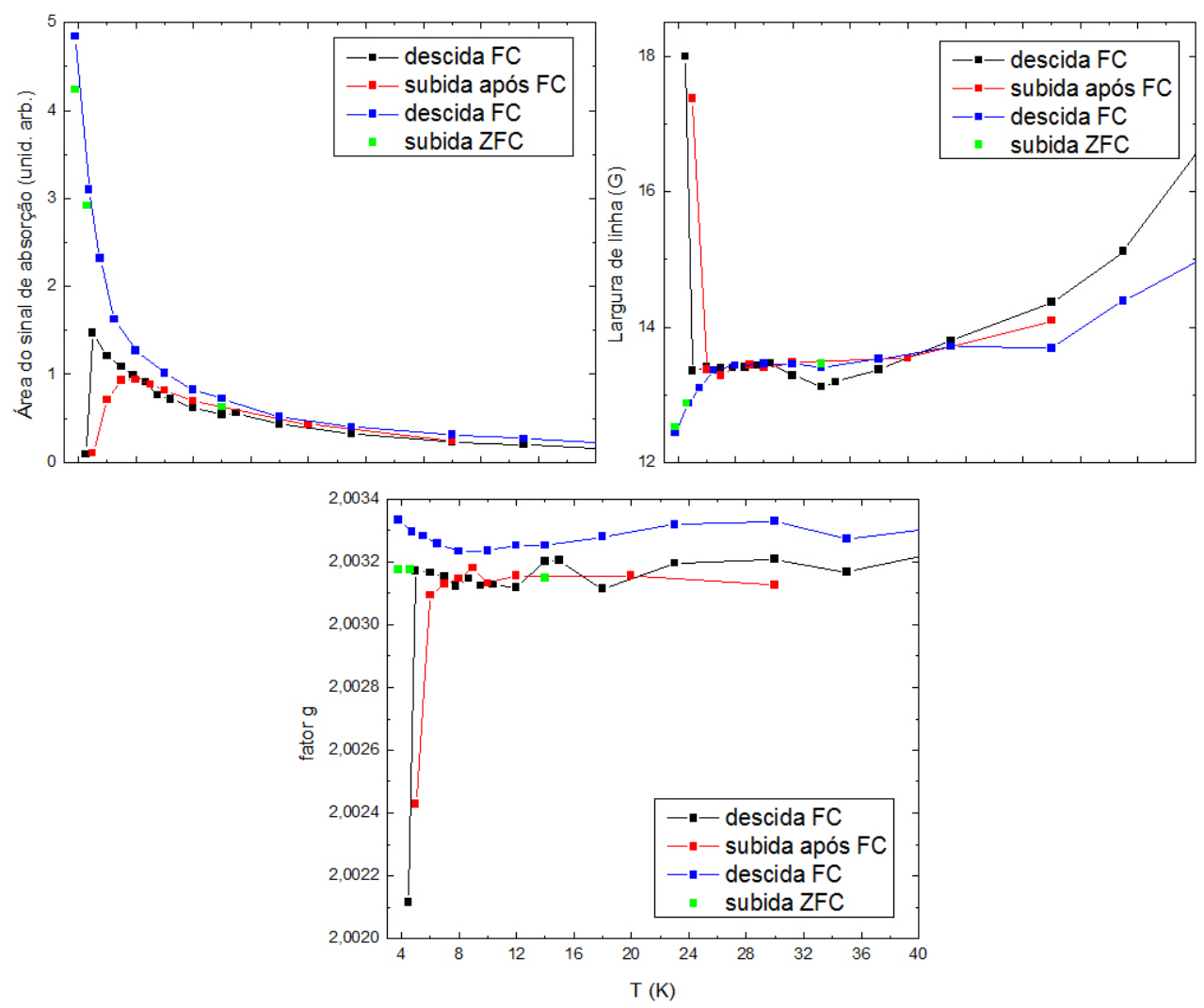

Figura 3.11 - Variação térmica dos parâmetros do espectro de RPE em banda $X$ da amostra (PANIDB3ESSA) 0.5 .

Fonte: Elaborada pelo autor.

a altas temperaturas $(>150 \mathrm{~K})$ e a baixas temperaturas o termo de Curie (curva verde) é predominante.

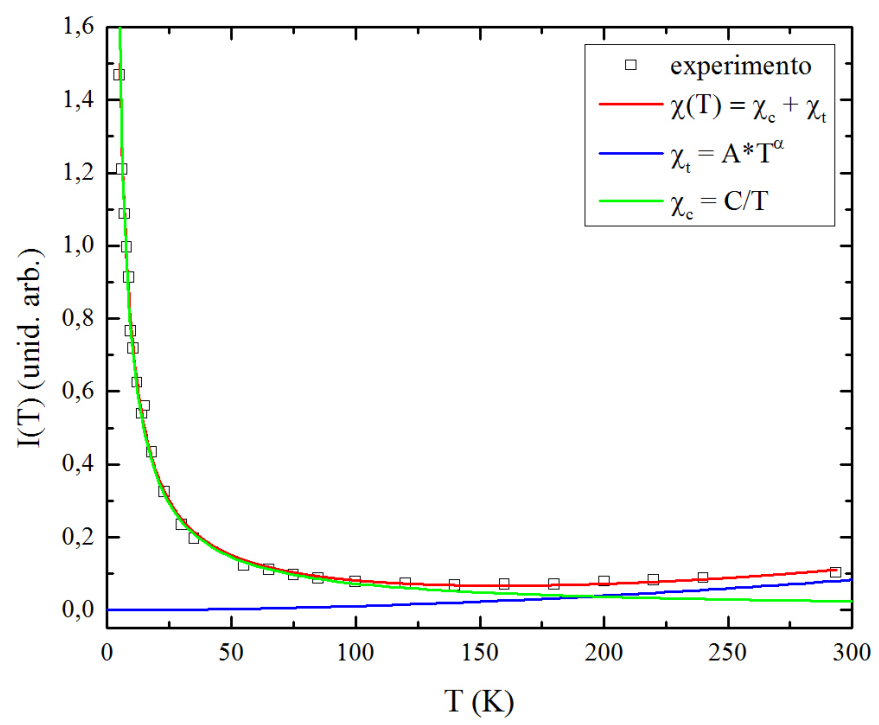

Figura 3.12 - Variação térmica da área do sinal de absorção da amostra (PANI-DB3ESSA) 0.5 . Fonte: Elaborada pelo autor.

O aumento e o máximo na área do sinal de RPE e o estreitamento da largura de linha 
tem o comportamento semelhante ao descrito para a amostra (PANI-DDoEPSA) 0.5 , sendo explicado pela localização dos portadores e a formação de um estado ordenado entre os spins da cadeia de polianilina. No entanto, o comportamento a temperatura mais altas parece estar mais relacionado à presença de um bipolaron.

\subsection{Discussão sobre as variações entre medidas diferentes}

As diferenças observadas entre medidas feitas sob as mesmas condições podem estar relacionadas com a história magnética da amostra, ou ainda as ciclagens térmicas podem estar degradando a estrutura de alguma maneira. Não foi possível testar estas possibilidades, pois apenas uma amostra com cada dopante foi disponibilizada pelos colaboradores, que não tinham previsão de realizar nova síntese a curto prazo. Aquecer a amostra acima da temperatura ambiente não foi uma opção, porque submeter o filme a temperaturas mais altas pode amorfizar as regiões cristalinas e modificar as propriedades elétricas e magnéticas do material. Descartando a degradação com a ciclagem térmica, apresentamos a seguir um possível fenômeno que pode estar ligado a esta variação da temperatura do máximo a cada medida. Durante o resfriamento, os anéis fenilênicos das cadeias dentro dos cristalitos podem estar "congelando" com ângulos diferentes entre si.

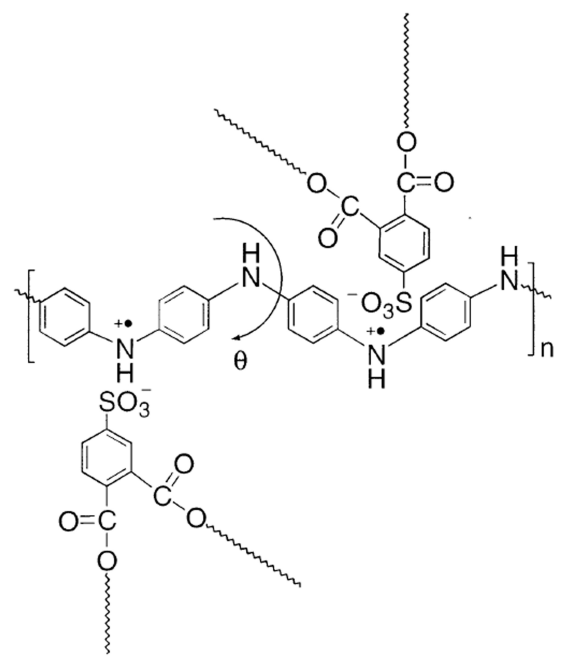

Figura 3.13 - Esquema da cadeia de PANI com a molécula do dopante mostrando o ângulo $\theta$ entre os anéis fenilênicos.

Fonte: RANNOU et al. ${ }^{89}$.

Isso levaria as distâncias entre os defeitos polarônicos a variarem sutilmente, alterando a energia de interação $J$ entre elas. Termocromismo nesse material foi reportado como resultado 
das diferenças na estrutura devido a reorganização durante o "congelamento" dos dopantes mostrando que, além dos fenômenos puramente eletrônicos, a condutividade macroscópica pode envolver aspectos morfológicos e de percolação num material heterogêneo consistituído de áreas mais ordenadas e melhores condutoras coexistentes com áreas menos ordenadas e de baixa condutividade. ${ }^{86}$ A localização dos portadores de carga (pólarons, $+\bullet$ ) observada para dopantes congelados implica comprimento da ligação conjugada (dupla) menor. Na estrutura do radical poli(semiquinona) da cadeia da polianilina dopada, a distância da conjugação depende do valor do ângulo torcional entre o anel fenilênico e o plano da cadeia em zigzag da PANI (ângulo $\theta$ na Figura 3.13). Acredita-se que o congelamento do dopante acarrete um aumento no valor médio desse ângulo através de uma modulação das interações iônicas entre o grupo $-\mathrm{SO}_{3}^{-}$e o sítio dopado $-(\mathrm{NH})^{\bullet+} .{ }^{89}$ Sendo assim, as diferenças entre os parâmetros dos espectros de RPE analisados neste trabalho são indicativos de que os aspectos morfológicos afetam não só as propriedades elétricas como também as propriedades magnéticas do material.

\section{Conclusões}

Neste capítulo, foram apresentados os resultados de RPE em filmes automontados de polianilinas dopadas com dois plastificantes distintos. Em um deles, a (PANI-DDoEPSA) 0.5 demonstrou-se a existência de pólarons de spin 1/2 interagentes através de um comportamento típico de população e despopulação do tripleto excitado no modelo de um dímero de spin total 1. Para a (PANI-DB3ESSA $)_{0.5}$, o comportamento dos espectros em temperaturas mais altas é condizente com a despopulação do estado tripleto de um bipólaron. Os resultados apresentados aqui retomam a discussão sobre o bipolaron de spin zero ser o mais estável defeito em polímeros condutores e as outras possibilidades de defeitos com spin não nulo nesses materiais bem como a possibilidade de interação entre eles.

Outra questão importante discutida foi a reprodutibilidade dos dados. Apesar de o comportamento geral ser aparentemente mantido entre medidas feitas sob condições semelhantes, mostramos que o congelamento da estrutura em diferentes estados estruturais devido ao ângulo entre os anéis fenilênicos pode ter um papel relevante na interação de troca entre os spins dos pólarons nas amostras estudadas. 


\section{Considerações finais}

Neste trabalho, sistemas sujeitos à interações antiferromagnéticas foram caracterizados utilizando-se a técnica de espectroscopia de ressonância paramagnética eletrônica em diferentes frequências, em função da orientação do campo magnético aplicado e da temperatura das amostras. Dois desses sistemas consistem em óxidos de metal de transição com ordem magnética de longo alcance, a saber, o sistema multiferróico óxido de bismuto-manganês, $\mathrm{BiMn}_{2} \mathrm{O}_{5}$, estudado em forma policristalina e o oxiborato de ferro, $\mathrm{Fe}_{3} \mathrm{O}_{2} \mathrm{BO}_{3}$, para o qual amostras monocristalinas estavam disponíveis. Além desses, filmes de polianilinas dopadas com plastificante foram estudados.

Os espectros de RPE do multiferróico $\mathrm{BiMn}_{2} \mathrm{O}_{5}$, obtidos a partir de medidas multi frequência em altos campos magnéticos na fase ordenada, foram identificados como modos de ressonância antiferromagnética e ajustados aplicando-se a teoria fenomenológica da ressonância antiferromagnética proposta por Yosida e Nagamiya. A partir desse ajuste, as constantes magnéticas de anisotropia foram obtidas e a importância delas discutida, uma vez que a anisotropia magnética é considerada uma das causas da magnetoelasticidade que dá origem a ferroeletricidade neste material.

$\mathrm{O}$ oxiborato de ferro $\mathrm{Fe}_{3} \mathrm{O}_{2} \mathrm{BO}_{3}$, conhecido como ludwigita homometálica de ferro, é um material complexo, com duas sub-redes de ferro independentes, apresentando diferentes temperaturas de transição de fase e coexistência de antiferromagnetismo e paramagnetismo entre as temperaturas de $112 \mathrm{~K} \mathrm{e} 70 \mathrm{~K}$, além de correlação eletrônica já à temperatura ambiente. Uma variedade de ajustes cuidadosos das linhas largas e sobrepostas dos espectros de RPE em função da orientação do campo magnético em banda $X$ permitiu a identificação de dois dímeros $\mathrm{Fe}^{3+}-\mathrm{Fe}^{2+}$ não-equivalentes em acordo com a estrutura da rede cristalina a partir da anisotropia Zeeman. Os valores principais do tensor $g$ são típicos de um sistema com spin efetivo $S_{0}=1 / 2$, coerente com um acoplamento antiferromagnético no dímero. $A$ análise dos resultados em banda $Q$ revelou espectros equivalentes em campo, não colaborando para resolução dos mesmos. Ainda assim, o ajuste desses espectros revelou a mesma relação estrutural dos dímeros obtida em banda $\mathrm{X}$, porém com os valores de $g$ efetivo diferentes. Para explicar essa diferença, sugeriu-se um modelo de competição entre a interação de troca antiferromagnética e a interação de troca dupla, comumente utilizado em sistemas com valência mista, que permitiu uma estimativa da integral de transferência de carga, relacionada ao hopping eletrônico entre os sítios de ferro no dímero. 
Os espectros de RPE em função da temperatura em filmes automontados de polianilinas dopadas com plastificantes foram ajustados utilizando uma soma de lorentzianas de absorção e dispersão, que modelam uma linha dysoniana no limite em que a espessura da amostra é menor ou igual ao skin depth da micro-onda. Os parâmetros obtidos, como a área, largura de linha, campo central e razão de assimetria da linha, evidenciaram um comportamento de população e despopulação de um estado tripleto típico de dímeros de spin 1. Diferenças nos parâmetros com ciclagens térmicas sugere o congelamento da estrutura em diferentes estados condizente com a existência de termocromismo nesses polímeros. 


\section{REFERÊNCIAS}

1 BENCINI, A.; GATTESCHI, D. EPR of exchange coupled systems. New York: Dover Publications, 2012.

2 WEIL, J. A.; BOLTON, J. R. Electron paramagnetic resonance: elementary theory and practical applications. New York: John Wiley \& Sons, 2007.

3 ATHERTON, N. M. Principles of electron paramagnetic resonance. New York: Ellis Horwood, 1993.

4 BRUSTOLON, M. Electron paramagnetic resonance: a practitioner's toolkit. New York: John Wiley \& Sons, 2009.

5 SCHWEIGER, A.; JESCHKE, G. Principles of pulse electron paramagnetic resonance. Oxford: Oxford University Press, 2001.

6 ABRAGAM, A.; BLEANEY, B. Electron paramagnetic resonance of transition ions. New York: Dover, 1986.

7 POOLE, C. P. Electron spin resonance: a comprehensive treatise on experimental techniques. New York: Dover Publications, 1996.

8 PILBROW, J. R. Transition ion electron paramagnetic resonance. Oxford: Oxford University Press, 1990.

9 NAPOLITANO, L. M. B.; NASCIMENTO, O. R.; CABALEIRO, S.; CASTRO, J.; CALVO, $\mathrm{R}$. Isotropic and anisotropic spin-spin interactions and a quantum phase transition in a dinuclear Cu(II) compound. Physical Review B, v. 77, n. 21, p. 214423, 2008.

10 VAN DEN BRINK, J.; KHOMSKII, D. I. Multiferroicity due to charge ordering. Journal of Physics: condensed matter, v. 20, n. 43, p. 434217, 2008.

11 KANAMORI, J. Anisotropy and magnetostriction of ferromagnetic and antiferromagnetic materials. In: RADO, G.; SUHL, H. (Eds.) Magnetism. New York: Academic Press Inc., 1963. p. 128.

12 DAGOTTO, E. Complexity in strongly correlated electronic systems. Science, v. 309, n. 5732, p. 257-262, 2005. 
13 KIM, J. W.; HAAM, S. Y.; OH, Y. S.; PARK, S.; CHEONG, S.-W.; SHARMA, P. A.; JAIME, M.; HARRISON, N.; HAN, J. H.; JEON, G.-S.; COLEMAN, P.; KIM, K. H. Observation of a multiferroic critical end point. Proceedings of the National Academy of Sciences of the United States of America, Washington, v. 106, n. 37, p. 15573-6, 2009.

14 HUR, N.; PARK, S.; SHARMA, P. A.; AHN, J. S.; GUHA, S.; CHEONG, S. W. Electric polarization reversal and memory in a multiferroic material induced by magnetic fields. Nature, v. 429, n. 6990, p. 392-395, 2004.

15 MOREAU, J.-M.; MICHEL, C.; GERSON, R.; JAMES, W. J. Ferroelectric $\mathrm{BiFeO}_{3}$ x-ray and neutron diffraction study. Journal of Physics and Chemistry of Solids, v. 32, n. 6, p. 1315-1320, 1971.

16 MUNOZ, A.; ALONSO, J. A.; CASAIS, M. T.; MARTÍNEZ-LOPE, M. J.; MARTINEZ, J. L.; FERNÁNDEZ-DÍAZ, M. T. Magnetic structure and properties of $\mathrm{BiMn}_{2} \mathrm{O}_{5}$ oxide: $A$ neutron diffraction study. Physical Review B, v. 65, n. 14, p. 144423, 2002.

17 VECCHINI, C.; CHAPON, L. C.; BROWN, P. J.; CHATTERJI, T.; PARK, S.; CHEONG, S.-W.; RADAELLI, P. G. Commensurate magnetic structures of $\mathrm{RMn}_{2} \mathrm{O}_{5}(\mathrm{R}=\mathrm{Y}, \mathrm{Ho}, \mathrm{Bi})$ determined by single-crystal neutron diffraction. Physical Review B, v. 77, n. 13, p. 134434, 2008.

18 GRANADO, E.; ELEOTÉRIO, M.; GARCÍA-FLORES, A.; SOUZA, J.; GOLOVENCHITS, E.; SANINA, V. Magnetoelastic and thermal effects in the $\mathrm{BiMn}_{2} \mathrm{O}_{5}$ lattice: a high-resolution x-ray diffraction study. Physical Review B, v. 77, n. 13, p. 134101, 2008.

19 SANTANA, V. Medidas de ressonância de spin eletrônico (RSE) em polianilina dopada com plastificante e de condutividade a.c. e RSE em óxidos. 2013. Dissertação (Mestrado em Ciências) - Instituto de Geociências e Ciências Exatas, Universidade Estadual Paulista Júlio de Mesquita Filho, Rio Claro, 2013.

20 PARDI, L. A.; KRZYSTEK, J.; TELSER, J.; BRUNEL, L.-C. Communications. Journal of Magnetic Resonance, v. 146, n. 2, p. 375-378, 2000.

21 NAGAMIYA, T.; YOSIDA, K.; KUBO, R. Antiferromagnetism. Advances in Physics, v. 4, n. 13, p. 1-112, 1955.

22 YOSIDA, K. Theory of the antiferromagnetic resonance absorption in $\mathrm{CuCl}_{22} \mathrm{H}_{2} \mathrm{O}$. Progress of Theoretical Physics, v. 7, n. 5, p. 425-432, 1952.

23 SUSHKOV, A. B.; AGUILAR, R. V.; PARK, S.; CHEONG, S.-W.; DREW, H. D. Electromagnons in multiferroic $\mathrm{YMn}_{2} \mathrm{O}_{5}$ and $\mathrm{TbMn}_{2} \mathrm{O}_{5}$. Physical Review Letters, v. 98, n. 2, p. 027202, 2007. 
24 SUSHKOV, A. B.; MOSTOVOY, M.; AGUILAR, R. V.; CHEONG, S.-W.; DREW, H. D. Electromagnons in multiferroic $\mathrm{RMn}_{2} \mathrm{O}_{5}$ compounds and their microscopic origin. Journal of Physics: condensed matter, v. 20, n. 43, p. 434210, 2008.

25 KHOMSKII, D. I. Transition metal compounds. Cambridge: Cambridge University Press, 2014.

26 YOSIDA, K. On the antiferromagnetism of single crystals. Progress of Theoretical Physics, v. 6 , n. 5 , p. $691-701,1951$.

27 KOTLIAR, G.; VOLLHARDT, D. Strongly correlated materials: Insights from dynamical mean-field theory. Physics Today, v. 57, n. 3, p. 53-60, 2004.

28 FAZEKAS, P. Lecture notes on electron correlation and magnetism. Singapore: World Scientific, 1999.

29 MIR, M.; GUIMARÃES, R. B.; FERNANDES, J. C.; CONTINENTINO, M. A.; DORIGUETTO, A. C.; MASCARENHAS, Y. P.; ELLENA, J.; CASTELLANO, E. E.; FREITAS, R. S.; GHIVELDER, L. Structural transition and pair formation in $\mathrm{Fe}_{3} \mathrm{O}_{2} \mathrm{BO}_{3}$. Physical Review Letters, v. 87, n. 14, p. 147201, 2001.

30 FERNANDES, J. C.; GUIMARÃES, R. B.; CONTINENTINO, M. A.; GHIVELDER, L.; FREITAS, R. S. Specific heat of $\mathrm{Fe}_{3} \mathrm{O}_{2} \mathrm{BO}_{3}$ : Evidence for a wigner glass phase. Physical Review B, v. 61, p. R850-R853, 2000. doi:10.1103/PhysRevB.61.R850.

31 LARREA, J. A.; SÁNCHEZ, D. R.; BAGGIO-SAITOVITCH, E. M.; FERNANDES, J. C.; GUIMARÃES, R. B.; CONTINENTINO, M. A.; LITTERST, F. J. Magnetism and charge ordering in $\mathrm{Fe}_{3} \mathrm{O}_{2} \mathrm{BO}_{3}$ ludwigite. Journal of Magnetism and Magnetic Materials, v. 226-230, pt. 2, p. 1079-1080, 2001.

32 LARREA, J.; SÁNCHEZ, D.; LITTERST, F.; BAGGIO-SAITOVITCH, E.; FERNANDES, J.; GUIMARÃES, R.; CONTINENTINO, M. Magnetism and charge ordering in $\mathrm{Fe}_{3} \mathrm{O}_{2} \mathrm{BO}_{3}$ studied by Fe57 Mössbauer spectroscopy. Physical Review B, v. 70, n. 17, p. 174452, 2004.

33 GUIMARÃES, R. B.; MIR, M.; CONTINENTINO, M. A.; FERNANDES, J. C.; FONTES, M. B.; YUGUE, E. S.; BAGGIO-SAITOVITCH, E.; MOREIRA, A. M.; SPEZIALI, N. L. Current-voltage and X-ray measurements in $\mathrm{Fe}_{3} \mathrm{O}_{2} \mathrm{BO}_{3}$. Journal of Magnetism and Magnetic Materials, v. 226-230, pt. 2, p. 1983-1984, 2001.

34 BORDET, P.; SUARD, E. Magnetic structure and charge ordering in $\mathrm{Fe}_{3} \mathrm{BO}_{5}$ : A singlecrystal x-ray and neutron powder diffraction study. Physical Review B, v. 79, n. 14, p. 144408, 2009.

35 BRESE, N. E.; O'KEEFFE, M. Bond-valence parameters for solids. Acta Crystallographica $B$, v. 47, n. 2, p. 192-197, 1991. 
36 MATOS, M.; TERRA, J.; ELLIS, D. E.; PIMENTEL, A. S. First principles calculation of magnetic order in a low-temperature phase of the iron ludwigite. Journal of Magnetism and Magnetic Materials, v. 374, p. 148-152, 2015. doi:10.1016/j.jmmm.2014.08.025.

37 ATTFIELD, J. P.; CLARKE, J. F.; PERKINS, D. A. Magnetic and crystal structures of iron borates. Physica B: condensed matter, v. 180-181, pt. 2, p. 581-584, 1992.

38 KITTEL, C.; MCEUEN, P. Introduction to solid state physics. New York: Wiley, 1986.

39 GUIMARÃES, R.; MIR, M.; FERNANDES, J.; CONTINENTINO, M.; BORGES, H.; CERNICCHIARO, G.; FONTES, M.; CANDELA, D.; BAGGIO-SAITOVITCH, E. Cation-mediated interaction and weak ferromagnetism in $\mathrm{Fe}_{3} \mathrm{O}_{2} \mathrm{BO}_{3}$. Physical Review $B$, v. 60, n. 9, p. 66176622, 1999.

40 YE, F.; FERNANDEZ-BACA, J. A.; DAI, P.; LYNN, J. W.; KAWANO-FURUKAWA, H.; YOSHIZAWA, H.; TOMIOKA, Y.; TOKURA, Y. Electronically smecticlike liquid-crystal phase in a nearly half-doped manganite. Physical Review B, v. 72, n. 21, p. 212404, 2005.

41 SWINNEA, J. S.; STEINFINK, H. Crystal structure and Mossbauer spectrum of vonsenite, 2FeO.FeBO 3. American Mineralogist, v. 68, n. 7, p. 827-832, 1983.

42 DOS SANTOS, E. C.; FREITAS, D. C.; FIER, I.; FERNANDES, J. C.; CONTINENTINO, M. A.; DE OLIVEIRA, A. J. A.; WALMSLEY, L. Current controlled negative differential resistance behavior in $\mathrm{Co}_{2} \mathrm{FeO}_{2} \mathrm{BO}_{3}$ and $\mathrm{Fe}_{3} \mathrm{O}_{2} \mathrm{BO}_{3}$ single crystals. Journal of Physics and Chemistry of Solids, v. 90, p. 65-68, 2016. doi:10.1016/j.jpcs.2015.11.015.

43 DUMAS, J.; THOLENCE, J. L.; CONTINENTINO, M.; FERNANDES, J. C.; GUIMARÃES, R. B.; WHANGBO, M. H. Electron paramagnetic resonance in the quasi-two dimensional magnetic ludwigite $\mathrm{Fe}_{3} \mathrm{O}_{2} \mathrm{BO}_{3}$. Journal de Physique IV (Proceedings), v. 12, n. 9, p. 351-354, 2002.

44 DUMAS, J.; THOLENCE, J. L.; CONTINENTINO, M.; FERNANDES, J. C.; GUIMARÃES, R. B. Electron paramagnetic resonance in $\mathrm{Fe}_{3} \mathrm{O}_{2} \mathrm{BO}_{3}$. Journal of Magnetism and Magnetic Materials, v. 226-230, p. 468-469, 2001. doi:10.1016/S0304-8853(00)00705-8.

45 WHANGBO, M.-H.; KOO, H.-J.; DUMAS, J.; CONTINENTINO, M. A. Theoretical investigation of the spin exchange interactions and magnetic properties of the homometallic ludwigite $\mathrm{Fe}_{3} \mathrm{O}_{2} \mathrm{BO}_{3}$. Inorganic Chemistry, v. 41, n. 8, p. 2193-2201, 2002.

46 MOMMA, K.; IZUMI, F. Vesta for three-dimensional visualization of crystal, volumetric and morphology data. Journal of Applied Crystallography, v. 44, n. 6, p. 1272-1276, 2011.

47 PAKE, G. E.; PURCELL, E. M. Line shapes in nuclear paramagnetism. Physical Review, v. 74, n. 9 , p. $1184-1188,1948$. 
48 CARTER JR, C. W.; SWEET, R. M. (Ed.) Macromolecular crystallography - part A. San Diego: Academic Press, 1997. (Methods in Enzimology, v.276).

49 MACRAE, C. F.; BRUNO, I. J.; CHISHOLM, J. A.; EDGINGTON, P. R.; MCCABE, P.; PIDCOCK, E.; RODRIGUEZ-MONGE, L.; TAYLOR, R.; VAN DE STREEK, J.; WOOD, P. A. Mercury CSD 2.0 new features for the visualization and investigation of crystal structures. Journal of Applied Crystallography, v. 41, n. 2, p. 466-470, 2008. doi: $10.1107 /$ S0021889807067908.

50 TINKHAM, M. Paramagnetic resonance in dilute iron group fluorides. I. fluorine hyperfine structure. Proceedings of the Royal Society of London A: mathematical, physical and engineering sciences, v. 236, n. 1207, p. 535-548, 1956.

51 NIEBIESKIKWIAT, D.; SÁNCHEZ, R. D.; CANEIRO, A.; MORALES, L.; VÁSQUEZMANSILLA, M.; RIVADULLA, F.; HUESO, L. E. High-temperature properties of the $\mathrm{Sr}_{2} \mathrm{FeMoO}_{6}$ double perovskite: Electrical resistivity, magnetic susceptibility, and ESR. Physical Review B, v. 62, n. 5, p. 3340-3345, 2000.

52 SHCHERBAKOVA, M. Y.; ISTOMIN, V. E. Calculation of EPR spectra of Fe3+ with high zero-field splitting in polycrystalline materials. Physica Status Solidi B, v. 67, n. 2, p. 461-469, 1975.

53 BEINERT, H. Iron-sulfur clusters: nature's modular, multipurpose structures. Science, v. 277, n. 5326, p. 653-659, 1997.

54 ANDERSON, P. W.; HASEGAWA, H. Considerations on double exchange. Physical Review, v. 100, n. 2, p. 675-681, 1955.

55 ROSENCWAIG, A. Double exchange and electron hopping in magnetite. Canadian Journal of Physics, v. 47, n. 21, p. 2309-2317, 1969.

56 CORONADO, E.; DELHAÈS, P.; GATTESCHI, D.; MILLER, J. S. (Ed.) Molecular magnetism: from molecular assemblies to the devices. Dordrecht: Springer Science, 1996.

57 TAYLOR, C. P. S. The EPR of low spin heme complexes - relation of the $\tau_{2 g}$ hole model to the directional properties of the $g$ tensor, and a new method for calculating the ligand field parameters. Biochimica et Biophysica Acta (BBA) - protein structure, v. 491, n. 1, p. 137-148, 1977.

58 MORIYA, T.; YOSIDA, K. On the origin of the anisotropy energy of $\mathrm{CuCl}_{2}-2 \mathrm{H}_{2} \mathrm{O}$. Progress of Theoretical Physics, v. 9, n. 6, p. 663-675, 1953.

59 COSTA-FILHO, A. J.; NASCIMENTO, O. R.; CALVO, R. Electron paramagnetic resonance study of weak exchange interactions between metal ions in a model system: $\mathrm{Cu}(\mathrm{II}) \mathrm{Gly}-$ Trp. Journal of Physical Chemistry B, v. 108, n. 27, p. 9549-9555, 2004. 
60 CALVO, R. EPR measurements of weak exchange interactions coupling unpaired spins in model compounds. Applied Magnetic Resonance, v. 31, n. 1-2, p. 271-299, 2007.

61 GEUSIC, J. E.; PETER, M.; BOIS, E. O. Paramagnetic resonance spectrum of $\mathrm{Cr}+++$ in emerald. Bell System Technical Journal, v. 38, n. 1, p. 291-296, 1959.

62 SARTORI, J. C. Construção de um sistema para ressonância paramagnética eletrônica em baixa freqüência: banda $L$ e banda S. 1990. Tese (Doutorado em Física) - Instituto de Física de São Carlos, Universidade de São Paulo, 1990.

63 IVANOVA, N. B.; VASIL'EV, A. D.; VELIKANOV, D. A.; KAZAK, N. V.; OVCHINNIKOV, S. G.; PETRAKOVSKI, G. A.; RUDENKO, V. Magnetic and electrical properties of cobalt oxyborate $\mathrm{Co}_{3} \mathrm{BO}_{5}$. Physics of the Solid State, v. 49, n. 4, p. 651-653, 2007.

64 FREITAS, D.; CONTINENTINO, M.; GUIMARÃES, R.; FERNANDES, J.; ELLENA, J.; GHIVELDER, L. Structure and magnetism of homometallic ludwigites: $\mathrm{Co}_{3} \mathrm{O}_{2} \mathrm{BO}_{3}$ versus $\mathrm{Fe}_{3} \mathrm{O}_{2} \mathrm{BO}_{3}$. Physical Review B, v. 77, n. 18, p. 184422, 2008.

65 OSEROFF, S. B.; TORIKACHVILI, M.; SINGLEY, J.; ALI, S.; CHEONG, S.-W.; SCHULTZ, S. Evidence for collective spin dynamics above the ordering temperature in $\mathrm{La}_{1-x} \mathrm{Ca}_{x} \mathrm{MnO}_{3+\delta}$. Physical Review B, v. 53, n. 10, p. 6521-6525, 1996.

66 MIR, M.; JANCZAK, J.; MASCARENHAS, Y. P. X-ray diffraction single-crystal structure characterization of iron ludwigite from room temperature to $15 \mathrm{~K}$. Journal of Applied Crystallography, v. 39, n. 1, p. 42-45, 2006.

67 SHIRAKAWA, H.; LOUIS, E. J.; MACDIARMID, A. G.; CHIANG, C. K.; HEEGER, A. J. Synthesis of electrically conducting organic polymers: halogen derivatives of polyacetylene, $(\mathrm{CH})_{x}$. Journal of the Chemical Society, Chemical Communications, n. 16, p. 578-580, 1977. doi: $10.1039 /$ C39770000578.

68 HEEGER, A. J. Semiconducting and metallic polymers: the fourth generation of polymeric materials (nobel lecture). Angewandte Chemie International Edition, v. 40, n. 14, p. 25912611, 2001.

69 FAEZ, R.; REIS, C.; FREITAS, P. S. D.; KOSIMA, O. K.; RUGGERI, G.; DE PAOLI, M.-A. Polímeros condutores. Química Nova na Escola, v. 11, n. 1, p. 13-18, 2000.

70 SU, W. P.; SCHRIEFFER, J. R.; HEEGER, A. J. Solitons in polyacetylene. Physical Review Letters, v. 42, n. 25, p. 1698-1701, 1979.

71 SU, W. P.; SCHRIEFFER, J. R.; HEEGER, A. J. Soliton excitations in polyacetylene. Physical Review B, v. 22, n. 4, p. 2099-2111, 1980. 
72 BERTHO, D.; JOUANIN, C. Polaron and bipolaron excitations in doped polythiophene. Physical Review B, v. 35, n. 2, p. 626-633, 1987.

73 BRÉDAS, J. L.; SCOTT, J. C.; YAKUSHI, K.; STREET, G. B. Polarons and bipolarons in polypyrrole: evolution of the band structure and optical spectrum upon doing. Physical Review B, v. 30, n. 2, p. 1023-1025, 1984.

74 NASCIMENTO, O. R.; DE OliveIRA, A. J. A.; PEREIRA, E. C.; CORREA, A. A.; WALMSLEY, L. The ferromagnetic behaviour of conducting polymers revisited. Journal of Physics: condensed matter, v. 20, n. 3, p. 035214, 2007.

75 SARICIFTCI, N. S.; HEEGER, A. J.; CAO, Y. Paramagnetic susceptibility of highly conducting polyaniline: disordered metal with weak electron-electron interactions (fermi glass). Physical Review B, v. 49, n. 9, p. 5988-5992, 1994.

76 BUSSAC, M. N.; ZUPPIROLI, L. Bipolaron singlet and triplet states in disordered conducting polymers. Physical Review B, v. 47, n. 9, p. 5493-5496, 1993.

77 KAHOL, P. K.; SPENCER, W. R.; PINTO, N. J.; MCCORMICK, B. J. Magneticsusceptibility analysis of polyaniline and its derivatives in terms of triplet bipolarons. Physical Review B, v. 50, n. 24, p. 18647-18650, 1994.

78 KAHOL, P. K.; RAGHUNATHAN, A.; MCCORMICK, B. J. A magnetic susceptibility study of emeraldine base polyaniline. Synthetic Metals, v. 140, n. 2-3, p. 261-267, 2004.

79 KAHOL, P. K.; MEHRING, M. Exchange-coupled pair model for the non-curie-like susceptibility in conducting polymers. Synthetic Metals, v. 16, n. 2, p. 257-264, 1986.

80 ZUPPIROLI, L.; BUSSAC, M. N.; PASCHEN, S.; CHAUVET, O.; FORRO, L. Hopping in disordered conducting polymers. Physical Review B, v. 50, n. 8, p. 5196-5203, 1994.

81 DUFOUR, B.; RANNOU, P.; DJURADO, D.; JANECZEK, H.; ZAGORSKA, M.; DE GEYER, A.; TRAVERS, J.-P.; PRON, A. Low tg, stretchable polyaniline of metallic-type conductivity: Role of dopant engineering in the control of polymer supramolecular organization and in the tuning of its properties. Chemistry of Materials, v. 15, n. 8, p. 1587-1592, 2003.

82 DJURADO, D.; PRON, A.; TRAVERS, J.-P.; DUQUE, J. G. S.; PAGLIUSO, P. G.; RETTORI, C.; CHINAGLIA, D. L.; WALMSLEY, L. Magnetic field dependent magnetization of a conducting plasticized poly(aniline) film. Journal of Physics: condensed matter, v. 20, n. 28, p. $285228,2008$.

83 DJURADO, D.; PRON, A.; JACQUOT, J. F.; TRAVERS, J. P.; ADRIANO, C.; VARGAS, J. M.; PAGLIUSO, P. G.; RETTORI, C.; LESSEUX, G. G.; FIER, I.; WALMSLEY, L. Magnetic field dependence of the magnetic susceptibility and the specific heat of the doped plasticized polyaniline (PANI-DB3EPSA) 0.5 . Journal of Physics: condensed matter, v. 23, n. 20, p. 206004, 2011. 
84 SANTANA, V. T.; NASCIMENTO, O. R.; DJURADO, D.; TRAVERS, J. P.; PRON, A.; WALMSLEY, L. Evidence of weak ferromagnetism in doped plasticized polyaniline (PANIDDoESSA $)_{0.5}$ from electron spin resonance measurements. Journal of Physics: condensed matter, v. 25, n. 11, p. 116004, 2013.

85 SNIECHOWSKI, M.; DJURADO, D.; DUFOUR, B.; RANNOU, P.; PRON, A.; LUZNY, W. Direct analysis of lamellar structure in polyaniline protonated with plasticizing dopants. Synthetic Metals, v. 143, n. 2, p. 163 - 169, 2004.

86 DUFOUR, B.; RANNOU, P.; DJURADO, D.; ZAGORSKA, M.; KULSZEWICZ-BAJER, I.; PRON, A. The role of chain and dopant engineering in the preparation of processible conducting polymers with desired properties. Synthetic Metals, v. 135-136, p. 63-68, 2003. doi:10.1016/S0379-6779(02)00538-6.

87 DYSON, F. J. Electron spin resonance absorption in metals. II. theory of electron diffusion and the skin effect. Physical Review, v. 98, n. 2, p. 349-359, 1955.

88 WALMSLEY, L. Translating conduction-electron spin-resonance lines into lorentzian lines. Journal of Magnetic Resonance A, v. 122, n. 2, p. 209 - 213, 1996.

89 RANNOU, P.; DUFOUR, B.; TRAVERS, J. P.; PRON, A.; DJURADO, D.; JANECZEK, $\mathrm{H}$.; SEK, D. Temperature-induced transitions in doped polyaniline: correlation between glass transition, thermochromism and electrical transport. Journal of Physical Chemistry B, v. 106, n. 41, p. 10553-10559, 2002.

90 MENON, R.; YOON, C. O.; MOSES, D.; HEEGER, A. J. Metal-insulator transition in doped conducting polymers. In: SKOTHEIN, T. A.; ELSENBAUMERT, R. L.; REYNOLDS, J. R. (Eds.) Handbook of conducting polymers. New York: Marcel Dekker, 2nd ed. 1998. p. 27-84.

91 DE GRAAF, C.; BROER, R. Magnetic interactions in molecules and solids. New York: Springer, 2016.

92 DUFOUR, B.; RANNOU, P.; FEDORKO, P.; DJURADO, D.; TRAVERS, J.-P.; PRON, A. Effect of plasticizing dopants on spectroscopic properties, supramolecular structure, and electrical transport in metallic polyaniline. Chemistry of Materials, v. 13, n. 11, p. 4032-4040, 2001.

93 FEDORKO, P.; FAURE-VINCENT, J.; FIER, I.; WALMSLEY, L.; SNIECHOWSKI, M.; JACQUOT, J. F.; PRON, A.; TRAVERS, J. P.; DJURADO, D. Effect of structural anisotropy on electrical and magnetic properties of polyaniline conducting films. Synthetic Metals, v. 166, n. 1, p. 63-69, 2013.

94 ELLIOTT, R. J. Theory of the effect of spin-orbit coupling on magnetic resonance in some semiconductors. Physical Review, v. 96, n. 2, p. 266-279, 1954. 
95 CHAUVET, O.; PASCHEN, S.; BUSSAC, M. N.; ZUPPIROLI, L. Triplet bipolarons in disordered conducting polymers: an ESR study. Europhysics Letters, Les Ulis, v. 26, n. 8, p. 619, 1994. 


\section{Resultado dos ajustes de $g_{\text {eff }}^{2}(\theta, \phi)$}

Os tensores (gg) para as espécies I e II em banda X e em banda $Q$ foram determinados a partir do ajuste dos dados de $g_{\text {eff }}^{2}$ da figura 2.10 pela equação (2.4) e o resultado é mostrado a seguir.

$$
(\mathbf{g g})_{I}^{X}=\left(\begin{array}{ccc}
5.595 & 0 & 0 \\
0 & 2.579 & 0 \\
0 & 0 & 5.591
\end{array}\right),(\mathbf{g g})_{I I}^{X}=\left(\begin{array}{ccc}
2.727 & 1.081 & 0 \\
1.081 & 5.439 & 0 \\
0 & 0 & 5.591
\end{array}\right)
$$

e

$$
(\mathbf{g g})_{I}^{Q}=\left(\begin{array}{ccc}
4.347 & 0 & 0 \\
0 & 3.485 & 0 \\
0 & 0 & 4.382
\end{array}\right) \text { e }(\mathbf{g g})_{I I}^{Q}=\left(\begin{array}{ccc}
3.553 & 0.345 & 0 \\
0.345 & 4.327 & 0 \\
0 & 0 & 4.382
\end{array}\right)
$$

Diagonalizando $(\mathbf{g g})_{I I}^{X, Q}$, temos:

$$
R_{X}^{\prime} \cdot(\mathbf{g g})_{I I}^{X} \cdot R_{X}=\left(\begin{array}{ccc}
5.818 & 0 & 0 \\
0 & 2.349 & 0 \\
0 & 0 & 5.591
\end{array}\right) \text { e } R_{Q}^{\prime} \cdot(\mathbf{g g})_{I I}^{Q} \cdot R_{Q}=\left(\begin{array}{ccc}
4.458 & 0 & 0 \\
0 & 3.422 & 0 \\
0 & 0 & 4.382
\end{array}\right)
$$

É possível notar que $R_{X, Q}^{\prime} \cdot(\mathbf{g g})_{I I}^{X, Q} \cdot R_{X, Q} \approx(\mathbf{g g})_{I}^{X, Q}$ com um erro máximo de $4 \%$.

Com as matrizes de rotação dadas por

$$
R_{X}=\left(\begin{array}{ccc}
0.3302 & -0.9439 & 0 \\
0.9439 & 0.3302 & 0 \\
0 & 0 & 1
\end{array}\right) \text { e } R_{Q}=\left(\begin{array}{ccc}
0.3556 & -0.9346 & 0 \\
0.9346 & 0.3556 & 0 \\
0 & 0 & 1
\end{array}\right)
$$

que correspondem a um ângulo de rotação em torno do eixo $z$ (plano $x y$ ) de $70.7^{\circ}$ e $69.2^{\circ}$, respectivamente. 
Lembrando que a raiz quadrada de uma matriz diagonal é simplesmente a raiz quadrada de seus elementos, temos que

$$
\begin{array}{r}
\mathbf{g}_{I}^{X}=\sqrt{(\mathbf{g g})_{I}^{X}}=[2.37,1.60,2.36] \\
\mathbf{g}_{I I}^{X}=\sqrt{R_{X}^{\prime} \cdot(\mathbf{g g})_{I I}^{X} \cdot R_{X}}=[2.41,1.53,2.36] \\
\mathbf{g}_{I}^{Q}=\sqrt{(\mathbf{g g})_{I}^{Q}}=[2.09,1.87,2.09] \\
\mathbf{g}_{I I}^{Q}=\sqrt{R_{Q}^{\prime} \cdot(\mathbf{g g})_{I I}^{Q} \cdot R_{Q}}=[2.11,1.85,2.09]
\end{array}
$$

Os valores principais do tensor $g$ para o conjunto I são iguais aos do conjunto II quando comparados na mesma banda, $\mathbf{g}_{I}^{X, Q} \simeq \mathbf{g}_{I I}^{X, Q}$, dentro de um erro experimental em torno de $5 \%$. Dadas essas considerações, os dois centros anisotrópicos são os mesmos deslocados de um ângulo de aproximadamente $70^{\circ}$ no plano $a b$. A interpretação para esse cálculo encontra-se no texto principal em que os valores principais do tensor $g$ para cada banda foram obtidos a partir da média entre os valores do tensor principal dos conjuntos I e II. 


\section{Sobreposição das linhas do espectro em banda $X$}

A sobreposição das componentes dos espectros em banda $X$ está ilustrada nos dados do plano $x y$ na Figura B.1, em que o tracejado corresponde a largura das linhas simetricamente distribuída em torno do campo central de cada uma das três linhas ajustadas no espectro de cada orientação.

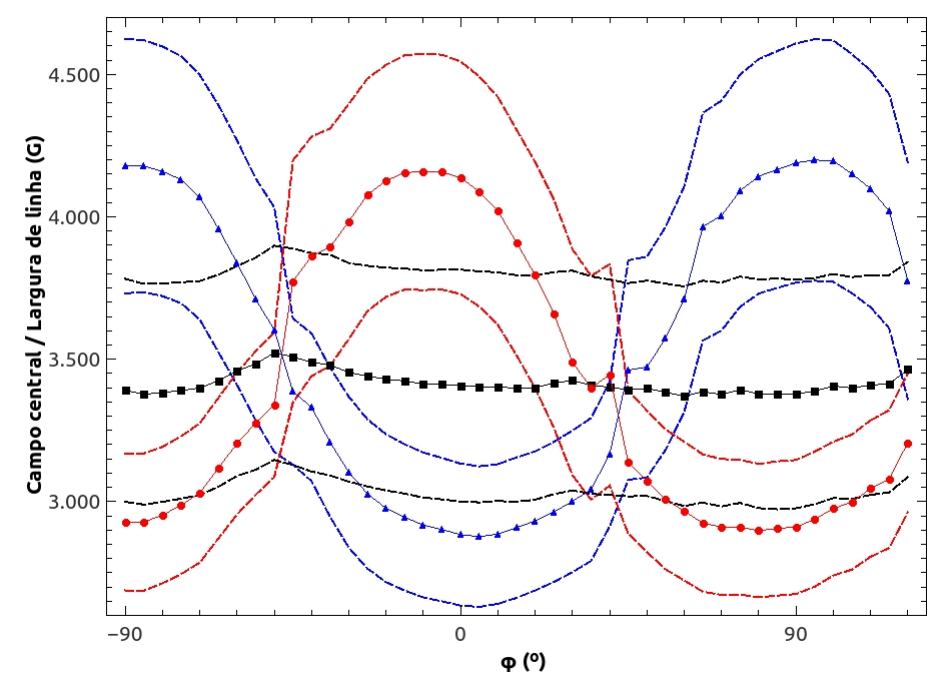

Figura B.1 - Gráfico do campo central das componentes dos espectros do plano $a b$ em banda X. As linhas tracejadas correspondem a largura de linha dessas componentes distribuídas simetricamente em torno do campo central de cada uma delas.

Fonte: Elaborada pelo autor. 


\section{Anexo}

Solid State Communications 207 (2015) 40-43

\section{Antiferromagnetic resonance of polycrystalline $\mathrm{BiMn}_{2} \mathrm{O}_{5}$}

V.T. Santana ${ }^{\mathrm{a}, \mathrm{b}, \mathrm{d}, *, \text { L. Walmsley }^{\mathrm{b}} \text {, I. Fier }}{ }^{\mathrm{b}}$, R.-A. Eichel ${ }^{\mathrm{c}}$, P. Jakes ${ }^{\mathrm{c}}$, I. Chumak ${ }^{\mathrm{d}}$, A. Ozarowski ${ }^{\mathrm{e}}$, J. van Tol ${ }^{\mathrm{e}}$, O.R. Nascimento ${ }^{\text {a }}$

a Instituto de Física de São Carlos, Universidade de São Paulo (USP), Caixa Postal 369, CEP 13560-970, São Carlos, São Paulo, Brazil bepartamento de Física, Instituto de Geociências e Ciências Exatas, Universidade Estadual Paulista (UNESP), Caixa Postal 178, CEP 13500-970, Rio Claro. S. P., Brazil

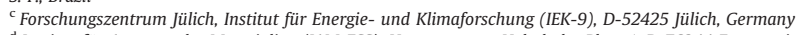

dinstitut für Angewandte Materialien (IAM-ESS), Hermann-von-Helmholtz-Platz 1, D-76344 Eggenstein-Leopoldshafen, Germany

e National High Magnetic Field Laboratory, Center for Interdisciplinary Magnetic Resonance, Florida State University, Tallahassee, FL 32310, USA

\section{A R T I C L E I N F O}

\section{Article history:}

Received 5 November 2014

Received in revised form

6 February 2015

Accepted 11 February 2015

by C. Lacroix

Available online 20 February 2015

Keywords:

A. Multiferroics

D. Magnetic anisotropy

E. Antiferromagnetic resonance

\begin{abstract}
A B S T R A C T
Multi-frequency electron spin resonance (ESR) measurements in polycrystalline samples of $\mathrm{BiMn}_{2} \mathrm{O}_{5}$ were employed to observe antiferromagnetic resonances (AFMR) in the range 0-14 $T$ below the Née temperature. The experimental data were analyzed using the phenomenological theory of Yosida and Nagamiya. Three resonance modes were identified in the $x z(a c)$ plane from the data at $5 \mathrm{~K}$. Macroscopic constants of anisotropy $K_{1}=12.5 \times 10^{6} \mathrm{erg} / \mathrm{cm}^{3}$ and $K_{2}=7.0 \times 10^{6} \mathrm{erg} / \mathrm{cm}^{3}$ were calculated allowing for the single-site anisotropy constant $K^{\prime}$ to be estimated at $T=0 \mathrm{~K}$. The obtained value shows reasonable agreement with theoretical predictions.
\end{abstract}

C 2015 Published by Elsevier Ltd.

\section{Introduction}

An interesting class of multiferroic materials is the $\mathrm{RMn}_{2} \mathrm{O}_{5}$ ( $\mathrm{R}$ being a rare earth or $\mathrm{Bi}$ and $\mathrm{Y}$ ) due to the physics phenomena involved. These materials have an antiferromagnetic transition $T_{N} \sim 40 \mathrm{~K}$, with the ferroelectric-paraelectric transition taking place close to this temperature, $T_{C} \sim 38 \mathrm{~K}[1,2]$. They are type II multiferroics, in which the ferroelectricity occurs only in the magnetically ordered state [3]. Although the mechanism of ferroelectricity for this class is not fully understood, one of the proposed ones states that magnetically induced changes in bond lengths between $\mathrm{Mn}$ ions of different valences result in a net ferroelectric moment [3].

In spite of being isostructural to the $\mathrm{RMn}_{2} \mathrm{O}_{5}, \mathrm{BiMn}_{2} \mathrm{O}_{5}$ has a distinct magnetic ground state, remaining commensurate below $T_{N}$. It has an antiferromagnetic spin ordering with the easy axis almost parallel to the $a$ axis without spiral ordering [4] and with a small polarization in the $b$ axis [2].

In this work, we intend to shed light onto the magnetic properties of this material by measuring multi-frequency electron spin resonance (ESR) in polycrystalline samples of $\mathrm{BiMn}_{2} \mathrm{O}_{5}$. Macroscopic constants of magnetic anisotropy obtained from the

* Corresponding author at: Instituto de Física de São Carlos, Universidade de São Paulo (USP), Caixa Postal 369, CEP 13560-970, São Carlos, São Paulo, Brazil. Paulo (USP), Caixa Post
Tel.: + 551935269164.

E-mail address: vstadeu@ursa.ifsc.usp.br (V.T. Santana).

http://dx.doi.org/10.1016/j.ssc.2015.02.007

0038-1098/ 2015 Published by Elsevier Ltd. data allowed an estimation of the microscopic single-site constant of anisotropy that may be the most important contribution to the magnetic anisotropy of this system.

\section{Experimental}

Stoichiometric amounts of $\mathrm{Bi}\left(\mathrm{NO}_{3}\right)_{3}$ and $\mathrm{C}_{6} \mathrm{H}_{9} \mathrm{MnO}_{6}$ were mixed in a $50 \mathrm{~mol} \%$ excess of citric acid and ethylene glycol. The solution was heated at $90{ }^{\circ} \mathrm{C}$, stirred until a gel was formed, and then dried by slowly heating up to $600{ }^{\circ} \mathrm{C}$ for $12 \mathrm{~h}$. The samples were milled and finally calcined for $12 \mathrm{~h}$ at $8500^{\circ} \mathrm{C}$ in air resulting in a dark gray powder. X-ray powder diffractions were performed in DebyeScherrer mode using a STOE STADI/P powder diffractometer (Mo$\mathrm{K} \alpha{ }_{1}$ radiation, $2 \theta$ range: $3-60^{\circ}$ ) at IAM-ESS. Structure refinements were performed using the Rietveld method at Winplotr software package confirming the phase (see Fig. 1). High frequency ESR measurements were performed at Tallahasse and X-band ESR experiments were performed using a Varian E-109 spectrometer at Instituto de Física de São Carlos (USP).

\section{Results}

The spectra at $328.8 \mathrm{GHz}$ at three different temperatures are displayed in Fig. 2. At $50 \mathrm{~K}$, above the Néel temperature of $40 \mathrm{~K}$, a 


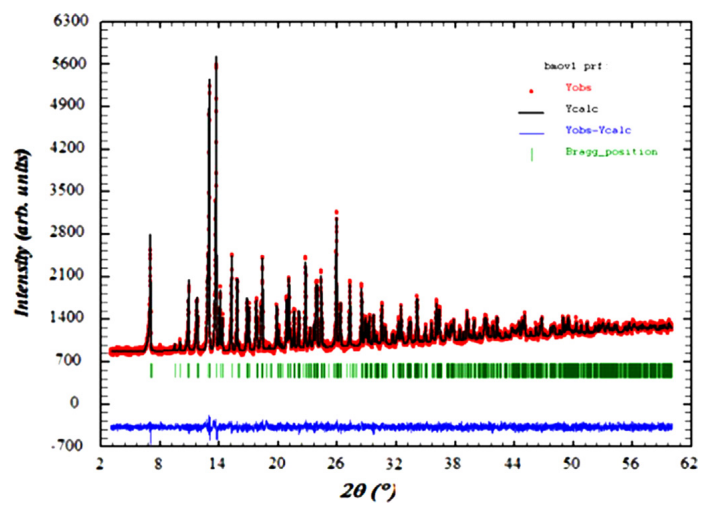

Fig. 1. X-ray powder diffraction for $\mathrm{BiMn}_{2} \mathrm{O}_{5}$ at room temperature. It has a Pbam structure with lattice parameters ( $\AA$ ): $a=7.5605(1), b=8.5305(1), c=5.7594(1)$.

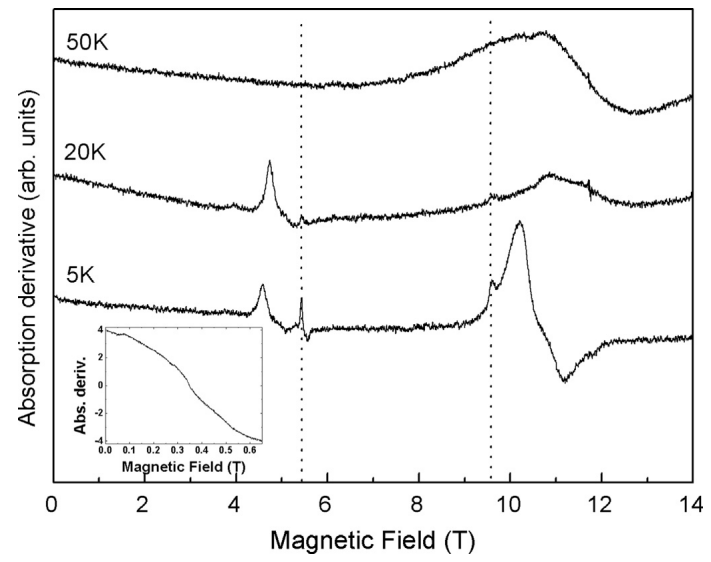

Fig. 2. Temperature dependence of EPR spectra at $328.8 \mathrm{GHz}$ for a polycrystalline sample of $\mathrm{BiMn}_{2} \mathrm{O}_{5}$. Inset: X-band EPR spectrum at $300 \mathrm{~K}$.

broad resonance line with $g \sim 2$ is seen. It is most probably due to $\mathrm{Mn}^{4+}$ and is observed at $300 \mathrm{~K}$ with $g \sim 2$ and $\Delta H_{1 / 2}=680 \mathrm{mT}$ (inset) using X-band ESR. Below the Néel temperature, both at $20 \mathrm{~K}$ and $5 \mathrm{~K}$ two resonances are observed which are attributed to AFMR modes. The one seen at the lower field is not seen at $50 \mathrm{~K}$, confirming that it appears only in the antiferromagnetic phase. The higher field one is also ascribed to an AFMR mode, albeit observed broader and in a higher field in the paramagnetic phase at $50 \mathrm{~K}$. The small resonances marked with a dashed line are due to molecular oxygen.

In Fig. 3, the spectra at $5 \mathrm{~K}$ for different frequencies are shown. For the lower frequencies, the experiments were performed only for fields up to $5 \mathrm{~T}$. The position of the molecular oxygen lines are identified with an asterisk, as simulated and identified with the parameters taken from reference [5]. In Fig. 4, the experimental AFMR data are displayed together with the modes found using Yosida and Nagamiya theory of antiferromagnetic resonance discussed below.

\section{Discussion of the AFMR theory}

Two sublattices with equal modulus and antiparallel directions are considered. Demagnetizing fields and damping effects are

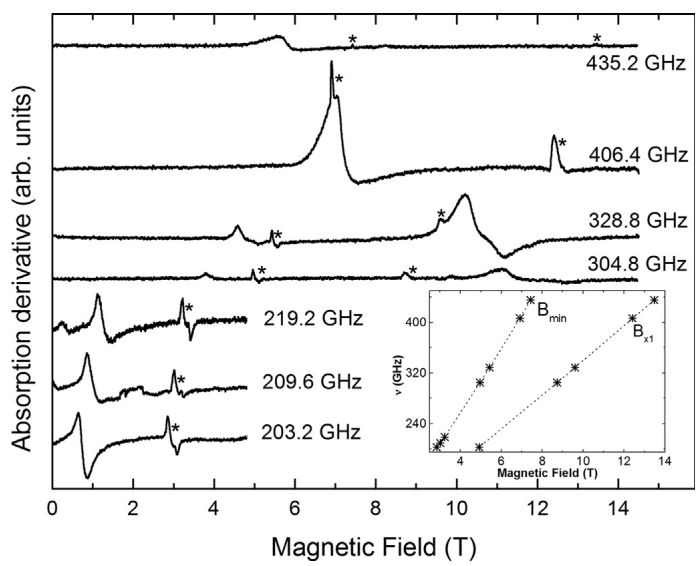

Fig. 3. Multi frequency EPR spectra for $\mathrm{BiMn}_{2} \mathrm{O}_{5}$ at $5 \mathrm{~K}$. The resonance lines marked with an asterisk are due to molecular oxygen. Inset: position of the molecular oxygen resonances identified according to the modes in Ref. [5].

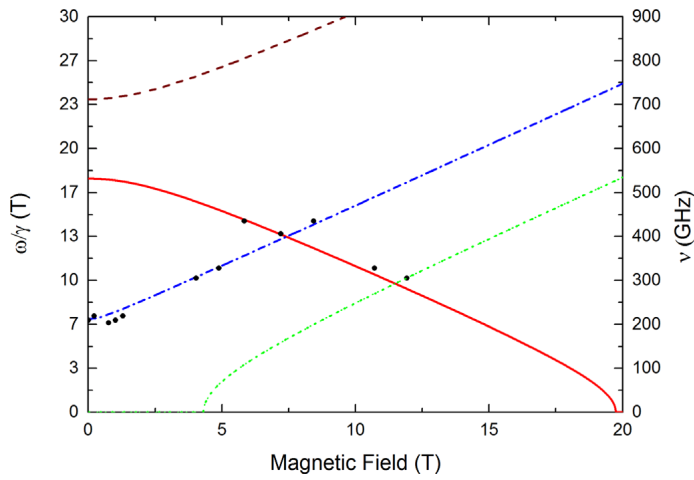

Fig. 4. (Color online) Full circles show the frequency-field dependence of the resonance lines observed in the multi frequency EPR spectra of Fig. 3. AFMR modes obtained from Eq. (5) for the field parallel to the easy axis (dashed and full line), perpendicular to the easy axis (dotted line), and making an angle of $43^{\circ}$ with the easy axis (dot-dashed line) are shown. The parameters used in Eq. (5) that best adjust the experimental data are $\mathrm{g}=2.2, K_{1}=7.0 \times 10^{8}\left(\mathrm{emu} \mathrm{Oe} \mathrm{mol}^{-1}\right)$, and $K_{2}=3.9 \times 10^{8}\left(\mathrm{emu} \mathrm{Oe} \mathrm{mol}^{-1}\right)$

neglected. Following Nagamiya, Yosida and Kubo [6], we search for an expression for the frequencies of the antiferromagnetic resonance, starting from the rate of change of the angular momentum of the whole system, which is equal to the torque acting on the magnetic vector of the system. For each sublattice, it is expressed as:

$\frac{1}{\gamma} \frac{d}{d t} \mathbf{M}^{ \pm}=\mathbf{M}^{ \pm} \times\left(\mathbf{H}+\mathbf{H}_{\mathbf{E}}^{ \pm}+\mathbf{H}_{\mathbf{A}}^{ \pm}\right)$

In Eq. (1), $\gamma=g \mu_{B} / \hbar$ with $g$ being the spectroscopic splitting factor and $\mu_{B}$ the Bohr magneton. The fields $\mathbf{H}_{\mathrm{E}}^{ \pm}$and $\mathbf{H}_{\mathrm{A}}^{ \pm}$are the exchange and anisotropy magnetic fields of each sublattice, respectively. The field of anisotropy comes from the phenomenological model of the magnetic anisotropy energy. For a crystal with orthorhombic symmetry, it is expressed as $[6,7]$ :

$E_{A}=\frac{1}{2}\left(K_{1} \beta^{+2}+K_{2} \gamma^{+2}\right)+\frac{1}{2}\left(K_{1} \beta^{-2}+K_{2} \gamma^{-2}\right)$

where $\beta^{ \pm}$and $\gamma^{ \pm}$are respectively the direction cosines for the $y$ and $z$ axis of the magnetic moments on the two sublattices. This 
phenomenological approach is valid only when the exchange interaction is so strong that the magnetizations of each sublattice are approximately antiparallel even in the presence of an applied magnetic field [8]. If no magnetic field is applied, the magnetization vector lies in the direction in which $E_{A}$ is minimal. This direction is the easy axis of anisotropy that we identified as the $x$ direction ( $a$ axis). Applying a magnetic field at an angle $\theta_{H}$ from the easy axis gives the magnetization a tendency to turn to a direction perpendicular to the magnetic field, prevented by the restoring force arising from the magnetic anisotropy, with the components of the field of anisotropy given by:

$H_{A x}^{ \pm}=0, \quad H_{A y}^{ \pm}=-\frac{K_{1}}{M_{0}} \beta^{ \pm}, \quad H_{A z}^{ \pm}=-\frac{K_{2}}{M_{0}} \gamma^{ \pm}$

Here $M_{0}$ is the modulus of the magnetization. The angle $\varphi$ between the easy axis and the magnetization direction depends on both the angle $\theta_{H}$ and the value of the magnetic field, and have been calculated by Yosida [6,7]:

$\tan 2 \varphi=\frac{\sin 2 \theta_{H}}{\cos 2 \theta_{H}-\left(\chi_{\perp}-\chi_{\|}\right) 2 H^{2} / K_{j}}$

in which $K_{j}=K_{1}$ if $K_{2}>K_{1}$ or $K_{j}=K_{2}$ otherwise. The frequency of the oscillations with the magnetic field applied in a plane containing the easy axis is then given by:

$$
\begin{aligned}
& \left(\frac{\omega}{\gamma}\right)^{4}-\left(\frac{\omega}{\gamma}\right)^{2}\left[H^{2}\left(\alpha^{2} \cos ^{2} \varphi+1\right)+c_{2}+c_{1}\left\{\cos ^{2}\left(\varphi-\theta_{H}\right)-2 \sin ^{2}\left(\varphi-\theta_{H}\right)\right\}\right] \\
& +H^{4} \alpha^{2} \cos ^{2} \varphi-H^{2}\left[c _ { 1 } \left\{\alpha \cos ^{2} \varphi \cos 2\left(\varphi-\theta_{H}\right)\right.\right. \\
& \left.+\alpha \cos \varphi \sin \theta_{H} \sin \left(\varphi-\theta_{H}\right)+\sin \varphi \cos \theta_{H} \sin \left(\varphi-\theta_{H}\right)\right\} \\
& \left.+c_{2}\left(\alpha \cos ^{2} \varphi-\sin ^{2} \varphi\right)\right]+c_{1} \cos 2\left(\varphi-\theta_{H}\right)\left[c_{2}-c_{1} \sin ^{2}\left(\varphi-\theta_{H}\right)\right]=0
\end{aligned}
$$

for a magnetic field applied in the $x y$ axis. If it is applied in the $x z$ axis, subscripts 1 and 2 should be interchanged in Eq. (5). Here $c_{1}=2 K_{1} / \chi_{\perp}$ and $c_{2}=2 K_{2} / \chi_{\perp}$, with $\chi_{\|}$and $\chi_{\perp}$ being the magnetic susceptibility parallel and perpendicular to the easy axis respectively, taken from reference [9]. The factor $\alpha=\left(1-\chi_{\|} / \chi_{\perp}\right)$ accounts for the nonzero parallel susceptibility at $5 \mathrm{~K}$. From reference [9], we have identified the $a, b$ and $c$ directions with $x$, $y$ and $z$ axis respectively.

\section{Application to $\mathrm{BiMn}_{2} \mathrm{O}_{5}$ powder AFMR data}

From the magnetic structure determined by Muñoz et al. at $1.6 \mathrm{~K}$ [4], $\mathrm{Mn}^{3+}$ and $\mathrm{Mn}^{4+}$ sites are described by $F_{x}=-3.12 \mu_{B}$ and $C_{y}=-0.8 \mu_{B}$ and $G_{x}^{\prime}=2.44 \mu_{B}$ and $A^{\prime}{ }_{y}=0.6 \mu_{B}$. Thus, a two sublattice model is assumed, with the same modulus and antiparallel directions for $\mathrm{Mn}^{3+}$ and $\mathrm{Mn}^{4+}$. The $a, b$ and $c(x, y$ and $z)$ are respectively the easy, intermediate, and hard axis, also determined by single crystal susceptibility data [2,9].

The two positive solutions of Eq. (5) were obtained analytically using the software Matlab. In the search for an AFMR mode with the magnetic field parallel to the easy axis, we have been guided for the spin flop field data obtained for $\mathrm{BiMn}_{2} \mathrm{O}_{5}$ [2] using a linear interpolation to estimate the spin flop field at $5 \mathrm{~K}$ around $19 \mathrm{~T}$. Given this spin flop field, $K_{1}>K_{2}$ was a required condition for our data to be fitted by Eq. (5) for the magnetic field applied in the easy axis direction. The red full line shows this lower frequencies parallel mode in Fig. 4. The condition $K_{1}>K_{2}$ implies that the easy axis AFMR mode is observed in the $x z$ plane. The higher field data at $304.8 \mathrm{GHz}$ that belongs to this mode shows a large width, with a not very well defined center. The assumption that it is a superposition of this parallel and the perpendicular mode shown (dotted green line) can account better for the data. This perpendicular mode is identified with that with the magnetic field applied in the $z$ direction. The spin flop field of $19 T$ determines the smaller constant of anisotropy $K_{2}=3.9 \times 10^{8} \mathrm{emu} \mathrm{Oe} \mathrm{mol}^{-1}$ which corresponds to the field at which $\omega / \gamma$ equals to zero in Fig. 4, i.e., the higher magnetic field of the mode. The parallel and perpendicular modes shown in Fig. 4 have been found from Eq. (5) with $g=2.2$ and $\theta_{H}$ equals to 0 and $\pi / 2$ respectively. The dash and dot blue line mode is obtained from Eq. (5) with the same values of $g$ and $K_{2}$ and with a value of $K_{1}=7.0 \times 10^{8} \mathrm{emu} \mathrm{Oe} \mathrm{m^{-1 }}$ and $\theta_{H}=\pi / 4.17$ and is in reasonable agreement with nine resonance data, which we assume to belong to this AFMR mode. It is strongly affected by a change of $5 \%$ in the value of $K_{1}$, in contrast with other modes identified with the magnetic field parallel and the perpendicular to the easy axis shown in Fig. 4, which are almost insensitive to this change. The value of $K_{1}$ fixes the position of the high frequencies parallel mode (dashed brown line) shown in Fig. 4 , which is outside of the experimental frequency window.

Summarizing the obtained results, the AFMR at $5 \mathrm{~K}$ were observed in a powdered sample but only modes with the applied magnetic field in the $x z$ plane were observed. Three modes were identified according to the AFMR theory of Yosida and Nagamiya and to the value of the experimental spin flop field: a mode with the magnetic field applied in the direction of the easy axis ( $x$ axis); a data point belonging to a mode with the magnetic field applied perpendicular to the easy axis ( $z$ axis); and a mode with the magnetic field making an angle of approximately $43^{\circ}$ with the easy axis. This last mode starts at zero magnetic field. The zero field frequency of this mode is around $203 \mathrm{GHz}\left(6.8 \mathrm{~cm}^{-1}\right)$ and the electromagnon mode in $\mathrm{YMn}_{2} \mathrm{O}_{5}$ was observed at $7.2 \mathrm{~cm}^{-1}$ at $7 \mathrm{~K}$ [10]. Despite having similar energies, no clear elements are present to invoke magnon-phonon interaction to explain this mode. Besides, electromagnons are not expected for non spirals antiferromagnets, in particular are not expected in $\mathrm{BiMn}_{2} \mathrm{O}_{5}$ [11] The obtained constants of magnetic anisotropy can also be expressed in $\mathrm{erg} / \mathrm{cm}^{3}$. The molecular volume is calculated from $V_{m}=N_{A} V_{\text {cell }} / Z$ where $N_{A}$ is the Avogrado constant, $Z=4$ is the number of formula units in the unit cell and $V_{\text {cell }}$ is the cell volume in the antiferromagnetic phase of $\mathrm{BiMn}_{2} \mathrm{O}_{5}$ [9], yielding $K_{2}=7.0 \times 10^{6} \mathrm{erg} / \mathrm{cm}^{3}$ and $K_{1}=12.5 \times 10^{6} \mathrm{erg} / \mathrm{cm}^{3}$.

The microscopic origin of the magneto crystalline anisotropy is the spin-orbit coupling. The most common mechanism of magnetic anisotropy and usually the strongest one is the single-site anisotropy [12]. For a high spin $\mathrm{Mn}^{3+}$ in a square pyramidal crystal field $\left(t_{2 g}^{3} e_{g}^{1}\right)$, the $t_{2 g}$ state splits in an upper singlet and a lower doublet slightly split orbital ground state [12]. For a high spin $\mathrm{Mn}^{4+}$ in an octahedral crystal field $\left(t_{2 g}^{3}\right)$, the ground state is an orbital singlet [13]. In the case of an orbital singlet with half filled $t_{2 g}$ levels, the spin-orbit coupling gives second order matrix elements between the ground state and $e_{g}$ levels. In such case, the energy of interaction can be expressed as:

$K^{\prime} \sim \frac{\lambda^{2}}{\delta E}$

where $\lambda$ is the spin-orbit constant of the free ion and $\delta E$ is the crystal field splitting. It is important to remark that this situation is also valid for $\mathrm{Mn}^{3+}$ with a slightly split orbital ground level as discussed by Abragam and Bleaney [13], which classified both as A type ions. For a single axis of magnetic crystalline anisotropy, the single-site anisotropy energy can be written in the form [14]:

$H_{\text {single-site }}=-K^{\prime} \sum_{i} S_{x i}^{2}$

The uniaxial macroscopic constant of anisotropy $K$ at $T=0 \mathrm{~K}$ can be expressed in terms of the microscopic constant of the single-site anisotropy $K^{\prime}$ [14]:

$K=K^{\prime} S(S-1 / 2)$ 
Taking both $\mathrm{Mn}^{3+}$ and $\mathrm{Mn}^{4+}$ contributions into account in Eq. (8) respectively, $K=3 K^{\prime}+3 K^{\prime} / 2=9 K^{\prime} / 2$. Choosing the mean value between $K_{1}$ and $K_{2}$ to represent $K$, equal to $9.8 \times 10^{6} \mathrm{erg} / \mathrm{cm}^{3}$ or $4.6 \mathrm{~cm}^{-1} /$ molecule ( $Z=4$ and the cell volume given by reference 9 ) the single ion anisotropy $K^{\prime}=1.0 \mathrm{~cm}^{-1} /$ molecule. Using Eq. (6), a value of $\lambda \sim 10^{2} \mathrm{~cm}^{-1}$ implies a value of $\delta E \sim 10^{4} \mathrm{~cm}^{-1}$. It is in reasonable agreement with $\lambda=88 \mathrm{~cm}^{-1}$ and $\lambda=134 \mathrm{~cm}^{-1}$ for $\mathrm{Mn}^{3+}$ and $\mathrm{Mn}^{4+}$ respectively and an estimation of crystal field splitting of $10^{4} \mathrm{~cm}^{-1}$ for $\mathrm{d}^{3}$ electrons [13].

\section{Conclusions}

Polycrystalline samples of the multiferroic system $\mathrm{BiMn}_{2} \mathrm{O}_{5}$ were synthesized and the resonances observed below the Néel temperature were identified as antiferromagnetic resonance lines. The experimental AFMR data at $5 \mathrm{~K}$ showed reasonable agreement with the modes obtained using Yosida and Nagamiya AFMR theory. The AFMR modes observed in the powder sample corresponds to those of an applied magnetic field parallel to $x z$ plane. Three modes were identified: a mode with the magnetic field applied in the direction of the easy axis ( $x$ axis); a mode with the magnetic field applied perpendicular to the easy axis ( $z$ axis); and a mode with the magnetic field making an angle of approximately $43^{\circ}$ with the easy axis. The macroscopic constants of anisotropy $K_{1}=12.5 \times 10^{6} \mathrm{erg} / \mathrm{cm}^{3}$ and $K_{2}=7.0 \times 10^{6} \mathrm{erg} / \mathrm{cm}^{3}$ have been obtained from the experimental data. From the value of these constants, the microscopic single-site anisotropy constant $K^{\prime}$ has been estimated at $T=0 \mathrm{~K}$ using the mean value of the macroscopic constants and the obtained value has shown reasonable agreement with the theoretical predictions.

\section{Acknowledgments}

BEPE/FAPESP, CNPq, Karlsruher Institut für Technologie (IAMESS), National High Magnetic Field Laboratory - Center for Interdisciplinary Magnetic Resonance are gratefully acknowledged.

\section{Appendix}

The model expressed by Eq. (5) has four mathematical solution for $\omega / \gamma$ from which we can choose the two positive. This leads to two modes for each value of $\theta_{H}$ as follows:

$$
\begin{aligned}
\frac{\omega}{\gamma}= & \frac{1}{2 \sqrt{2}}\left\{-2 c_{1}+4 c_{2}+4 H^{2}+2 \alpha^{2} H^{2}+2 \alpha^{2} H^{2} \cos 2 \varphi\right. \\
& +6 c_{1} \cos \left[2\left(\varphi-\theta_{H}\right) \pm \sqrt{2}\left[3 c_{1}^{2}-8 c_{1} c_{2}+8 c_{2}^{2}-8 \alpha c_{1} H^{2}\right.\right. \\
& -4 \alpha^{2} c_{1} H^{2}+16 \alpha c_{2} H^{2}+8 \alpha^{2} c_{2} H^{2}+8 H^{4}-8 \alpha^{2} H^{4}+3 \alpha^{4} H^{4} \\
& +4 H^{2}\left[-\left(2+2 \alpha+\alpha^{2}\right) c_{1}+2\left(2+2 \alpha+\alpha^{2}\right) c_{2}+\alpha^{2}\left(-2+\alpha^{2}\right) H^{2}\right] \\
& \times \cos 2 \varphi+\alpha^{4} H^{4} \cos 4 \varphi+8 \alpha c_{1} H^{2} \cos \left(4 \varphi-2 \theta_{H}\right)+6 \alpha^{2} c_{1} H^{2} \\
& \times \cos \left(4 \varphi-2 \theta_{H}\right)+4 c_{1}^{2} \cos \left[2\left(\varphi-\theta_{H}\right)\right]-8 c_{1} c_{2} \cos \left[2\left(\varphi-\theta_{H}\right)\right] \\
& +16 c_{1} H^{2} \cos \left[2\left(\varphi-\theta_{H}\right)\right]+24 \alpha c_{1} H^{2} \cos \left[2\left(\varphi-\theta_{H}\right)\right]+12 \alpha^{2} c_{1} H^{2} \\
& \times \cos \left[2\left(\varphi-\theta_{H}\right)\right]+c_{1}^{2} \cos \left[4\left(\varphi-\theta_{H}\right)\right]+8 c_{1} H^{2} \cos 2 \theta_{H} \\
& \left.\left.+16 \alpha c_{1} H^{2} \cos 2 \theta_{H}+6 \alpha^{2} c_{1} H^{2} \cos 2 \theta_{H}\right]^{1 / 2}\right\}^{1 / 2} .
\end{aligned}
$$

The modes expressed by Eq. (A.1) comprise both planes containing the easy axis. However, the equation to be employed is exactly (A.1) for one of them while for the other one, Eq. (A.1) must be employed with $c_{1}$ and $c_{2}$ interchanged [6]. In our fitting, we used $c_{1}$ and $c_{2}$ interchanged.

\section{References}

[1] S.-W. Cheong, M. Mostovoy, Nat. Mater. 6 (2007) 13.

[2] J.W. Kim, S.Y. Haam, Y.S. Oh, S. Park, S.-W. Cheong, P.A. Sharma, M. Jaime, N. Harrison, J.H. Han, G.-S. Jeona, P. Coleman, K.H. Kim, Proc. Natl. Acad. Sci. 37 (2009) 8106 .

[3] J. van den Brink, D.I. Khomiskii, J. Phys. Condens. Matter 20 (2008) 434217. 4] A. Muñoz, J.A. Alonso, M.T. Casais, M.J. Martinez-L

[5] L.A. Pardi, J. Krzystek, J. Telser, L.-C. Brunel, J. Magn. Reson. 146 (2000) 375. 6] T. Nagamiya, K. Yosida, R. Kubo, Adv. Phys. 4 (13) (1955) 1.

7] Kei Yosida, Prog. Theor. Phys. 7 (1952) 425.

[8] J. Kanamori, in: G.T. Rado, H. Suhl (Eds.), Magnetism, vol. 1, Academic Press, New York, 1963.

[9] E. Granado, M.S. Eleotério, A.F. García-Flores, J.A. Souza, E.I. Golovenchits, V.A. Sanina, Phys. Rev. B 77 (2008) 134101.

[10] A.B. Sushkov, R. Valdés Aguilar, S. Park, S.-W. Cheong, H.D. Drew, Phys. Rev, Lett. 98 (2008) 027202.

[11] A.B. Sushkov, M. Mostovoy, R. Valdés Aguilar, S.-W. Cheong, H.D. Drew, J. Phys. Condens. Matter 20 (2008) 434210

[12] Daniel I. Khomskii, Transition Metal Compounds, Cambridge University Press, United Kingdom, 2014

[13] A. Abragam, B. Bleaney, Electron Paramagnetic Resonance of Transition Ions, New York: Dover, 1986.

[14] Kei Yosida, Prog. Theor. Phys. 6 (1951) 691. 